\title{
Selective Precipitation and Recovery of Rare Earth Elements from Acid Mine Drainage
}

\author{
Robyn Lauren Christoferson \\ West Virginia University, rlc0061@mix.wvu.edu
}

Follow this and additional works at: https://researchrepository.wvu.edu/etd

Part of the Civil Engineering Commons, and the Environmental Engineering Commons

\section{Recommended Citation}

Christoferson, Robyn Lauren, "Selective Precipitation and Recovery of Rare Earth Elements from Acid Mine Drainage" (2020). Graduate Theses, Dissertations, and Problem Reports. 7825.

https://researchrepository.wvu.edu/etd/7825

This Thesis is protected by copyright and/or related rights. It has been brought to you by the The Research Repository @ WVU with permission from the rights-holder(s). You are free to use this Thesis in any way that is permitted by the copyright and related rights legislation that applies to your use. For other uses you must obtain permission from the rights-holder(s) directly, unless additional rights are indicated by a Creative Commons license in the record and/ or on the work itself. This Thesis has been accepted for inclusion in WVU Graduate Theses, Dissertations, and Problem Reports collection by an authorized administrator of The Research Repository @ WVU. For more information, please contact researchrepository@mail.wvu.edu. 


\title{
Selective Precipitation and Recovery of Rare Earth Elements from Acid Mine Drainage
}

\author{
Robyn Christoferson \\ Thesis submitted to the \\ Benjamin M. Statler College of Engineering and Mineral Resources \\ At West Virginia University \\ In partial fulfillment of the requirements \\ For the degree of \\ Master of Science \\ In \\ Civil and Environmental Engineering \\ Lian-Shin Lin, Ph.D., Chair \\ Karen Buzby, Ph.D. \\ Paul Ziemkiewicz, Ph.D. \\ John Quaranta, Ph.D.
}

\section{Department of Civil and Environmental Engineering \\ Morgantown, West Virginia}

2020

Keywords: Acid Mine Drainage, Selective Precipitation, Rare Earth Element (REE), Copyright 2020 Robyn Christoferson 


\section{ABSTRACT \\ Selective Precipitation and Recovery of Rare Earth Elements from Acid Mine Drainage \\ Robyn Christoferson}

The ability to secure rare earth elements (REEs) in the United States is of concern due to the rapid growth in demand and the monopolistic supply chain. The demand for REEs has skyrocketed in recent years due to the development of many green technologies. The United States and many other countries are currently reliant on China for REEs, who currently control greater than $90 \%$ of the global supply. Due to the severe impact of previous Chinese export quotas, it is important to lessen the reliance on importation and explore methods of recycling REEs from secondary sources. A secondary REE source of interest is acid mine drainage (AMD), which has been shown to contain REE concentrations far above that of natural water sources.

Focusing on AMD sources in northeastern West Virginia, the objectives of this study include 1) determining the viability of recovering REEs from AMD via selective precipitation, 2) assessing correlations between the raw water characteristics and the quality of the REE sludges produced, and 3) determining the effects of redox condition and flocculant usage on the precipitation procedure. To satisfy the first objective, acid mine drainage was collected and $\mathrm{pH}$ adjusted sequentially between $\mathrm{pHs} 3.0$ and 8.0. The $\mathrm{pH}$ ranges of gangue metal and REE precipitation were analyzed to determine if efficient separation of REEs could occur. Based on the analysis, recovery of REEs was efficient due to the well defined separation of removal $\mathrm{pH}$ ranges.

To achieve the second objective, AMD samples were collected from seven sites across northeastern WV. Each sample was adjusted sequentially to $\mathrm{pH} 4.0,5.0$, and 8.0. The composition of the precipitates and overall REE recovery were analyzed and compared for each sample. Linear regression was then used to assess correlations between raw water characteristics and the grade of the precipitates. It was determined that the precipitate grade was independent of the raw water REE concentration and could not be accurately predicted using raw water characteristics.

The third objective was achieved by the repeating the precipitation procedure under varying redox conditions, which included complete oxidation, partial reduction with nitrogen sparging, and partial reduction without nitrogen sparging. The effects were assessed by comparing changes in precipitation patterns of gangue metals and REEs. The completely oxidized condition led to a greater separation of $\mathrm{pH}$ range between the metals and REEs when compared to the partially reduced conditions. The effects of flocculant usage were also examined for this objective. Jar tests were conducted to determine optimal dosage during the precipitation procedure. The flocculated precipitates were analyzed to determine if there were any differences in composition to the precipitates without flocculant. The use of flocculant was shown to increase overall REE recovery but decrease the weight percent of REE in the precipitate. Based on these findings, recommendations are provided to optimize the efficiency of the selective precipitation procedure. 


\section{ACKNOWLEDGEMENTS}

I would like to express the deepest appreciation to my supervisor and committee chair, Dr. LianShin Lin, who offered endless guidance and counseling throughout my time at WVU. Your persistent and patient support throughout my graduate journey is the reason I was able to complete my research. I would also like to pay special thanks to Dr. Karen Buzby, who's assistance throughout my research and writing is immeasurable.

I would like to thank Dr. Paul Ziemkiewicz and Dr. John Quaranta for both serving on my advisory committee and offering encouragement and advice for my current and future work.

I am grateful for the financial support of the Department of Energy, National Energy Technology Laboratory, without which this research could not have been completed.

I dedicate my thesis to my loved ones who supported me unconditionally through this process even when I doubted myself. To my parents who were there for me every step of the way and answered each frantic phone call. To my grandmother who offered a weekend getaway when work was too stressful. To my friends on campus who kept me sane during the long workdays. Lastly, to my significant other who was there for me through the highs and the lows of it all. 


\section{TABLE OF CONTENTS}

\section{Contents}

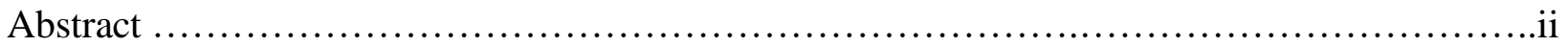

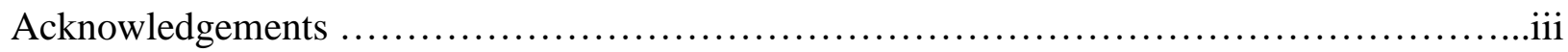

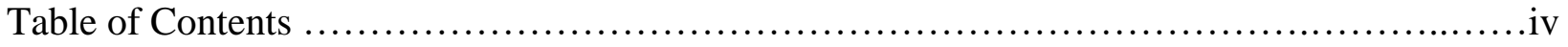

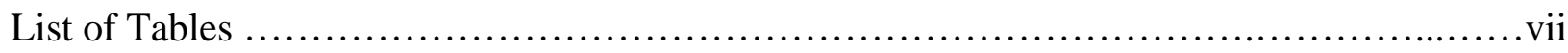

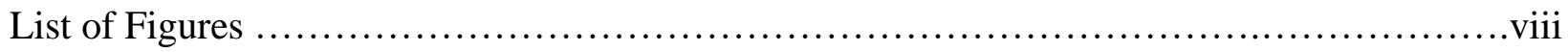

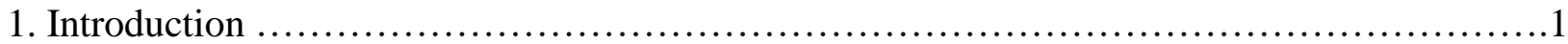

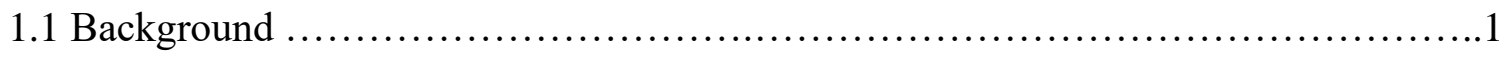

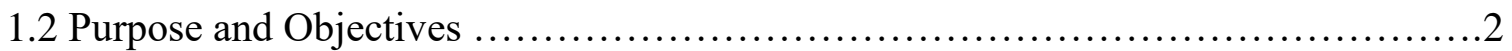

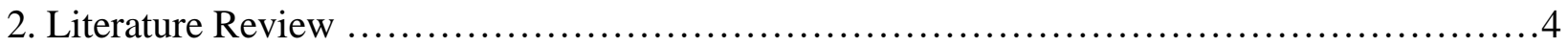

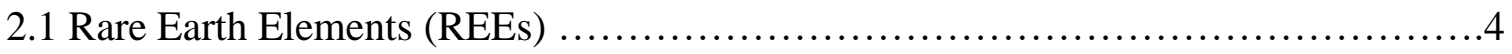

2.2 Acid Mine Drainage (AMD) ..................................................

3. Selective Precipitation of Acid Mine Drainage in $0.5 \mathrm{pH}$ Increments .......................9

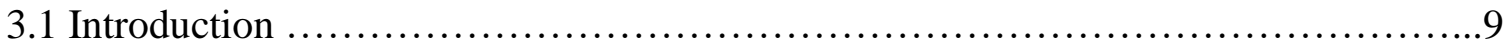

3.2 Sample Collection ..............................................................

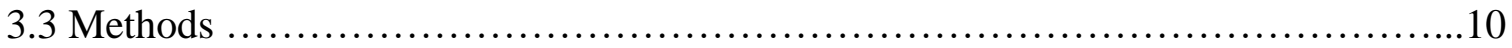

3.3.1 The $0.5 \mathrm{pH}$ Step Precipitation ....................................... 10

3.3.2 Sample Preparation for Analysis ...................................10

3.3.3 Calculation of Percent Removal ......................................11

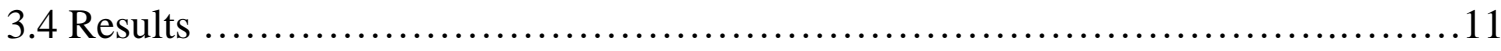

3.4.1 Raw Water Characteristics .............................................11

3.4.2 The $0.5 \mathrm{pH}$ Step Precipitation ........................................13

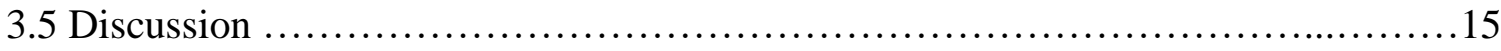

3.5.1 The $0.5 \mathrm{pH}$ Step Precipitation ......................................15

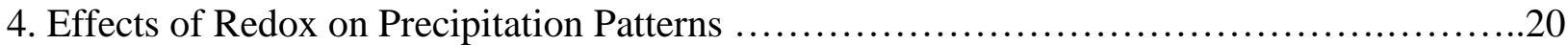




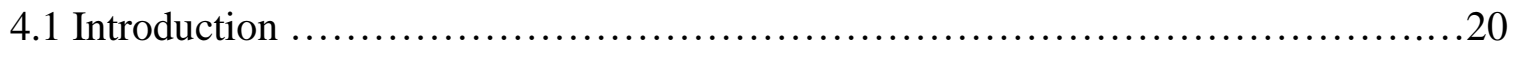

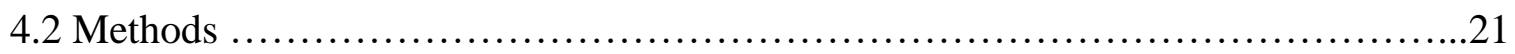

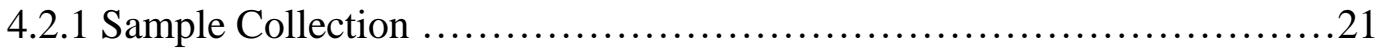

4.2.2 Completely Oxidized Precipitation Procedure ...........................21

4.2.3 Partially Reduced Precipitation Procedure - With and Without Nitrogen

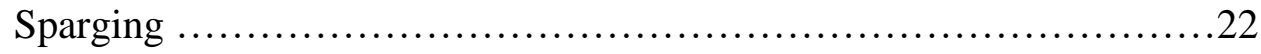

4.2.4 Seeding Test for REE Recovery ....................................22

4.2.5 Sample Preparation for Analysis ...................................23

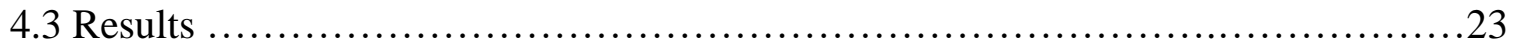

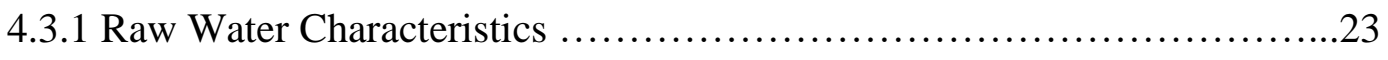

4.3.2 Fully Oxidized Precipitation Procedure .....................................25

4.3.3 Partially Reduced Precipitation Procedure Without Nitrogen Sparging .....26

4.3.4 Partially Reduced Precipitation Procedure With Nitrogen Sparging........27

4.3.5 Seeding Test for REE Recovery ...................................29

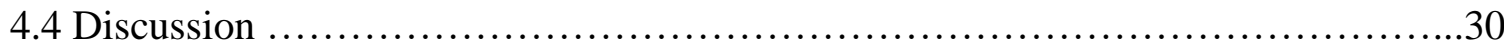

4.4.1 Effects of Redox Conditions on Major Metal Removal .....................30

4.4.2 Effects of Redox Conditions on REE Recovery ...........................32

4.4.3 REE Recovery when Seeding with Iron, Aluminum, and Raw AMD .......32

4.4.4 Separation of REE and Gangue Metals.................................33

5. Comparison of Seven Acid Mine Drainage Locations for REE Recovery ......................35

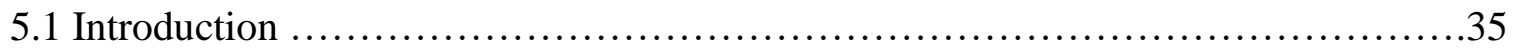

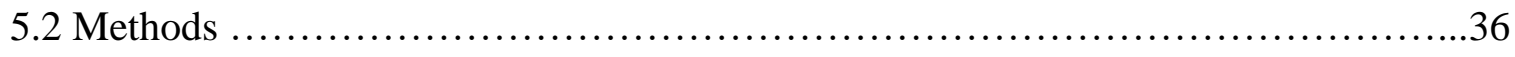

5.2.1 Site Characterization ................................................ 36

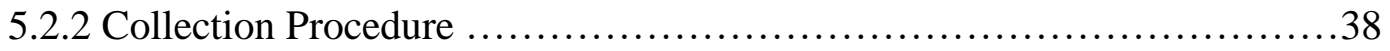

5.2.3 Precipitation Procedure ….......................................... 38

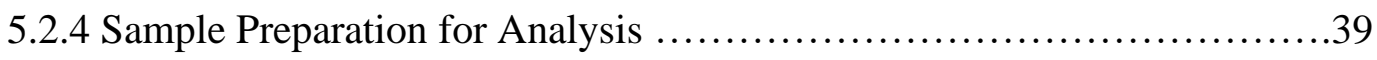

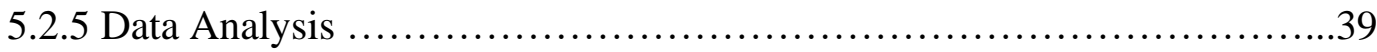

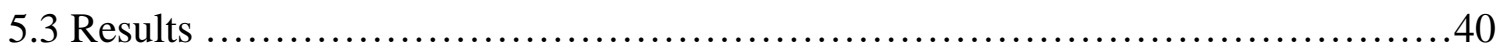


5.3.1 Composition $\mathrm{pH} 4.0$ Precipitates ...................................40

5.3.2 Composition $\mathrm{pH} 5.0$ Precipitates ....................................42

5.3.3 Composition $\mathrm{pH}$ 8.0 Precipitates ..................................44

5.3.4 Rare Earth Recovery .............................................45

5.3.5 Correlation of Raw Water Characteristics and REE Grade and

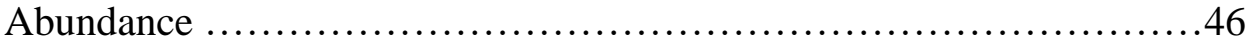

5.4 Discussion .................................................................. 49

5.4.1 Precipitate Composition .............................................49

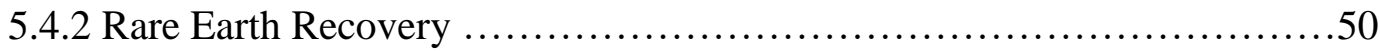

5.4.3 Correlation of REE Grade to Raw Water Characteristics ...................51

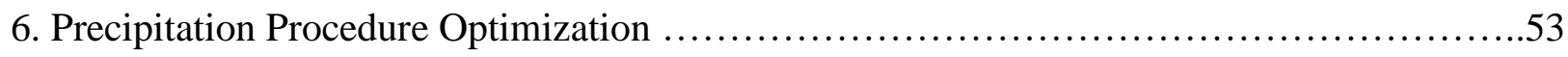

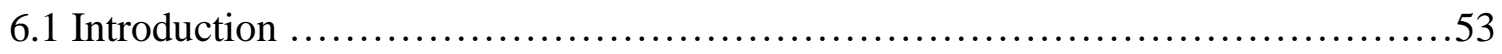

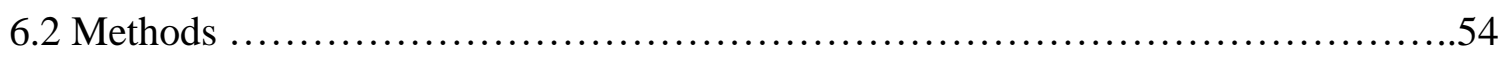

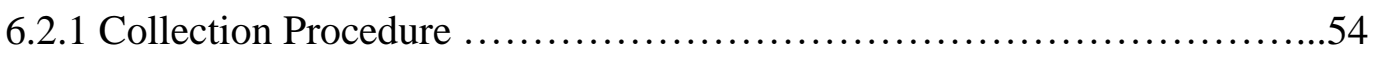

6.2.2 2-Step and 3-Step Precipitation Procedure ............................54

6.2.3 Precipitation with the Addition of Flocculant..............................54

6.2.4 Sample Preparation for Analysis .....................................55

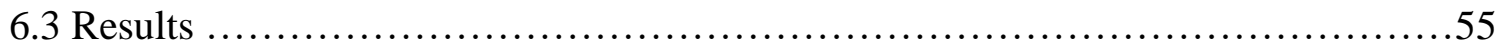

6.3.1 2-Step Precipitation Procedure ......................................55

6.3.2 3-Step Precipitation Procedure ........................................56

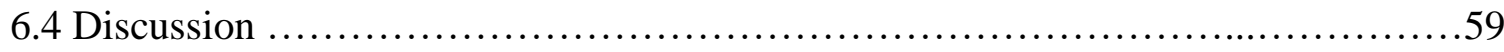

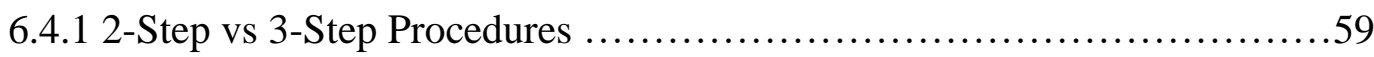

6.4.2 Effects of Flocculant on Precipitates ....................................60

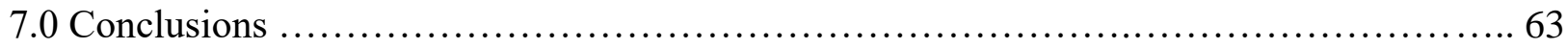

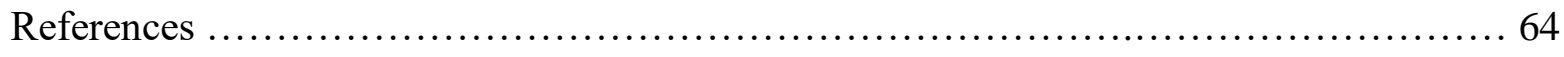




\section{LIST OF TABLES}

Table 2-1 - Precipitation pHs reported in the literature for the major AMD metals and REEs.....8

Table 3-1 - AQ-2 raw water characteristics measured on-site during collection.................12

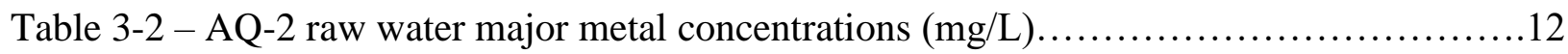

Table 3-3 - AQ-2 raw water rare earth element concentrations. Rare earth elements are separated by LREE and HREE. Sc was grouped with LREE and Y was grouped with HREE............13

Table 3-4 - Comparison of the Pourbaix predicted $\mathrm{pH}$ endpoints and the observed $\mathrm{pH}$ endpoints for the major metals and REEs. Expected $\mathrm{pH}$ endpoints derived from Pourbaix diagrams by

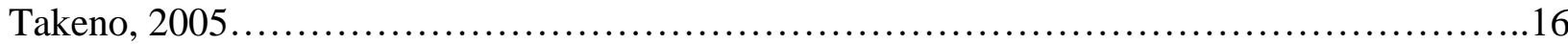

Table 4-1 - AQ-2 raw water characteristics measured on-site during sample collection........24

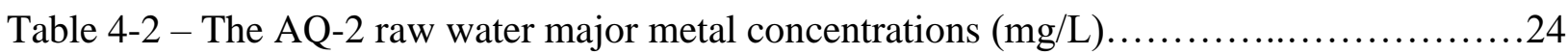

Table 4-3 - The AQ-2 raw water rare earth element concentrations (ug/L). Rare earth elements are separated by LREE and HREE. Sc was grouped with LREE and Y was grouped with

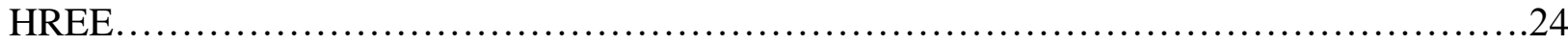

Table 5-1 - Raw water specific conductance, $\mathrm{pH}$, and ORP for the collection sites.............37

Table 5-2 - Dissolved metal concentrations in $\mathrm{mg} / \mathrm{L}$ for the raw AMD collected at all seven

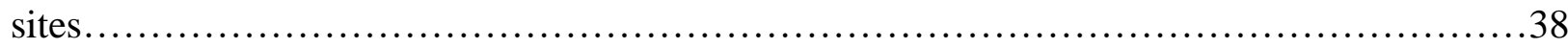

Table 5-3 - Rare earth element concentrations of the raw AMD collected at all seven sites......38

Table 5-4 - Composition of the $\mathrm{pH} 4.0$ precipitates of the seven AMD sites analyzed. ..........41

Table 5-5 - Percent composition of the $\mathrm{pH} 5.0$ precipitates of the seven AMD sites analyzed...43

Table 5-6 - Percent composition of the $\mathrm{pH} 8.0$ precipitates of the seven AMD sites analyzed...44

Table 5-7 - Correlation of raw water characteristics to the REE grade of the $\mathrm{pH} 8.0$ precipitates

Table 6-1 - Concentrations of the metals and REEs ( $\mathrm{mg} / \mathrm{kg}$ ) for the $\mathrm{pH} 4.0$ precipitates for the 3step precipitations with and without flocculant addition................................57

Table 6-2 - Concentrations of the metals and REEs $(\mathrm{mg} / \mathrm{kg})$ for the $\mathrm{pH} 5.0$ precipitates for the 2and 3 -step precipitations with and without flocculant addition...........................57

Table 6-3 - Concentrations of the metals and REEs ( $\mathrm{mg} / \mathrm{kg}$ ) for the $\mathrm{pH} 8.0$ precipitates for the 2and 3-step precipitations with and without flocculant addition.

Table 6-4 - Comparison of REE grade and recovery between the 2-step and 3-step precipitation procedures, as well as with and without flocculant addition at $\mathrm{pH} 5.0 \ldots \ldots \ldots \ldots \ldots \ldots \ldots \ldots . . .58$ 


\section{LIST OF FIGURES}

Figure 1-1 -Locations of active and passive AMD treatment sites across WV operated by the West Virginia Department of Environmental Protection (WVDEP) (Water Treatment 2020)......1

Figure 2-1 - Active and passive treatment methods for acid mine drainage...................6

Figure 3-1 - Percent removal of metals during the $0.5 \mathrm{pH}$ step precipitation. Percent removal was calculated by comparing concentrations from the raw AMD to the treated filtrates..............14

Figure 3-2 - Percent removal of the REEs from the $0.5 \mathrm{pH}$ step precipitation. The REEs were separated into the heavy REEs (Y, Gd-Lu), light REEs ( $\mathrm{La}-\mathrm{Eu})$, and scandium.

Figure 3-3 - Removal of aluminum plotted with the removal of scandium during the $0.5 \mathrm{pH}$ step adjustment.

Figure 4-1 - Percent removal of metals during the fully oxidized AMD (a), partially reduced with oxidizing conditions (b), and partially reduced with reducing conditions (c). Percent removal was calculated by comparing concentrations from the raw AMD to the treated filtrates.

Figure 4-2 - Percent removal of the REEs from the fully oxidized AMD (a), partially reduced with oxidizing conditions (b), and partially reduced with reducing conditions (c). The REEs were separated into the heavy REEs (Y, Gd-Lu), light REEs (La - Eu), and scandium..........29

Figure 4-3 - Removal of REEs from pH 8.0 filtrate after seeding with iron precipitate, aluminum precipitate, and raw AMD.

Figure 4-4 - Comparison of metal and REE removal from AMD in fully oxidized conditions, oxidizing conditions, and reducing conditions. The removal of iron (a), aluminum (b), scandium (c), HREE (d), and LREE (e) were compared between the three precipitation conditions........34

Figure 5-1 - Locations across northern West Virginia of the seven AMD collection sites: AQ-2, AQ-8, AQ-50, AQ-51-5, AQ-3, AQ-65, and AQ-67................................. 37

Figure 5-2 - Weight percentages of the $\mathrm{pH} 4.0$ precipitates of the seven AMD sites............42

Figure 5-3 - Weight percentages of the $\mathrm{pH} 5.0$ precipitates of the seven AMD sites............43

Figure 5-4 - Weight percentages of the $\mathrm{pH} 8.0$ precipitates of the seven AMD sites............45

Figure 5-5 - Percent recovery of the light rare earth elements and scandium for the seven AMD samples

Figure 5-6 - Percent recovery of the heavy rare earth elements and yttrium for the seven AMD samples 
Figure 5-7 - Comparison of the raw water REE concentration and the resulting $\mathrm{pH} 8.0$ precipitate REE grade for all seven AMD sources.....................................47

Figure 5-8 - The comparison of REE grade to the ratio of iron to aluminum (A) and major metals

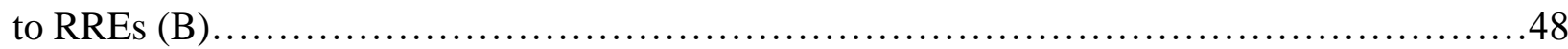

Figure 6-1 - Percent of overall recovery of rare earth elements from raw water for the 2-step procedure without flocculant (a), 2-step procedure with flocculant addition (b), 3-step procedure without flocculant (c), and the 3 -step procedure with flocculant addition (d) ...................58

Figure 6-2-Comparison of $\mathrm{pH} 8.0$ precipitate REE and silica percentage. This data was collected from a 3-step precipitation of AQ-50 raw water. 


\section{Introduction}

\subsection{Background}

Whether it has been in underground or surface mines, coal mining has supplied the primary fuel source of the United States since 1961. There are three major coal producing regions in the US, which are the Appalachian coal region, the interior coal region, and the western coal region. In the year 2019 approximately $27 \%$ of the total coal produced in the US was mined in the Appalachian coal region (13.2\% coming from West Virginia) (U.S. Energy Information Administration 2020).

West Virginia has a long history of coal mining, beginning in the early 1800 's. Until 1977, there were no major regulations for the management of environmental impacts of mining. Many of the mines prior to the implementation of the Surface Mining Control and Reclamation Act of 1977 (SMRCA) caused the creation of acid mine drainage (AMD) due to the exposure of sulfidic materials post mining. Many of these mine sites are considered abandoned mine lands (AML), as no one other than governmental departments are responsible for reclamation. While there is progress being made towards reclamation of these AML as seen below in Figure 1-1, there are still thousands of miles of waterways affected by AMD across the United States.

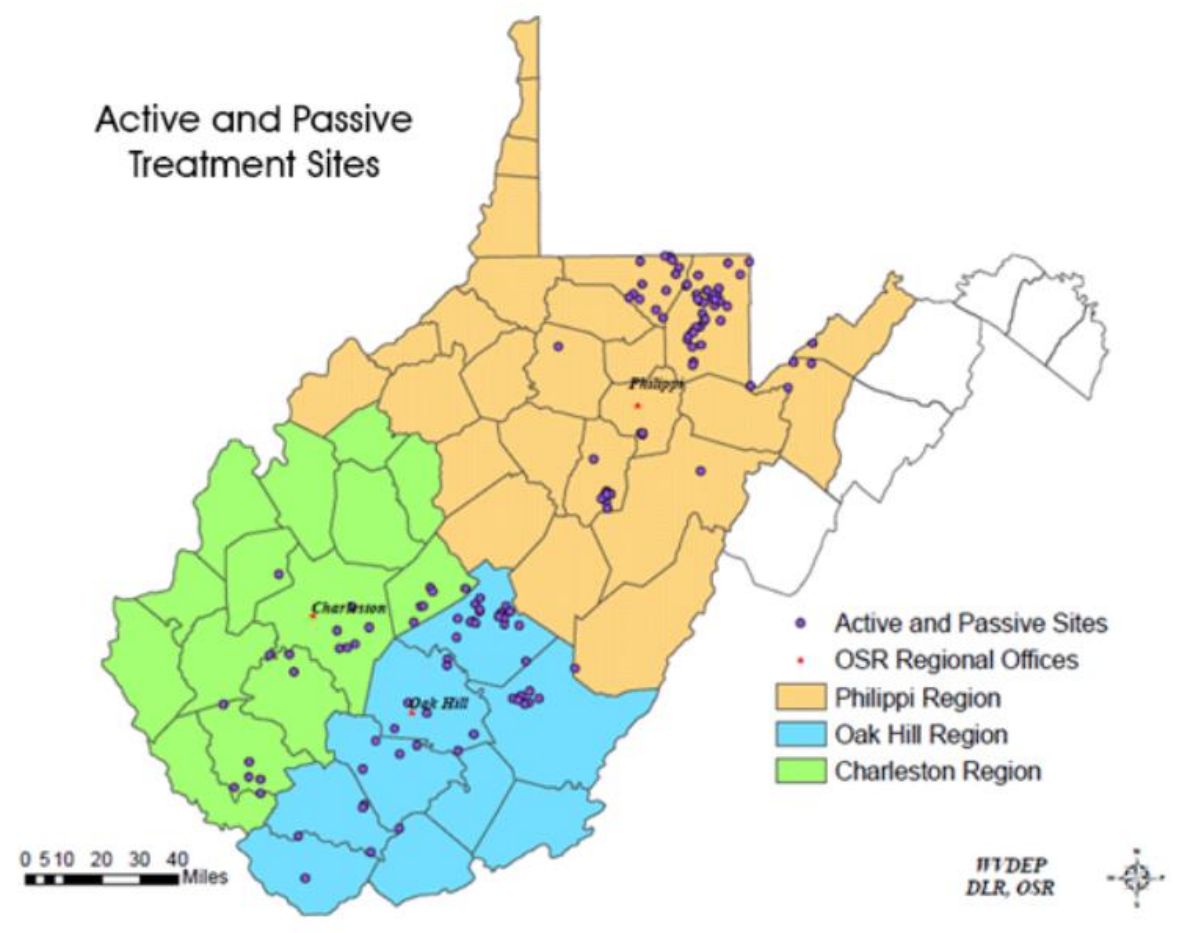

Figure 1-1: Locations of active and passive AMD treatment sites across WV operated by the West Virginia Department of Environmental Protection (WVDEP) (Water Treatment 2020) 
While the sludges produced during active treatment of AMD are generally thought of as waste materials, they are great sources of heavy metals. Wei et al. (2005) determined that relatively pure iron and aluminum precipitates could be generated via selective precipitation of AMD. In addition to heavy metals, the concentrations of rare earths in AMD are substantially higher than in natural water sources and rare earth elements (Verplanck et al. 2004, Zhao et al. 2007, Stewart et al. 2017). Due to this, it is possible that AMD could provide an efficient source for REE recycling and recovery.

The rare earth elements are 17 chemically similar elements which are of high value due to their widespread uses. The demand for REEs has been increasing yearly due to their use in many different industries. Rare earths are mainly used either as process enablers or as building blocks of new technologies (Hatch 2012). Their use as process enablers include fluid cracking catalysts, automotive catalysts, and polishing media. REEs are also commonly used in many green technologies, like the magnets within wind turbines and rechargeable batteries.

Currently, the REE market is monopolized by Chinese exports. China is responsible for greater than $90 \%$ of the REE supply globally while containing only $40 \%$ of global REE reserves (Jacoby \& Jiang 2010). While at least 34 countries have REE deposits, these deposits might not be economically viable to mine or the country itself does not have the capability for downstream processing (Alonso et al. 2012, Binnemans et al. 2013, Zhanheng 2011). The need for new sources of rare earths is strengthened by the growing global demand and the reliance on China as the main source of REEs. In recent years, changes to Chinese export quotas has severely impacted the REE market, suggesting that the ability for importation might not be guaranteed in the future. Prior to 2010, the export quotas did not significantly impact the market as supply was matched by demand (Hatch 2012). However, the export quotas enacted in 2010 reduced exports by $72 \%$, which granted them more control on the pricing of REEs (Jacoby \& Jiang 2010). While many countries were concerned with meeting demands for REEs, China viewed the supply cuts as opportunities for other countries to expand and develop alternative sources for REEs. In 2012, the Chinese Ministry of Commerce (MOC) announced that exports would decrease by $40 \%$ from the previous year which resulted in a spike in REE prices (Hatch 2012). Although the trade dispute filed by the World Trade Organization led to the removal of the offending export quotas by 2015 , the possibility of future quotas exists. It is important to consider secondary waste streams as well as primary mines as possible future REE sources.

\subsection{Purpose and Objectives}

This study focused on the development and optimization of a selective precipitation procedure for REE recovery from acid mine drainage (AMD). Previous research has shown that REEs can be recovered from AMD through precipitation with gangue metals. This study continues and expands upon that research by assessing the removal $\mathrm{pH}$ ranges of dissolved metals and REEs for various AMD sources. In addition, the effects of redox conditions and flocculant use were determined to create a precipitation procedure for widespread application. To 
better aid in AMD site surveying, the variability of the produced sludges and the correlations of precipitate grade to raw water characteristics were also assessed across 7 AMD sites.

The broad objectives of this research include the following:

1) Determine the viability and create a procedure to recover rare earth elements from acid mine drainage via selective precipitation.

2) Assess the possible correlations between raw water characteristics of AMD and the REE grade of the resulting precipitates to determine if raw water characteristics can improve the surveying of AMD locations

3) Determine the effects of redox conditions and flocculant use to optimize the precipitation procedure and produce sludges of at least $1 \%$ REE.

To achieve the scope of the first objective involved collecting acid mine drainage and adjusting $\mathrm{pH}$ sequentially between $\mathrm{pHs} 3.0$ and 8.0. The $\mathrm{pH}$ ranges of gangue metal and REE precipitation were analyzed to determine if efficient separation of REEs could occur.

To achieve the scope of the second objective, AMD samples were collected from seven sites across northeastern WV. Each sample was adjusted sequentially to $\mathrm{pH}$ 4.0, 5.0, and 8.0. The composition of the precipitates and overall REE recovery were analyzed and compared for each sample. Linear regression was then used to assess correlations between raw water characteristics and the grade of the precipitates. It was determined that the precipitate grade was independent of the raw water REE concentration and could not be accurately predicted using raw water characteristics.

To achieve the scope of the third objective, the precipitation procedure was repeated under varying redox conditions, which included complete oxidation, partial reduction with nitrogen sparging, and partial reduction without nitrogen sparging. The effects were assessed by comparing changes in precipitation patterns of gangue metals and REEs. The completely oxidized condition led to a greater separation of $\mathrm{pH}$ range between the metals and REEs when compared to the partially reduced conditions. The effects of flocculant usage were also examined for this objective. Jar tests were conducted to determine optimal dosage during the precipitation procedure. The flocculated precipitates were analyzed to determine if there were any differences in composition to the precipitates without flocculant. The use of flocculant was shown to increase overall REE recovery but decrease the weight percent of REE in the precipitate. Based on these findings, recommendations are provided to optimize the efficiency of the selective precipitation procedure. 


\section{Literature Review}

\subsection{Rare Earth Elements (REEs)}

The rare earth elements (REEs) consist of 17 metallic elements that share similar chemical properties. REEs include the lanthanides: lanthanum (La), cerium $(\mathrm{Ce})$, praseodymium $(\mathrm{Pr})$, neodymium $(\mathrm{Nd})$, promethium $(\mathrm{Pm})$, samarium $(\mathrm{Sm})$, europium $(\mathrm{Eu})$, gadolinium $(\mathrm{Gd})$, terbium (Tb), dysprosium (Dy), holmium (Ho), erbium (Er), thulium (Tm), ytterbium (Yb), and lutetium (Lu). Promethium is not generally included when discussing the REEs in general because it is extremely rare and radioactive. Very low concentrations are present in the Earth's crust at any given time. Scandium (Sc) and yttrium (Y) are not lanthanides but are chemically similar and are grouped into the REEs as well. (Binnemans et al. 2013, Byrne \& Li 1995, and Hatch 2012).

These rare earths are usually separated into 2 subgroups based on atomic weight and behavior. The two groups are light rare earth elements (LREEs) and heavy rare earth elements (HREEs). Generally, the LREEs consist of lanthanum through europium, while the HREEs consist of gadolinium through lutetium and yttrium (Hatch 2012). However, the placement of REEs into these groups is debatable. Gadolinium has been reported to display characteristics of both LREEs and HREEs. Byrne \& Li (1995) reported that Gd shares the strong inner-sphere complexation of LREEs while still maintaining a weaker outer-sphere complexation characteristic of HREEs. Due to the disagreements on the placements of the REEs into the two groups, some have adopted the use of a third subgroup, middle rare earth elements (MREEs). With the third subgroup, the LREEs include $\mathrm{La}, \mathrm{Ce}, \mathrm{Pr}, \mathrm{Nd}$, and Sm. The MREEs are Eu, Gd, Tb, Dy, and Y. Finally, the HREEs include Ho, Er, Tm, Yb, and Lu (Hedin et al. 2019). While the use of MREEs is becoming more prevalent in the current literature, this research will continue to use the LREEs and HREEs as defined above by Hatch (2012).

The demand for REEs has been increasing drastically during the past decade due to advancements made in green and sustainable technology. It has been projected by Alonso et al. (2012) that the demand for the most valuable REEs, Nd and Dy, will increase by $700 \%$ and $2600 \%$ by 2037 , respectively. While many different industries rely on REEs, the main uses of REEs are either as process enablers or building blocks (Ayora et al. 2016 and Hatch 2012). Their use as process enablers include fluid cracking catalysts, automotive catalysts, and polishing media. REEs are also commonly used as building blocks in many green technologies, like the magnets within wind turbines and rechargeable batteries.

\subsection{Acid Mine Drainage (AMD)}

Acid mine drainage (AMD) is the product of oxygen and water exposure to metal sulfides that are prevalent in mined areas. The most important metal sulfide that contributes to AMD creation is pyrite, or $\mathrm{FeS}_{2}$. When pyrite is exposed to water and oxygen, the iron sulfide is 
oxidized and produces ferrous iron $\left(\mathrm{Fe}^{2+}\right)$, sulfate, and acidity. If there is an excess of oxygen present, the ferrous iron will oxidize to ferric iron $\left(\mathrm{Fe}^{3+}\right)$. Depending on the $\mathrm{pH}$ of the AMD, the ferric iron will either precipitate out of solution or stay in solution and react with pyrite. The reaction between ferric iron and pyrite is where the bulk of the acidity comes from during AMD production. These chemical reactions are as described below in Equations 1-4 (Singer and Strumm 1970).

1. $\mathrm{FeS}_{2}+7 / 2 \mathrm{O}_{2}+\mathrm{H}_{2} \mathrm{O}->\mathrm{Fe}^{2+}+2 \mathrm{SO}_{4}{ }^{2+}+2 \mathrm{H}^{+}$

Equation 1

2. $\mathrm{Fe}^{2+}+1 / 4 \mathrm{O}_{2}+\mathrm{H}^{+}->\mathrm{Fe}^{3+}+1 / 2 \mathrm{H}_{2} \mathrm{O}$

Equation 2

3. $\mathrm{Fe}^{3+}+3 \mathrm{H}_{2} \mathrm{O}->\mathrm{Fe}(\mathrm{OH})_{2}+3 \mathrm{H}^{+}$

Equation 3

4. $\mathrm{FeS}_{2}+14 \mathrm{Fe}^{3+}+\mathrm{H}_{2} \mathrm{O}->12 \mathrm{Fe}^{2+}+2 \mathrm{SO}_{4}^{2+}+16 \mathrm{H}^{+}$

Equation 4

The acidity and low $\mathrm{pH}$ associated with AMD creation causes heavy metals and REEs to leach from the surrounding minerals. The composition of the parent rock material strongly influences the dissolved metal concentrations of AMD (Merten et al. 2005). The metals which are most associated with acid mine drainage include iron $(\mathrm{Fe})$, aluminum $(\mathrm{Al})$, copper $(\mathrm{Cu})$, cadmium (Cd), manganese (Mn), magnesium (Mg), and zinc (Zn) (Gray 1996, Kirby et al. 1999, and Skousen et al. 1998). In addition to the dissolved heavy metals, REEs are often found to be at concentrations substantially higher in AMD than natural water sources (Verplanck et al. 2004, Zhao et al. 2007, Stewart et al. 2017).

While the REE concentrations of AMD are beneficial as a secondary source for REE recovery, the high concentration of leached heavy metals is a cause for environmental concern. Aside from metal toxicity, the other major environmental impacts of AMD include increased acidity, low $\mathrm{pH}$, and changes to natural sedimentation processes (Gray 1997). When AMD is introduced to water systems, these changes have been shown to negatively impact the flora and fauna present. DeNicola et al. (2002) studied the impacts of AMD on benthic communities in streams and determined that the increased metal concentrations significantly decreased the survival of the caddisfly species present. Similar effects were reported by Soucek et al. (2000), where the effects of AMD on Puckett's Creek led to the increased mortality rate of Daphnia magna (aka water fleas) due to the low $\mathrm{pH}$ and dissolved metal concentrations.

It is estimated that in the US, approximately 12,400 miles of streams and rivers are severely impacted by acid mine drainage (Skousen et al. 2019). However, the main source of AMD is not from active mine sites. Active mines do not significantly contribute to AMD pollution in the US because they are regulated by the Surface Mining Control and Reclamation Act of 1977 (SMRCA), which regulates the mine discharges for parameters such as metal concentration and $\mathrm{pH}$. The majority of AMD is caused by abandoned mine lands (AML) because they do not have anyone responsible for their treatment (Skousen and Ziemkiewicz 2000). While 
SMRCA does have a reclamation program specifically for AML, the difficulty is in locating and treating the nonpoint source pollution.

There are many different treatment methods for AMD, which include active and passive methods shown below in Figure 2-1. Passive treatment methods do not use chemical additions and instead rely on naturally occurring processes to remediate polluted sites, both biotic and abiotic. The efficiency of the passive treatment often varies depending on the quality of the incoming AMD as well as the type of passive treatment chosen. Currently, passive treatment is not as reliable as active treatment in the long term (Skousen and Ziemkiewicz 2000).

Active treatment methods mainly rely on aeration to oxidize and the addition of alkaline chemicals to neutralize the $\mathrm{pH}$. Various alkaline chemicals have been used for $\mathrm{pH}$ neutralization, but common chemicals include lime (calcium oxide), caustic soda (sodium hydroxide), and ammonia (Skousen and Ziemkiewicz 2000). When the solution $\mathrm{pH}$ increases due to these chemicals, the dissolved metals begin to precipitate out of solution. The metal precipitates are then settled out of solution in settling ponds before the water is discharged.

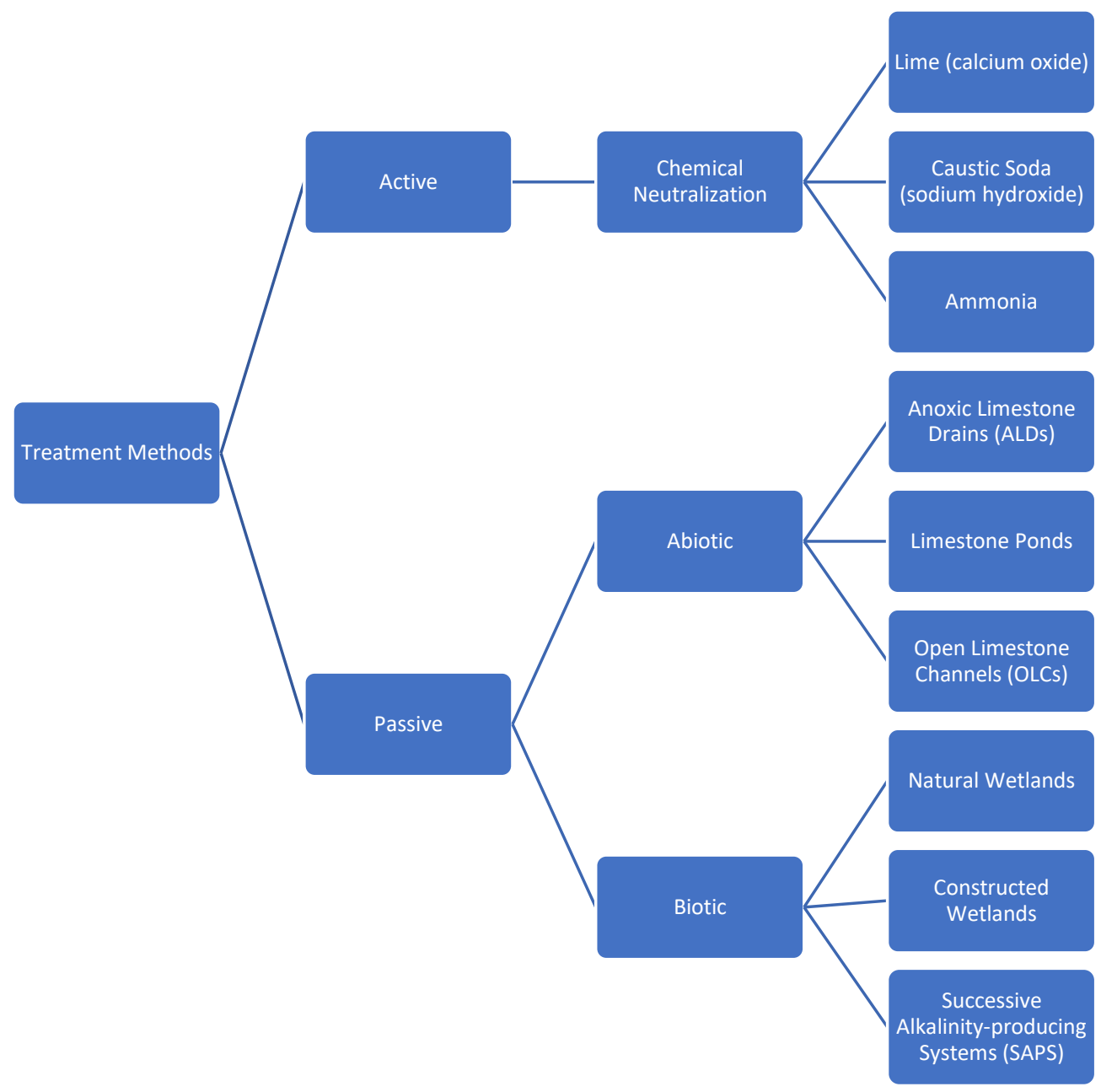

Figure 2-1: Active and passive treatment methods for acid mine drainage 
When using chemical neutralization, the raise in $\mathrm{pH}$ causes the dissolved metals to begin precipitating out. The precipitation of the major components of AMD is well documented, with $\mathrm{pH}$ ranges reported given below in Table 2-1. The major component of AMD, iron, has two common oxidation states, +2 (ferrous) and +3 (ferric). While values varied across AMD samples, generally the ferric iron precipitated out between pH 3.0 and 4.5 (Balintova et al. 2011, Jenke \& Diebold 1983, Matlocke et al. 2002, Skousen et al. 1998, Wei et al. 2005). Ferrous iron does not begin precipitating out of solution until pH 8.0 (Balintova et al. 2011, Skousen et al. 1998). Aluminum, another major component of many sources of AMD, has been reported to precipitate between $\mathrm{pH} 4.0$ and 5.0. If the $\mathrm{pH}$ is raised above 9.0, then the precipitated aluminum will begin to dissolve back into solution (Balintova et al. 2011, Jenke \& Diebold 1983, Matlocke et al. 2002, Skousen et al. 1998). However, Wei et al. (2005) have reported aluminum removal occurring between pH 6.0 and 7.0. Manganese is reported to precipitate out between $\mathrm{pH} 6.0$ and 9.0, while magnesium precipitates above pH 8.0 (Balintova et al. 2011, Jenke \& Diebold 1983, Skousen et al. 1998). Jenke \& Diebold (1983) state that both zinc and copper precipitate out between $\mathrm{pH} 5.0$ and 6.0

The recovery of rare earths during $\mathrm{pH}$ neutralization of AMD has also been assessed. REEs have been shown to be removed from solution at $\mathrm{pHs}$ above the bulk of metal removal (iron and aluminum). Hedin et al. (2019) have reported 90\% REE recovery above pH 6.0, with MREE and HREE enrichment in the precipitates. Verplanck et al. (2004) observed REE recovery at a slightly lower $\mathrm{pH}$ of 5.13. HREE enrichment of the precipitate was also reported. Finally, Zhang \& Honaker (2018) reported a similar $\mathrm{pH}$ range for REE recovery. Greater than $80 \%$ of the REEs were recovered between $\mathrm{pH} 4.85$ and 6.11, with MREE enrichment in the precipitates. 
Table 2-1: Precipitation pHs reported in the literature for the major AMD metals and REEs.

\begin{tabular}{|c|c|c|c|c|c|}
\hline Element & $\begin{array}{c}\text { Precipitation } \\
\text { pH Range }\end{array}$ & Source & Element & $\begin{array}{c}\text { Precipitation } \\
\text { pH Range }\end{array}$ & Source \\
\hline \multirow{4}{*}{ Fe3+ } & 3.5 & $\begin{array}{c}\text { Balintova et al. } \\
\text { (2011) and } \\
\text { Skousen et al. } \\
(1998)\end{array}$ & \multirow{3}{*}{ Mn } & 9.0 & $\begin{array}{l}\text { Balintova et al. } \\
\text { (2011) }\end{array}$ \\
\hline & $3.0-4.0$ & $\begin{array}{c}\text { Jenke \& Diebold } \\
\text { (1983) }\end{array}$ & & $6.0-8.0$ & $\begin{array}{l}\text { Jenke \& Diebold } \\
\text { (1983) }\end{array}$ \\
\hline & $3.0-4.5$ & $\begin{array}{l}\text { Matlocke et al. } \\
(2002)\end{array}$ & & $9.0-9.5$ & $\begin{array}{c}\text { Skousen et al. } \\
\text { (1998) }\end{array}$ \\
\hline & $3.5-4.0$ & Wei et al. (2005) & Mg & 8.0 & $\begin{array}{c}\text { Jenke \& Diebold } \\
(1983)\end{array}$ \\
\hline $\mathrm{Fe} 2+$ & 8.5 & $\begin{array}{c}\text { Balintova et al. } \\
\text { (2011) and } \\
\text { Skousen et al. } \\
(1998)\end{array}$ & $\mathbf{C u}$ & $5.0-6.0$ & $\begin{array}{c}\text { Jenke \& Diebold } \\
\text { (1983) }\end{array}$ \\
\hline \multirow{4}{*}{ Al } & 5.0 & $\begin{array}{l}\text { Balintova et al. } \\
\text { (2011) }\end{array}$ & $\mathbf{Z n}$ & $5.0-6.0$ & $\begin{array}{c}\text { Jenke \& Diebold } \\
\text { (1983) }\end{array}$ \\
\hline & 4.0 & $\begin{array}{c}\text { Jenke \& Diebold } \\
(1983)\end{array}$ & \multirow{3}{*}{ REEs } & 6 & $\begin{array}{c}\text { Hedin et al. } \\
(2019)\end{array}$ \\
\hline & 4.5 & $\begin{array}{c}\text { Skousen et al. } \\
\text { (1998) }\end{array}$ & & 5.13 & $\begin{array}{c}\text { Verplanck et al. } \\
(2004)\end{array}$ \\
\hline & $6.0-7.0$ & Wei et al. (2005) & & $4.85-6.11$ & $\begin{array}{c}\text { Zhang \& Honaker } \\
\text { (2018) }\end{array}$ \\
\hline
\end{tabular}




\section{Selective Precipitation of Acid Mine Drainage in $0.5 \mathrm{pH}$ Increments}

\subsection{Introduction}

Rare earth elements (REEs) consist of 17 elements which are grouped together due to their similar chemical properties. These elements include the 15 lanthanides: lanthanum (La), cerium $(\mathrm{Ce})$, praseodymium $(\mathrm{Pr})$, neodymium $(\mathrm{Nd})$, promethium $(\mathrm{Pm})$, samarium $(\mathrm{Sm})$, europium (Eu), gadolinium (Gd), terbium ( $\mathrm{Tb}$ ), dysprosium (Dy), holmium (Ho), erbium (Er), thulium (Tm), ytterbium (Yb), and lutetium (Lu). The rare earth elements also include yttrium (Y) and scandium (Sc). It is common for the REEs to be separated into at least two subgroups based on atomic weight, light rare earths (LREEs) and heavy rare earths (HREEs). LREEs are the elements lanthanum through europium, while HREEs are gadolinium through lutetium (Byrne \& Li 1995).

The demand for REEs has been increasing yearly due to their use in many different industries. It has been projected by Alonso et al. (2012) that the demand for the most valuable REEs, Nd and Dy, will increase by $700 \%$ and $2600 \%$ over the next 25 years, respectively. Rare earths are mainly used either as process enablers or as building blocks of new technologies (Hatch 2012). Their use as process enablers include fluid cracking catalysts, automotive catalysts, and polishing media. REEs are also commonly used in many green technologies, like the magnets within wind turbines and rechargeable batteries.

Currently, the REE market is monopolized by Chinese exports. China is responsible for greater than $90 \%$ of the REE supply globally while containing only $40 \%$ of global REE reserves (Jacoby \& Jiang 2010). While at least 34 countries have REE deposits, these deposits might not be economically viable to mine or the country itself does not have the capability for downstream processing (Alonso et al. 2012, Binnemans et al. 2013, Zhanheng 2011). The need for new sources of rare earths is strengthened by the growing global demand and the reliance on China as the main source of REEs. It is important to consider secondary waste streams as well as primary mines as possible future REE sources.

One secondary REE source which should be considered is acid mine drainage (AMD) (Ayora et al. 2016, Stewart et al. 2017). AMD is the result of oxygen and water exposure to the iron-sulfide compounds that are prevalent in the mined areas. The oxidation of the iron-sulfide compounds causes acidification through the production of sulfuric acid and hydrogen ions. The acidification allows for the leaching of rare earth elements and heavy metals from the surrounding geologic materials. The concentration of REE in acid mine drainage has been found to be significantly higher than natural waters (Verplanck et al. 2004, Zhao et al. 2007, Stewart et al. 2017) The acidity, $\mathrm{pH}$, and heavy metal concentrations of AMD pose a serious risk to human health and can significantly impact the environment (Akcil \& Koldas, 2006, and Gray 1997). 
Due to the environmental and human health risks, large AMD streams are often treated to reduce environmental impacts. One of the main treatment methods for AMD is to actively treat with a neutralizing agent, which can include lime, sodium hydroxide, or ammonium (Johnson \& Hallberg 2005). This process raises the $\mathrm{pH}$ of the AMD, which also aides in ferrous iron oxidation and the precipitation of some aqueous metal species. It has also been shown that rare earth elements can be precipitated from acid mine drainage (Hedin et al. 2019 and Zhang \& Honaker 2018). This presents an opportunity for a process which incorporates both AMD treatment and REE recovery. This process is explored in this research via sequential $\mathrm{pH}$ adjustment of an acid mine drainage sample to determine the $\mathrm{pH}$ of removal for the major metal and REE constituents.

\subsection{Sample Collection}

Acid mine drainage was collected from site AQ-2, an AMD treatment facility 6.5 miles south of Morgantown. The AMD was collected upstream of the clarifier, through an access hatch to the inlet pipe. Water was collected in 5-gallon buckets and transported back to the lab. In addition, a $250 \mathrm{~mL}$ plastic bottle was collected with no head space for metal analysis. The water temperature, pressure, conductance, specific conductance, $\mathrm{pH}$, and ORP were recorded in field using a YSI field meter. Ferrous iron concentration was determined using the phenanthroline method (Hach method 8146). If ferrous iron was present, the water was completely oxidized through the addition of $30 \%$ hydrogen peroxide prior to $\mathrm{pH}$ adjustment.

\subsection{Methods}

\section{$\underline{3.3 .10 .5 \mathrm{pH} \text { Step Precipitation }}$}

The raw AMD collected from AQ-2 was adjusted to pHs ranging from 3.0 to 9.0 in 0.5 $\mathrm{pH}$ increments. A 5-gallon bucket containing 16L of fully oxidized AMD was adjusted to each $\mathrm{pH}$ step using $4 \mathrm{~N}$ sodium hydroxide. One bucket was adjusted for each $\mathrm{pH}$ step to ensure there was enough precipitate for analysis. The sodium hydroxide was mixed in a dropwise method until the target $\mathrm{pH}$ was acquired. Equilibrium was assumed when there was no change in $\mathrm{pH}$ after one hour. For the buckets adjusted to $\mathrm{pH} 3.0,3.5$, and 4.0, sodium hydroxide was added to the target $\mathrm{pH}$. The AMD was then filtered via vacuum filtration through a $0.22 \mathrm{um}$ filter. For the buckets adjusted to $\mathrm{pH} 4.5$ - 9.0, the AMD was adjusted to $\mathrm{pH} 4.0$ using the 4N sodium hydroxide. Each bucket was then filtered to remove the iron precipitate. The filtrate was then adjusted to the target $\mathrm{pH}$. The adjusted AMD was filtered via vacuum filtration, with the precipitate and filtrate samples collected for analysis.

\subsubsection{Sample Preparation for Analysis}

Samples of the raw AMD and the filtrates and precipitates from each $\mathrm{pH}$ step were collected. The collected precipitate slurries were dewatered, and the weight and volume of each 
were recorded. The aqueous samples which were collected during the staged-precipitation process were preserved with $70 \%$ trace metal grade nitric acid to prevent metal precipitation before analysis. For each sample, $50 \mathrm{~mL}$ was transferred to a plastic centrifuge tube with a screw cap closure. The sample was then labeled with the corresponding code and set aside for analysis. All samples were analyzed using inductively coupled plasma optical emission spectrometry (ICP-OES) and inductively coupled plasma mass spectrometry (ICP-MS) for major metal (Al, $\mathrm{Ca}, \mathrm{Cd}, \mathrm{Co}, \mathrm{Cr}, \mathrm{Cu}, \mathrm{Fe}, \mathrm{Mg}, \mathrm{Mn}, \mathrm{Ni}$, and Zn) and REE (Sc, Y, La, Ce, Pr, Nd, Sm, Eu, Gd, Tb, Dy, Ho, Er, Tm, Yb, and Lu) concentrations by the NRCCE Analytical Laboratory.

\subsubsection{Calculation of Percent Removal}

The percent removal was calculated for each element to assess their removal efficiencies at all $\mathrm{pH}$ steps. The major metal and REE concentrations of the filtrate samples were compared to the raw water concentration. This was accomplished by dividing the difference between the samples by the raw water concentrations. The resulting value was then changed to a percentage to reflect the total removal. The REE percent removal was calculated by separating the rare earth elements into LREEs (Y, La, Ce, Pr, Nd, Sm, Eu), HREEs (Gd, Tb, Dy, Ho, Er, Tm, Yb, and $\mathrm{Lu}$ ), and scandium. These elements were grouped this way due to their similar recovery behaviors.

\subsection{Results}

\subsubsection{Raw Water Characteristics}

The temperature of the raw water was $13{ }^{\circ} \mathrm{C}$, which was consistent with previous temperatures taken from that site. The $\mathrm{pH}$ was 2.59 , and the ORP was $457.1 \mathrm{mV}$. This indicated that the raw water was not completely oxidized. The conductance and specific conductance were $2024 \mathrm{uS} / \mathrm{cm}$ and $2627 \mathrm{uS} / \mathrm{cm}$, respectively. Aluminum (92.2 mg/L), calcium (121.7 mg/L), iron $(174.7 \mathrm{mg} / \mathrm{L})$, and magnesium $(39.2 \mathrm{mg} / \mathrm{L})$ were the majority of the metals present in the raw water. Cadmium, cobalt, chromium, copper, manganese, nickel, and zinc were present at much lower concentrations, ranging from 0.0 to $2.0 \mathrm{mg} / \mathrm{L}$. As suggested by the low ORP measured on site, the raw water was not completely oxidized. The ferrous iron concentration was $85.91 \mathrm{mg} / \mathrm{L}$, which is approximately $50 \%$ of total iron concentration of the sample. 
Table 3-1: AQ-2 raw water characteristics measured on-site during collection

\begin{tabular}{|c|c|c|c|}
\hline Temperature $\left({ }^{\circ} \mathbf{C}\right)$ & 13 & $\begin{array}{c}\text { Conductance } \\
(\mathbf{u S} / \mathbf{c m})\end{array}$ & 2024 \\
\hline ORP (mV) & 457.1 & Pressure (mmHg) & 726.8 \\
\hline $\mathbf{p H}$ & 2.59 & $\begin{array}{c}\text { Initial Fe } \\
(\mathbf{m g} / \mathbf{L})\end{array}$ & 85.91 \\
\hline $\begin{array}{c}\text { Specific Conductance } \\
(\mathbf{u S} / \mathbf{c m})\end{array}$ & 2627 & \multicolumn{2}{|l}{} \\
\cline { 1 - 3 }
\end{tabular}

Table 3-2: AQ-2 raw water major metal concentrations (mg/L)

\begin{tabular}{|c|c|c|c|}
\hline $\begin{array}{c}\text { Major } \\
\text { Metal }\end{array}$ & $\begin{array}{c}\text { Concentration } \\
(\mathbf{m g} / \mathbf{L})\end{array}$ & $\begin{array}{c}\text { Major } \\
\text { Metal }\end{array}$ & $\begin{array}{c}\text { Concentration } \\
(\mathbf{m g} / \mathbf{L})\end{array}$ \\
\hline $\mathbf{A l}$ & 92.2 & $\mathbf{F e}$ & 174.7 \\
\hline $\mathbf{C a}$ & 121.7 & $\mathbf{M g}$ & 39.2 \\
\hline $\mathbf{C d}$ & 0.0 & $\mathbf{M n}$ & 1.6 \\
\hline $\mathbf{C o}$ & 0.3 & $\mathbf{N i}$ & 0.7 \\
\hline $\mathbf{C r}$ & 0.1 & $\mathbf{Z n}$ & 2.0 \\
\hline $\mathbf{C u}$ & 0.1 & \multicolumn{2}{|l}{} \\
\cline { 1 - 2 } & & &
\end{tabular}


Table 3-3: AQ-2 raw water rare earth element concentrations. Rare earth elements are separated by LREE and HREE. Sc was grouped with LREE and Y was grouped with HREE.

\begin{tabular}{|c|c|c|c|}
\hline $\begin{array}{c}\text { REE } \\
\text { (Heavy) }\end{array}$ & $\begin{array}{c}\text { Concentration } \\
(\mathrm{ug} / \mathrm{L})\end{array}$ & $\begin{array}{c}\text { REE } \\
\text { (Light) }\end{array}$ & $\begin{array}{c}\text { Concentration } \\
(\mathrm{ug} / \mathrm{L})\end{array}$ \\
\hline $\mathbf{Y}$ & 102.7 & Sc & 52.0 \\
\hline Gd & 29.1 & $\mathbf{L a}$ & 17.6 \\
\hline $\mathbf{T b}$ & 5.2 & $\mathrm{Ce}$ & 66.8 \\
\hline Dy & 33.1 & Pr & 11.1 \\
\hline Ho & 6.2 & Nd & 56.6 \\
\hline $\mathbf{E r}$ & 17.9 & $\mathrm{Sm}$ & 18.2 \\
\hline $\mathbf{T m}$ & 2.5 & $\mathbf{E u}$ & 4.9 \\
\hline $\mathbf{Y b}$ & 14.4 & & \\
\hline $\mathbf{L u}$ & 2.2 & & \\
\hline
\end{tabular}

\section{$\underline{3.4 .20 .5 \mathrm{pH} \text { Step Precipitation }}$}

The $0.5 \mathrm{pH}$ step precipitation procedure showed recovery of the metals across a wide $\mathrm{pH}$ range, as seen in Figure 3-1. The majority of the iron (100\%), chromium (92\%), and cadmium (86\%) was removed by $\mathrm{pH} 4.0$. There was no apparent increase in chromium or cadmium removal after this $\mathrm{pH}$ step because the concentration was below detection. Aluminum was recovered between $\mathrm{pH} 4.0$ and 5.5, with $98 \%$ removal by $\mathrm{pH} 5.0$, reaching $100 \%$ by $\mathrm{pH} 5.5$. Copper began precipitating at $\mathrm{pH} 4.5$ and showed $92 \%$ recovery by $\mathrm{pH} 6.0$. As with chromium and cadmium, apparent removal of copper did not exceed $92 \%$ removal as the concentration was below the detection limit. Zinc precipitation occurred between $\mathrm{pH} 6.0$ and reached 100\% removal by $\mathrm{pH} 8.5$. However, $97 \%$ of zinc removal was completed by $\mathrm{pH} 7.5$. Both nickel and cobalt followed very similar removal patterns. Both elements had bulk precipitation between $\mathrm{pH}$ 
6.0 and 9.0. By pH 9.0, 99\% of nickel and 100\% of cobalt was removed. Manganese began to precipitate around $\mathrm{pH} 4.5$, with the bulk of the removal beginning at $\mathrm{pH} 7.0$. $\mathrm{By} \mathrm{pH} 9.0$, only $85 \%$ of the manganese was removed. Both calcium and magnesium had very low recovery from the raw water during the $\mathrm{pH}$ adjustments. Neither were removed efficiently by $\mathrm{pH} 9.0$ with only $8 \%$ of the calcium removed, while $12 \%$ of the magnesium was removed.

The recovery of rare earth elements at each $\mathrm{pH}$ step is shown in Figure 3-2. The REEs were separated into HREEs ( $\mathrm{Gd}$ - Lu, Y), LREEs ( $\mathrm{La}$ - Eu), and scandium. This separation was done to group elements with similar behaviors, as well as to observe differences between the heavy and light REEs. The scandium was recovered considerably earlier than either the HREEs or LREEs, between $\mathrm{pH} 4.0$ and 5.5 (99\% recovery). The removal of scandium followed the same pattern of aluminum, (Figure 3-3), with the bulk of removal occurring between $\mathrm{pH} 4.0$ and 5.0. The recovery of HREE and LREE behaved somewhat differently. Both the HREE and LREE showed similar recoveries at $\mathrm{pH} 3.5,4.0$, and 4.5, but the HREEs had more efficient recovery for the $\mathrm{pH}$ range 5.0 - 6.5. At $\mathrm{pH} 5.0,5.5,6.0$, and 6.5, the HREEs were $20 \%, 47 \%, 85 \%$, and $98 \%$ recovered, respectively. However, the LREE recoveries were much lower at 13\%, 23\%, 53\%, and $88 \%$, respectively for the same $\mathrm{pH}$ steps. The LREEs did not show $98 \%$ recovery until $\mathrm{pH}$ 7.5.

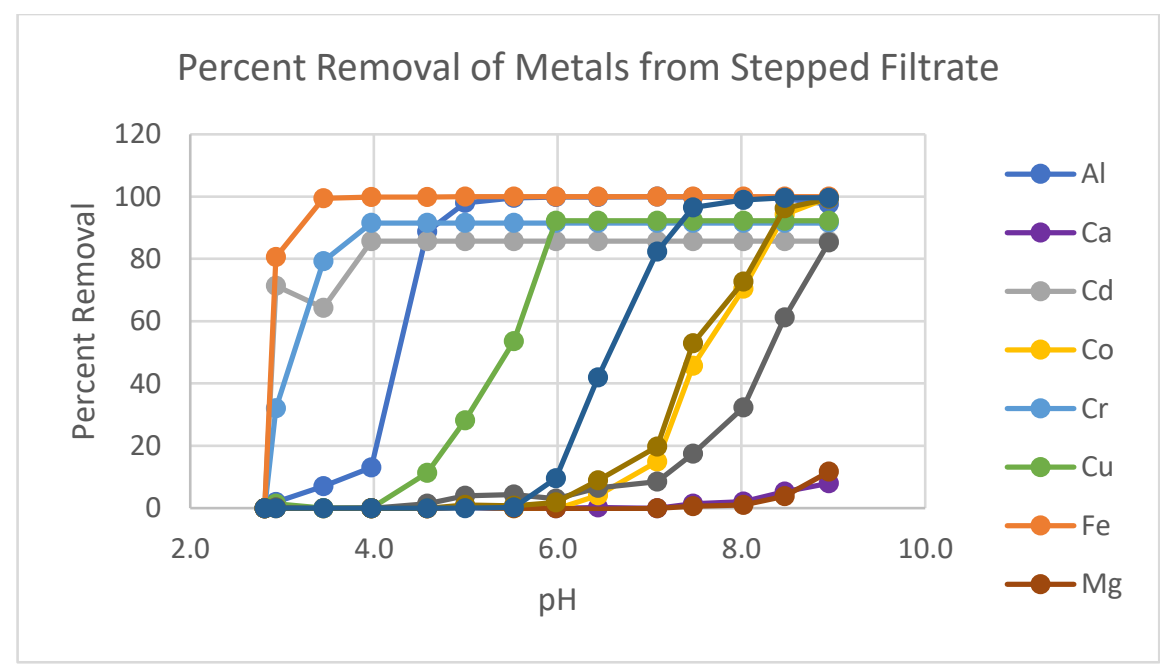

Figure 3-1: Percent removal of metals during the $0.5 \mathrm{pH}$ step precipitation. Percent removal was calculated by comparing concentrations from the raw AMD to the treated filtrates. 


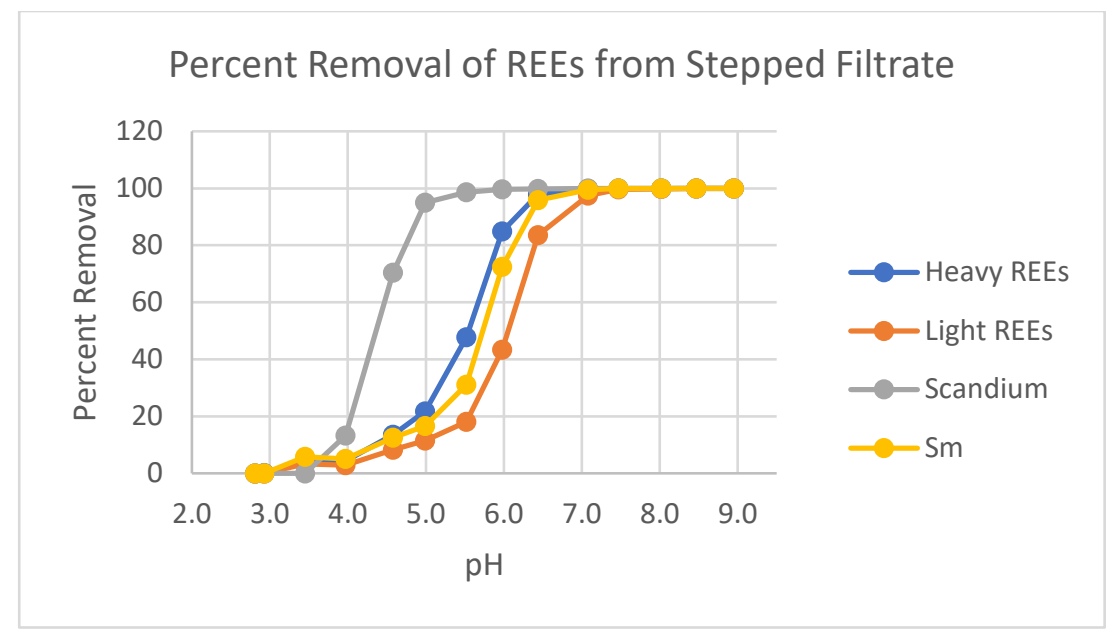

Figure 3-2: Percent removal of the REEs from the $0.5 \mathrm{pH}$ step precipitation. The REEs were separated into the heavy REEs (Y, Gd-Lu), light REEs ( $\mathrm{La}-\mathrm{Eu}$ ), samarium, and scandium

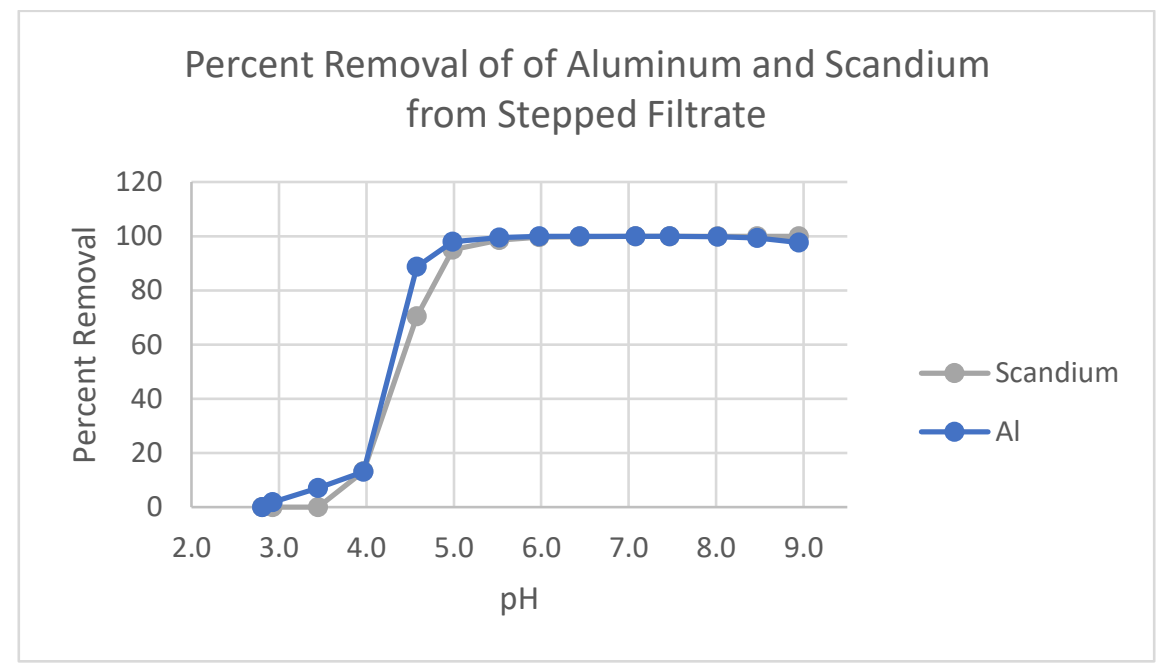

Figure 3-3: Removal of aluminum plotted with the removal of scandium during the $0.5 \mathrm{pH}$ step adjustment

\subsection{Discussion}

\section{$\underline{3.5 .10 .5 \mathrm{pH} \text { Step Precipitation }}$}

The stepwise $\mathrm{pH}$ adjustment of the AQ-2 AMD in $0.5 \mathrm{pH}$ increments was conducted to determine at which $\mathrm{pH}$ the major metals and REEs precipitate from raw AMD with its complex mix of dissolved solids. If the REEs were recovered in a $\mathrm{pH}$ range which was separate from the bulk metal precipitation, the recovery of the REEs via a sequential precipitation procedure could be achieved. The $\mathrm{pH}$ ranges for metal precipitation were initially estimated using Pourbaix 
diagrams, also known as potential/pH diagrams. These diagrams display the possible phases of aqueous constituents based on the $\mathrm{Eh}$ and $\mathrm{pH}$ of the system (Beverskog \& Puigdomenech 1996). Because these diagrams use thermodynamic data, they assume a pure system at standard conditions. As AMD consists of multiple constituents, the $\mathrm{pH}$ of precipitation for many metals may differ with that of the Pourbaix diagrams. A table of expected $\mathrm{pH}$ endpoints for removal and the observed $\mathrm{pH}$ endpoints is shown below in Table 3-4.

Table 3-4: Comparison of the Pourbaix predicted $\mathrm{pH}$ endpoints and the observed $\mathrm{pH}$ endpoints for the major metals and REEs. Expected $\mathrm{pH}$ endpoints derived from Pourbaix diagrams by Takeno, 2005

\begin{tabular}{|c|c|c|c|c|c|}
\hline Element & $\begin{array}{c}\text { Expected pH } \\
\text { Endpoint }\end{array}$ & $\begin{array}{c}\text { Observed pH } \\
\text { Endpoint }\end{array}$ & Element & $\begin{array}{c}\text { Expected pH } \\
\text { Endpoint }\end{array}$ & $\begin{array}{c}\text { Observed pH } \\
\text { Endpoint }\end{array}$ \\
\hline $\mathbf{A l}$ & 5.5 & 5.5 & $\mathbf{C e}$ & 11.0 & 7.5 \\
\hline $\mathbf{C a}$ & 10.5 & N/A* & $\mathbf{P r}$ & 9.0 & 7.0 \\
\hline $\mathbf{C d}$ & 10.0 & 4.0 & $\mathbf{N d}$ & 13.0 & 7.0 \\
\hline $\mathbf{C o}$ & 11.5 & 9.0 & $\mathbf{S m}$ & 12.0 & 7.0 \\
\hline $\mathbf{C r}$ & 5.0 & 4.0 & $\mathbf{E u}$ & 9.5 & 7.0 \\
\hline $\mathbf{C u}$ & 8.0 & 6.0 & $\mathbf{G d}$ & 12.0 & 7.0 \\
\hline $\mathbf{F e}$ & 4.0 & 3.5 & $\mathbf{T b}$ & 10.5 & 7.0 \\
\hline $\mathbf{M g}$ & 11.0 & N/A* & $\mathbf{D y}$ & 11.0 & 7.0 \\
\hline $\mathbf{M n}$ & 8.0 & $>9.0$ & $\mathbf{H o}$ & 11.0 & 7.0 \\
\hline $\mathbf{N i}$ & 9.0 & 9.0 & $\mathbf{E r}$ & 11.0 & 6.5 \\
\hline $\mathbf{Z n}$ & 10.0 & 9.0 & $\mathbf{T m}$ & 10.5 & 6.5 \\
\hline $\mathbf{S c}$ & 5.5 & 6.0 & $\mathbf{Y b}$ & N/A** & 6.5 \\
\hline $\mathbf{Y}$ & 10.5 & 7.0 & $\mathbf{L u}$ & 9.0 & 6.5 \\
\hline $\mathbf{L a}$ & 11.0 & 7.5 & & & \\
\hline
\end{tabular}

*observed $\mathrm{pH}$ endpoints for $\mathrm{Ca}$ and $\mathrm{Mg}$ are unknown because they largely stayed in solution during the experiment

**Expected $\mathrm{pH}$ endpoint for $\mathrm{Yb}$ was not able to be estimated from available Pourbaix diagrams

As seen above in Figure 3-1, the bulk of the major metals were removed between $\mathrm{pH} 3.0$ and 6.0. Both iron and aluminum contribute significantly to the total metal concentration, accounting for approximately $62 \%$. This is not a unique feature of the AQ- 2 acid mine drainage; 
high concentrations of iron and aluminum are commonly found in many AMD sources (Akcil \& Koldas 2006, Balintova \& Petrilakova 2011, Matlock, Howerton \& Atwood 2002).

Iron precipitation began at $\mathrm{pH} 3.0$ and completed by $\mathrm{pH} 3.5$. This was consistent with what was estimated by the Pourbaix diagrams, which was removal by $\mathrm{pH} 4.0 \mathrm{for}^{\mathrm{Fe}^{3+}}$. If the AMD had not been completely oxidized, the $\mathrm{Fe}^{2+}$ present would not have been completely removed until around $\mathrm{pH} 8.0$ (Beverskog \& Puigdomenech 1996). The observed removal of ferric iron is congruent with that observed by Wei et al. (2005) and Jenke \& Diebold (1983). The lower $\mathrm{pH}$ endpoint for iron removal is preferred for the separation of the major metals and the REEs.

Aluminum began slowly precipitating out of solution between $\mathrm{pH} 3.0$ and 4.0. Substantial removal was observed between $\mathrm{pH} 4.0$ and 5.5. The complete removal of aluminum occurred at the estimated $\mathrm{pH}$ of 5.5. While Wei et al. (2005) reported aluminum removal between $\mathrm{pH} 6.0$ and 7.0, our observed removal is consistent with that observed by Balintova et al. (2011) and Jenke \& Diebold (1983),

Cadmium, chromium, and copper accounted for less than $1 \%$ of the total aqueous metal concentration. Cadmium was removed between $\mathrm{pH} 3.0$ and $\mathrm{pH} 4.0$. This is significantly lower than the estimated $\mathrm{pH}$ endpoint. According to the Pourbaix diagrams, cadmium would not be at a solid state until $\mathrm{pH}$ 10.0. The early removal of cadmium could be due to the removal of iron during the same $\mathrm{pH}$ range. Iron has been shown to be an effective sorbent for heavy metal removal, so it is possible that the precipitation of such a large concentration of iron would coprecipitate cadmium earlier than expected (Chapman et al. 1983, Dzombak \& Morel 1990, Schaider et al. 2014)

Chromium removal was also observed between $\mathrm{pH} 3.0$ and 4.0. The estimated $\mathrm{pH}$ endpoint for chromium was $\mathrm{pH}$ 5.0. While the difference is not as prominent as cadmium, chromium was removed from solution earlier than expected. Copper was also removed earlier than expected. Copper was removed between $\mathrm{pH} 4.0$ and 6.0, which is consistent with the findings of Jenke \& Diebold (1983) and Balintova \& Petrilakova (2011). Complete removal was not expected until pH 8.0. Like cadmium, it is likely that these elements were co-precipitated by iron and aluminum.

Manganese, zinc, nickel and cobalt precipitated out between $\mathrm{pH} 6.0$ and 9.0. These elements also accounted for approximately $1 \%$ of the aqueous major metals. Of these elements, zinc was the first to show substantial removal. The bulk of zinc precipitation occurred between pH 6.0 and 7.0. Complete removal was observed by $\mathrm{pH} 9.0$, which was slightly below the expected $\mathrm{pH}$ of 10.0 estimated by the Pourbaix diagrams. This removal is also slightly above the $\mathrm{pH}$ range of 5.0 to 6.0 reported by Jenke \& Diebold (1983). However, the recovery of zinc we observed is follows the same pattern as that reported by Balintova \& Petrilakova (2011).

Both nickel and cobalt followed similar removal patterns, with the bulk of removal occurring between $\mathrm{pH} 7.0$ and 8.5. The similar removal patterns are interesting to observe due to the difference in expected $\mathrm{pH}$ endpoints. The estimated $\mathrm{pH}$ endpoint for nickel was 9.0, while the endpoint for cobalt was 11.5 . Nickel fully precipitated at the estimated $\mathrm{pH}$ endpoint, while cobalt 
was removed earlier than projected. The removal of nickel and cobalt together is unlikely due to the iron coprecipitation seen with cadmium and chromium. However, aluminum has also been shown to have an adsorption capacity for heavy metals. As shown by Kim and Kim (2012), both nickel and cobalt can be effectively coprecipitated using aluminum hydroxides. It is possible that the precipitated aluminum hydroxides present in the precipitation steps above $\mathrm{pH} 4.0$ contributed to the premature cobalt removal.

Manganese was one of the few elements to precipitate later than expected. Precipitation began at $\mathrm{pH} 4.0$, but substantial removal was not observed until $\mathrm{pH}$ 7.0. The bulk of manganese was removed by $\mathrm{pH} 9.0$ (85\%), however it is likely that precipitation would have continued past $\mathrm{pH}$ 9.0. The Pourbaix diagrams suggested that complete manganese removal would occur by $\mathrm{pH}$ 8.0. It is possible that a component of the complex mix of dissolved solids kept manganese soluble past the expected endpoint.

Aside from manganese, both magnesium and calcium showed minimal removal during the precipitation procedure. Accounting for $37 \%$ of the aqueous major metal concentration, both magnesium and calcium minimal removal between $\mathrm{pH} 8.0$ and 9.0. Because the $\mathrm{pH}$ endpoints for magnesium and calcium are above the $\mathrm{pH}$ range of the experiment (11 and 10.5, respectively), it is possible that the observed endpoints would be consistent with the Pourbaix endpoints.

The removal patterns observed suggest that the majority of the metal mass present can be precipitated and removed from solution by $\mathrm{pH} 5.5$ or will remain in solution. As previously mentioned, the bulk of the major metals consists of iron, aluminum, calcium, and magnesium. Both iron and aluminum are removed from solution at $\mathrm{pH} 3.5$ and 5.5, respectively. Magnesium and calcium mainly stayed in solution, with a small percent $(\sim 10 \%)$ precipitating between $\mathrm{pH} 8.0$ and 9.0.

The recovery of the rare earth elements occurred across a broad $\mathrm{pH}$ range, from $\mathrm{pH} 3.5$ to $\mathrm{pH}$ 7.5. However, the HREEs, LREEs, and scandium were recovered at different stages of the $\mathrm{pH}$ adjustment. Scandium was recovered at the lowest range between $\mathrm{pH} 4.0$ and 6.0, alongside aluminum removal. This is close to the expected recovery $\mathrm{pH}$ of 5.5, as stated by Takeno (2005). The observed removal of scandium in this $\mathrm{pH}$ range is congruent with that observed by Yagmurlu et al. (2018) where scandium was removed between $\mathrm{pH} 3.0$ and 5.0. The differences in recovery $\mathrm{pH}$ can be attributed to the different solution chemistries of the two samples (AMD vs. bauxite leachates).

The HREEs and LREEs were recovered at a higher $\mathrm{pH}$ range than scandium. The HREEs were recovered between $\mathrm{pH} 4.0$ and 6.5, while the LREE were recovered between $\mathrm{pH} 4.0$ and 7.5. However, the majority of HREE and LREE recovery did not occur until $\mathrm{pH}$ 5.0. The difference in HREE and LREE recovery is likely due to the tendency of HREE being easier to recover than LREEs. This was seen by Verplanck et al. (2004), where HREEs were preferentially enriched over LREEs.

Similar to the metals, the REEs were precipitated at a lower $\mathrm{pH}$ range than projected by Pourbaix diagrams (Takeno 2005). The predicted precipitation $\mathrm{pHs}$ of the REEs ranged from $\mathrm{pH}$ 9.0 to 13.0. It is possible that the earlier recovery of REEs is due to the presence of other metals 
which precipitated out during the same range. Zinc, manganese, cobalt, and nickel all precipitated out during the same $\mathrm{pH}$ range as the REEs, and may have promoted coprecipitation.

These precipitation endpoints are consistent with what was reported in the literature. This $\mathrm{pH}$ range is similar to that observed by Zhang \& Honaker (2018). During their coal refuse selective precipitation experiment, the REEs were $80 \%$ recovered between $\mathrm{pH} 4.85$ and 6.11 . The slight differences in recovery $\mathrm{pH}$ are likely due to the different raw water characteristics of the two water sources. Verplanck et al. (2004) also observed REE precipitation around the same $\mathrm{pH}$ range, beginning at $\mathrm{pH} 5.13$.

Apart from scandium, the $\mathrm{pH}$ range of REE recovery was separate from that of the bulk metal removal. Bulk major metal removal occurred by $\mathrm{pH}$ 5.5, and bulk REE recovery was between $\mathrm{pH} 5.0$ and 7.5. This indicates that the recovery of REEs via a sequential $\mathrm{pH}$ adjustment would be plausible in a staged precipitation procedure. If the iron and aluminum can be removed by $\mathrm{pH} 5.5$, then the resulting precipitate will be relatively enriched in REEs 


\section{Effects of Redox on Precipitation Patterns}

\subsection{Introduction}

The variability of acid mine drainage (AMD) can create issues when developing treatment methods. AMD is influenced by many environmental factors which can affect outflow volume, $\mathrm{pH}$, redox potential, and dissolved metal and rare earth concentrations (Gray 1996). One of the major factors influencing AMD quality is the surrounding mineral composition. This can affect both the $\mathrm{pH}$ of the drainage, as well as the concentration of dissolved constituents (EPA 1994). Minerals which contain high levels of pyrite or other metal sulfides can increase acid production, as well as increase the dissolved iron concentrations of the AMD. As well, minerals which are enriched in heavy metals or rare earth elements (REEs) can yield AMD enriched in those elements due to acid leaching.

The quality of AMD is influenced by the flow of water through the mined area (EPA 1994). The introduction of water to a mine site can influence both the $\mathrm{pH}$ of the AMD as well as the leaching of surrounding minerals. It is possible that during periods of heavy rain or snow melt that the introduction of outside water sources to AMD will increase the overall $\mathrm{pH}$ of the system (Sullivan \& Drever 2001). Metal/REE leaching from the surrounding minerals will be negatively impacted by the raise in $\mathrm{pH}$, lowering the concentrations observed in the AMD. The increase in $\mathrm{pH}$ can also initiate the precipitation of metals, such as iron and aluminum (Sullivan \& Drever 2001).

While the presence of oxygen is important in the creation of acid mine drainage because it initiates the reactions that form AMD. When oxygen reacts with pyrite, the products include ferrous iron, sulfate, and acidity. When the ferrous iron oxidizes into ferric iron, it has the ability to react with pyrite to create a more substantial amount of acidity. Access to oxygen during and after AMD creation will influence the redox conditions of the AMD and speciation of the dissolved metals (Gray 1997). AMD sites which are open to the air generally have oxidized redox conditions, while those areas completely submerged have reduced conditions (Elberling et al. 2003). The speciation of dissolved metals is important because changes in element behavior can affect treatment efficiency.

Notably, iron is an element which is commonly present in large concentrations in AMD and is also heavily influenced by redox conditions (Zhang \& Honaker 2018). Iron has two oxidation states, with ferrous iron $\left(\mathrm{Fe}^{2+}\right)$ being the reduced state and ferric iron $(\mathrm{Fe} 3+)$ being the oxidized state. The $\mathrm{pH}$ at which both precipitate out varies greatly, with ferric iron precipitating around $\mathrm{pH} 3.5$, while ferrous iron does not precipitate until around $\mathrm{pH} 8.0$ (Beverskog \& Puigdomenech 1996). Due to the difference in precipitation behavior, the redox potential of AMD is important for treatment. 
Redox potential should also be considered when trying to separate the bulk of the gangue metals from the REEs. With iron being one of the major constituents of AMD, it is preferred for the bulk of iron to be removed prior to REE recovery. Keeping AMD at its natural redox potential would also reduce the cost of the treatment method due to the removal of oxidizing compounds like hydrogen peroxide and reducing compounds like hydroxylamine hydrochloride.

However, iron has been shown to be an effective sorption material for REE recovery (Verplanck et al. 2004, Schaider et al. 2014) If some residual iron is present when recovering REEs, it is possible that it will improve overall recovery of the rare earths from solution. Because not all AMD sources are completely oxidized, it is uncertain whether the complete oxidation of the AMD is required for efficient REE recovery. This question is explored in this paper by conducting a selective precipitation procedure on 3 AMD samples with various redox conditions. One sample was completely oxidized, one was partially reduced and opened to the air to allow for oxidation, and one was partially reduced and sparged with nitrogen to exclude oxygen. The recoveries of the major metals and rare earth elements are compared between the three samples to determine the effects of redox conditions on REE recovery via selective precipitation.

\subsection{Methods}

\subsubsection{Sample Collection}

Acid mine drainage was collected from site AQ-2, an AMD treatment facility 6.5 miles south of Morgantown. The AMD was collected upstream of the clarifier through an access hatch to the inlet pipe. Water was collected in 5-gallon buckets and transported back to the lab. In addition, a $250 \mathrm{~mL}$ plastic bottle was collected with no head space for metal analysis. The water temperature, pressure, conductance, specific conductance, $\mathrm{pH}$, and ORP were recorded in the field using a YSI field meter. Ferrous iron concentration was determined using the phenanthroline method (Hach method 8146).

\subsubsection{Completely Oxidized Precipitation Procedure}

The AMD collected was used to assess the precipitation patterns of the dissolved metals and rare earth elements in completely oxidized and partially oxidized conditions. For the completely oxidized conditions, 16L of raw AMD was placed into a 5-gallon bucket. The ferrous iron concentration was reduced through the addition of $30 \%$ hydrogen peroxide until the ferrous iron concentration reached $0 \mathrm{mg} / \mathrm{L}$. The $\mathrm{pH}$ of the AMD was then adjusted stepwise to 4.0, 4.7, 5.0, 6.0, 7.0, 8.0, 9.0, and 10.0 with precipitate collection between each step. A solution of 4N sodium hydroxide was used to raise the $\mathrm{pH}$ to the desired target. The solution was assumed to be at equilibrium if there was no change in $\mathrm{pH}$ after one hour. Once at equilibrium, the AMD was then filtered via vacuum filtration through a 0.22 um MCE membrane filter. The precipitate and 
$50 \mathrm{~mL}$ of filtrate was collected for each $\mathrm{pH}$ step. The remaining filtrate was used for the following $\mathrm{pH}$ adjustment.

\subsubsection{Partially Reduced Precipitation Procedure - With and Without Nitrogen Sparging}

A 3.5L of raw AMD was placed into two 4L plastic bottles. Initially ferrous iron accounted for approximately $4 \%$ of the total iron concentration for both samples. Solid hydroxylamine hydrochloride $(0.5 \mathrm{~g})$ was mixed into the AMD of both bottles to raise the ferrous concentration to approximately $50 \%$ of the total iron concentration. The samples were partially reduced to allow for a greater difference between ferrous and ferric iron concentrations as compared to the fully oxidized sample. Additionally, the differences in behavior of ferrous and ferric iron under oxidizing and reducing conditions effects would be more apparent.

The precipitation procedure was the same as the fully oxidized sample. The unsparged sample was open to the atmosphere without nitrogen sparging. It was constantly mixed on a stirrer to create oxidizing conditions. The sparged sample was kept covered as much as possible. Nitrogen was bubbled into the AMD to expel dissolved oxygen and maintain reducing conditions. Maintaining a reducing condition was not possible when filtering the AMD between $\mathrm{pH}$ adjustments. To minimize the effects of oxygenation, the samples were filtered as quickly as possible and then sparged for 15 minutes before the next $\mathrm{pH}$ adjustment began.

\subsubsection{Seeding Test for REE Recovery}

Raw AMD, precipitated iron and precipitated aluminum were used as seeds to determine if they would facilitate REE sorption/recovery. The AMD used for the seeding test was the $\mathrm{pH}$ 8.0 filtrate collected from a separate 2-step precipitation which utilized the flocculant PE-6070. Total REE concentration of the $\mathrm{pH} 8.0$ filtrate was $4.5 \mathrm{ug} / \mathrm{L}$, approximately $1 \%$ of the original REE concentration of the raw AMD. The iron precipitate used was created by bringing raw AMD to a $\mathrm{pH}$ of 4.0 and is made up of $47.5 \%$ iron. The other major metals account for only $2 \%$ of the solid. The remaining composition is comprised mainly of sulfate, silica, and the hydroxides which are a part of the metal hydroxide precipitates. The aluminum precipitate is $24.3 \%$ aluminum, with the other major metals contributing $1.5 \%$ to solids content. The rest of the solid is comprised of sulfate, silica, and hydroxides. The metal and REE composition of the raw AMD used for seeding was the AMD used for the redox experiments, shown below in Tables 4-2 and 4-3.

The mass of iron and aluminum precipitate added to the $\mathrm{pH} 8.0$ filtrates was determined by doubling the concentration added during a preliminary seeding test. Three separate $1 \mathrm{~L}$ samples of the $\mathrm{pH} 8.0$ filtrate were collected into plastic screw top bottles. An iron precipitate slurry was added to seed the first $1 \mathrm{~L}$ sample of filtrate. The iron precipitate slurry used was a $\mathrm{pH}$ 4.0 sludge from a previous 3-step precipitation procedure of AQ-2 water. The volume of slurry was added to the 1L sample to reach $0.615 \mathrm{mg}$ iron (dry weight). An aluminum precipitate slurry was added to the second $1 \mathrm{~L}$ sample bottle. The slurry used was a pH 5.0 sludge from the same 3step precipitation as the iron precipitate. The aluminum-based precipitate slurry was added in 
volume to reach $0.615 \mathrm{mg}$ of aluminum (dry weight). Finally, raw water from the 3-step precipitation of AQ-2 was added to the third 1L sample bottle. The volume of raw water added was calculated to have a dry weight of $0.615 \mathrm{mg}$ of iron. After each bottle was dosed with the respective seeding media, the sample was mixed vigorously for 1 minute, then gently for 15 minutes. During the gentle mix, the $\mathrm{pH}$ of the solution was maintained at 8.0 using sodium hydroxide. After the 15-minute gentle mix, the 1L samples were removed from mixing and allowed to settle for 30 minutes. Each sample was then filtered through a 0.22 um filter paper via vacuum filtration. The filtrate was collected and preserved with $70 \%$ trace metal grade nitric acid for analysis.

\subsubsection{Sample Preparation for Analysis}

Samples of the raw AMD and filtrates and precipitates from each $\mathrm{pH}$ step were collected for all 3 redox conditions. The collected precipitate slurries were dewatered, and the weight and volume of each were recorded. The aqueous samples which were collected during the stagedprecipitation process were preserved with $70 \%$ trace metal grade nitric acid to prevent metal precipitation before analysis. For each sample, $50 \mathrm{~mL}$ was transferred to a plastic centrifuge tube with a screw cap closure. All samples were analyzed using inductively coupled plasma optical emission spectrometry (ICP-OES) and inductively coupled plasma mass spectrometry (ICP-MS) for metal and REE concentrations by the NRCCE Analytical Laboratory.

\subsection{Results}

\subsubsection{Raw Water Characteristics}

The temperature of the raw water was $12.6^{\circ} \mathrm{C}$, which was consistent with previous temperatures taken from that site. The $\mathrm{pH}$ was 2.52 , and the ORP was $503.2 \mathrm{mV}$. This indicated that the raw water was most likely completely oxidized. However, the sample was not fully oxidized and had a ferrous iron concentration of $8.97 \mathrm{mg} / \mathrm{L}$ ( $4 \%$ of the total iron concentration). The conductance and specific conductance were $2093 \mathrm{uS} / \mathrm{cm}$ and $2718 \mathrm{uS} / \mathrm{cm}$, respectively. Aluminum $(89.8 \mathrm{mg} / \mathrm{L})$, calcium $(92.4 \mathrm{mg} / \mathrm{L})$, iron $(224.2 \mathrm{mg} / \mathrm{L})$, and magnesium $(36.1 \mathrm{mg} / \mathrm{L})$ were the majority of the metals present in the raw water. Cadmium, cobalt, chromium, copper, manganese, nickel, and zinc were present at much lower concentrations, ranging from 0.0 to 2.0 $\mathrm{mg} / \mathrm{L}$. 
Table 4-1: AQ-2 raw water characteristics measured on-site during sample collection

\begin{tabular}{|c|c|c|c|}
\hline Temperature $\left({ }^{\circ} \mathbf{C}\right)$ & 12.6 & $\begin{array}{c}\text { Conductance } \\
(\mathbf{u S} / \mathbf{c m})\end{array}$ & 2093 \\
\hline ORP (mV) & 503.2 & Pressure (mmHg) & 726.6 \\
\hline $\mathbf{p H}$ & 2.52 & $\begin{array}{c}\text { Initial Fe } \mathbf{~ p}^{\mathbf{2}} \mathbf{C o n c} \\
(\mathbf{m g} / \mathbf{L})\end{array}$ & 8.97 \\
\hline $\begin{array}{c}\text { Specific Conductance } \\
(\mathbf{u S} / \mathbf{c m})\end{array}$ & 2718 & & \\
\hline
\end{tabular}

Table 4-2: The AQ-2 raw water major metal concentrations (mg/L)

\begin{tabular}{|c|c|c|c|}
\hline $\begin{array}{c}\text { Major } \\
\text { Metal }\end{array}$ & $\begin{array}{c}\text { Concentration } \\
(\mathbf{m g} / \mathbf{L})\end{array}$ & $\begin{array}{c}\text { Major } \\
\text { Metal }\end{array}$ & $\begin{array}{c}\text { Concentration } \\
(\mathbf{m g} / \mathbf{L})\end{array}$ \\
\hline $\mathbf{A l}$ & 89.8 & $\mathbf{F e}$ & 224.2 \\
\hline $\mathbf{C a}$ & 92.4 & $\mathbf{M g}$ & 36.1 \\
\hline $\mathbf{C d}$ & 0.0 & $\mathbf{M n}$ & 1.4 \\
\hline $\mathbf{C o}$ & 0.3 & $\mathbf{N i}$ & 0.7 \\
\hline $\mathbf{C r}$ & 0.1 & $\mathbf{Z n}$ & 2.0 \\
\hline $\mathbf{C u}$ & 0.2 & \multicolumn{2}{|l}{} \\
\hline
\end{tabular}


Table 4-3: The AQ-2 raw water rare earth element concentrations (ug/L). Rare earth elements are separated by LREE and HREE. Sc was grouped with LREE and Y was grouped with HREE.

\begin{tabular}{|c|c|c|c|}
\hline $\begin{array}{c}\text { REE } \\
\text { (Heavy) }\end{array}$ & $\begin{array}{c}\text { Concentration } \\
(\mathrm{ug} / \mathrm{L})\end{array}$ & $\begin{array}{c}\text { REE } \\
\text { (Light) }\end{array}$ & $\begin{array}{c}\text { Concentration } \\
(\mathrm{ug} / \mathrm{L})\end{array}$ \\
\hline $\mathbf{Y}$ & 88.2 & Sc & 50.2 \\
\hline Gd & 21.0 & $\mathbf{L a}$ & 16.7 \\
\hline $\mathbf{T b}$ & 3.7 & $\mathrm{Ce}$ & 61.6 \\
\hline Dy & 22.7 & Pr & 10.4 \\
\hline Ho & 4.3 & Nd & 50.6 \\
\hline $\mathbf{E r}$ & 12.4 & $\mathrm{Sm}$ & 14.7 \\
\hline $\mathbf{T m}$ & 1.9 & $\mathbf{E u}$ & 3.8 \\
\hline $\mathbf{Y b}$ & 10.0 & & \\
\hline $\mathbf{L u}$ & 1.6 & & \\
\hline
\end{tabular}

\subsubsection{Fully Oxidized Precipitation Procedure}

The removal of metals for each $\mathrm{pH}$ step of the fully oxidized sample is shown below in Figure 4-1a. Filtrate samples analyzed were taken from $\mathrm{pH}$ steps 2.5, 4.0, 4.7, 5.0, 6.0, 7.0, 8.0, 9.0, and 10.0. Iron, chromium, and cadmium displayed significant removal between $\mathrm{pH} 2.5$ and 4.0. $100 \%$ of iron, $94 \%$ of chromium, and $80 \%$ of cadmium was removed. It is likely that there was higher removal of chromium, but at $94 \%$ removal the concentration was below the detection limit. The final cadmium removal was $90 \%$.

The bulk of aluminum was removed by pH 5.0 (97\%) and reached 100\% removal by $\mathrm{pH}$ 6.0. Copper displayed gradual removal across the entire $\mathrm{pH}$ range of the experiment $(\mathrm{pH} 2.5$ 10.0). Removal was limited between $\mathrm{pH} 2.5$ and 5.0, with only $19 \%$ removed. After $\mathrm{pH} 5.0$, removal increased to $32 \%$ by $\mathrm{pH} 6.0,55 \%$ by $\mathrm{pH} 7.0,81 \%$ by $\mathrm{pH} 8.0$, and $94 \%$ for $\mathrm{pH} 9.0$ and 10.0. Zinc began precipitating at $\mathrm{pH} 7.0$, and reached $100 \%$ removal by $\mathrm{pH} 10.0$. Manganese 
began precipitating at $\mathrm{pH} 4.0$ but did not show significant precipitation until between $\mathrm{pH} 9.0$ and 10.0, where removal reached 99\%. Nickel removal occurred between $\mathrm{pH} 8.0$ and 10.0 and reached $94 \%$ by $\mathrm{pH} 10.0$. Cobalt had a similar removal trend to nickel and was removed between $\mathrm{pH} 8.0$ and 10.0. $\mathrm{By} \mathrm{pH} \mathrm{10.0,100 \%} \mathrm{of} \mathrm{the} \mathrm{cobalt} \mathrm{was} \mathrm{removed} \mathrm{from} \mathrm{the} \mathrm{filtrate.} \mathrm{Neither} \mathrm{calcium}$ nor magnesium precipitated out of the filtrate during $\mathrm{pH}$ adjustment to $\mathrm{pH} 10.0$.

The recovery of the rare earth elements showed the greatest difference between the HREEs, LREEs, and scandium, as seen in Figure 4-2a. The scandium was recovered in a similar trend to aluminum. The bulk of scandium was recovered between $\mathrm{pH} 4.0$ and 5.0 but $100 \%$ recovery was not achieved until $\mathrm{pH}$ 9.0. The HREEs and LREEs had a wide gap between recoveries in the $\mathrm{pH}$ range $4.0-8.0$, but both showed $99 \%$ recovery at $\mathrm{pH} 9.0$ and $100 \%$ recovery at $\mathrm{pH} 10.0$.

\subsubsection{Partially Reduced Precipitation Procedure - Without Nitrogen Sparging}

The removal of metals from the partially oxidized sample without nitrogen sparging (oxidizing conditions) differed significantly from the fully oxidized sample (Figure 4-1b). Unlike the oxidized sample, only $47 \%$ of the iron was removed at $\mathrm{pH} 4.0$. There was a steady increase in iron removal from $\mathrm{pH} 2.5$ to 7.0 , with $100 \%$ removal by $\mathrm{pH} 7.0$. Similarly to iron, cadmium also precipitated at a higher $\mathrm{pH}$ and was not fully removed until $\mathrm{pH}$ 7.0. Chromium did not appear to be as impacted by being in a partially reduced sample. The recovery of chromium was $93 \%$ by $\mathrm{pH}$ 4.7. Higher recovery was not observed for chromium due to the concentrations being at or below detection.

Aluminum removal was congruent with the oxidized sample, with $96 \%$ removal by $\mathrm{pH}$ 5.0, and 100\% removal by $\mathrm{pH}$ 6.0. Copper precipitated out between $\mathrm{pH} 4.0$ and 7.0 and reached $97 \%$ removal. The bulk of zinc removal occurred between $\mathrm{pH} 6.0$ and 7.0. By $\mathrm{pH} 7.0,81 \%$ of zinc was removed. However, zinc continued to be removed from the filtrate until pH 10.0 when $99 \%$ of had been removed.

Nickel, cobalt, manganese, calcium, and magnesium all displayed decreases in removal during the $\mathrm{pH}$ adjustments. Nickel and cobalt had similar precipitation trends, and reached 54\% removal and 50\% removal, respectively. $\mathrm{By} \mathrm{pH} 9.0$, the overall removal of nickel had reduced to $11 \%$, and cobalt removal reduced to $23 \%$. By $\mathrm{pH} 10.0$, the removals had increased to $58 \%$ for nickel and $62 \%$ for cobalt. It is not clear why removal would decrease and then increase for these elements. It does not appear that these decreases in removal are due to small changes in concentration being magnified when converted to a percentage. The concentration changes are more substantial and range from 5 to $10 \%$ of total concentration.

Manganese had three reductions in removal during the $\mathrm{pH}$ adjustments to $\mathrm{pH}$ 10.0. At $\mathrm{pH} 5.0$, the removal of manganese had reached $8 \%$, but was reduced to $1 \%$ by $\mathrm{pH} 6.0$. At $\mathrm{pH} 7.0$, the removal had increased to $18 \%$. The second decrease in recovery occurred at $\mathrm{pH} 8.0$ at $12 \%$ removal. The removal of manganese increased at $\mathrm{pH} 9.0$ to $28 \%$, but then decreased the third time at $\mathrm{pH} 10.0$ to $22 \%$. Similar to previous precipitation experiments, calcium and magnesium 
had overall low removal. By $\mathrm{pH} 10.0$, calcium removal was $0 \%$ and magnesium removal was $2 \%$. However, calcium removal peaked at $7 \%$ at $\mathrm{pH} 5.0$, and magnesium removal peaked at $10 \%$ at $\mathrm{pH} 7.0$.

The rare earth recovery of the partially reduced sample without sparging is shown in Figure 4-2b. Scandium recovery was not significantly altered with the partially reduced conditions. The bulk of scandium recovery occurred between $\mathrm{pH} 4.0$ and 5.0 (91\%), with 99\% recovery at $\mathrm{pH}$ 6.0. Unlike the fully oxidized sample, the HREE and LREE recoveries follow a similar precipitation pattern between $\mathrm{pH} 4.0$ to $\mathrm{pH}$ 7.0. The recoveries of HREEs and LREEs did not significantly differ across the $\mathrm{pH}$ range of the experiment, with both groups reaching $100 \%$ recovery at $\mathrm{pH}$ 7.0. The removal of both HREEs and LREEs decreased at $\mathrm{pH} 4.7$ and 9.0, much like some of the metals previously discussed.

\subsubsection{Partially Reduced Precipitation Procedure - With Nitrogen Sparging}

The removal of metals from partially reduced raw water with nitrogen sparging can be seen in Figure 4-1c. The removal of iron and cadmium was similar to the unsparged sample, but the complete removal of cadmium did not occur until $\mathrm{pH} 8.0$, and the removal of iron did not occur until $\mathrm{pH} 9.0$ ( $88 \%$ and $100 \%$ removal, respectively). The removal of both cadmium and iron was low between $\mathrm{pH} 2.5$ and 6.0, but greater removal between $\mathrm{pH} 6.0$ and 9.0.

The removal of chromium and aluminum was similar to the fully oxidized sample and the partially reduced sample that was not sparged. The bulk of aluminum was removed by $\mathrm{pH} 4.7$ (96\%), with $100 \%$ of removal occurring by $\mathrm{pH}$ 7.0. The majority of chromium was removed between pH 2.5 and 4.0 (75\%), and 93\% removal was achieved by $\mathrm{pH} 4.7$. Copper began precipitating out at $\mathrm{pH} 4.0$ and did not reach $97 \%$ removal until $\mathrm{pH}$ 8.0. Zinc was removed between $\mathrm{pH} 6.0$ and 9.0, when $100 \%$ removed was achieved.

Nickel and cobalt had improved removal compared to the fully oxidized sample and the unsparged reduced sample. The bulk of removal occurred between $\mathrm{pH} 7.0$ and 8.0, with $80 \%$ removal of nickel and $83 \%$ removal of cobalt. Nickel removal peaked at $93 \%$ at $\mathrm{pH} 10.0$, while cobalt removal reached $97 \%$ by $\mathrm{pH}$ 10.0. Manganese did not begin precipitating out until $\mathrm{pH} 7.0$, and only achieved $52 \%$ removal by $\mathrm{pH} 10.0$. Neither calcium nor magnesium had meaningful removal at any $\mathrm{pH}$.

Rare earth recovery for the sparged reduced sample is shown in Figure 4-2c. Scandium recovery did not significantly deviate from previous experiments. The bulk of scandium was removed between $\mathrm{pH} 4.5$ and 5.0, with continuing recovery until $\mathrm{pH} 7.0$. Recovery of scandium at $\mathrm{pH} 5.0$ was $90 \%$, and $98 \%$ at $\mathrm{pH} 6.0$ with $100 \%$ removal at $\mathrm{pH} 7.0$. There was a slight differentiation between recovery efficiency for HREEs and LREEs, with HREEs being preferentially recovered between $\mathrm{pH} 2.5$ and $\mathrm{pH}$ 6.0. Full recovery was reached at $\mathrm{pH} 8.0$ for both HREEs and LREEs. The recovery pattern for the sparged reduced sample was very similar to the unsparged reduced sample, with bulk removal between $\mathrm{pH} 4.5$ and 5.0. The oxidized 
sample displayed a more gradual recovery across the whole $\mathrm{pH}$ range. Similarly to the unsparged reduced sample, there was a slight decrease in LREE and HREE recovery.

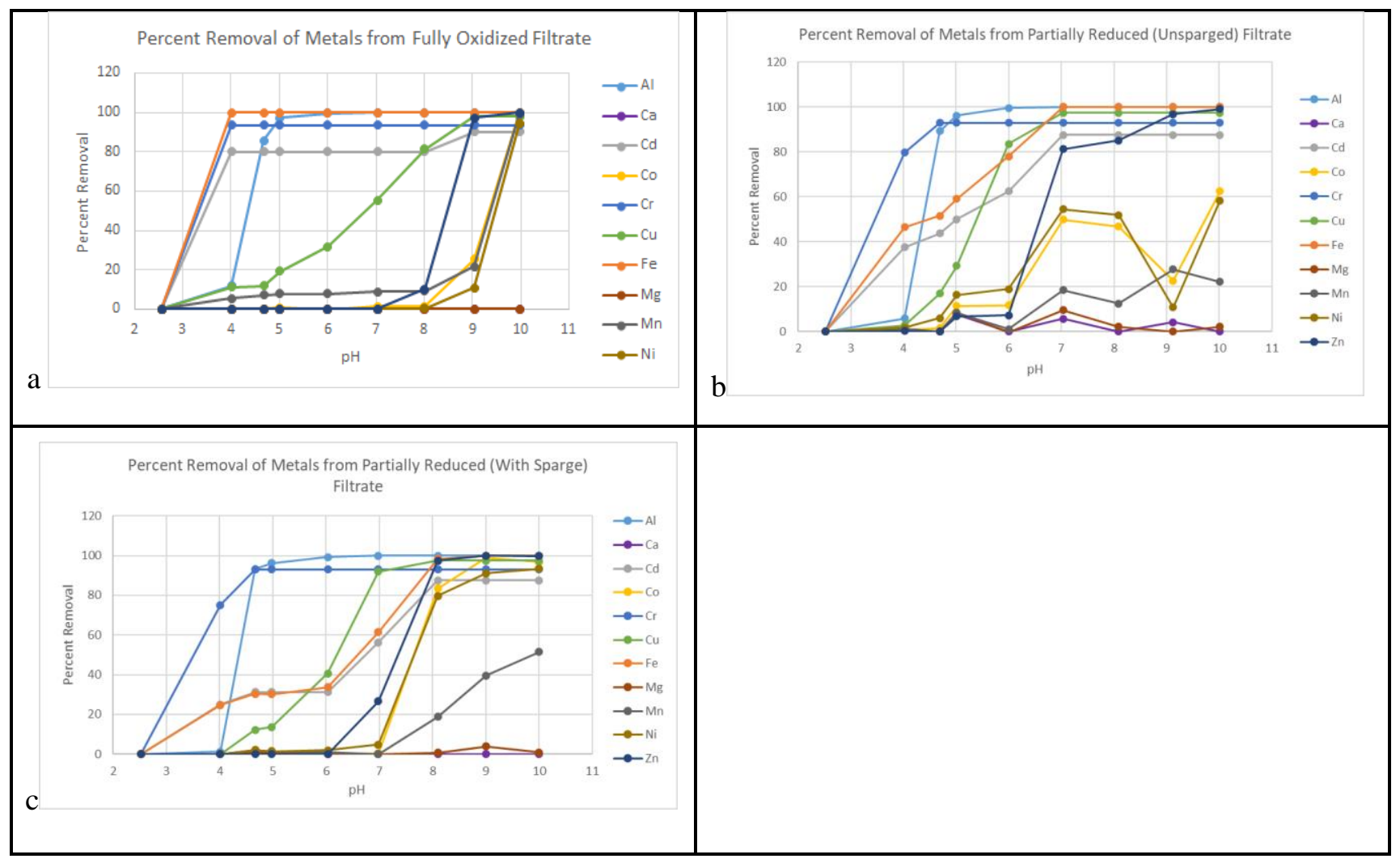

Figure 4-1: Percent removal of metals during the fully oxidized AMD (a), partially reduced with oxidizing conditions (b), and partially reduced with reducing conditions (c). Percent removal was calculated by comparing concentrations from the raw AMD to the treated filtrates. 


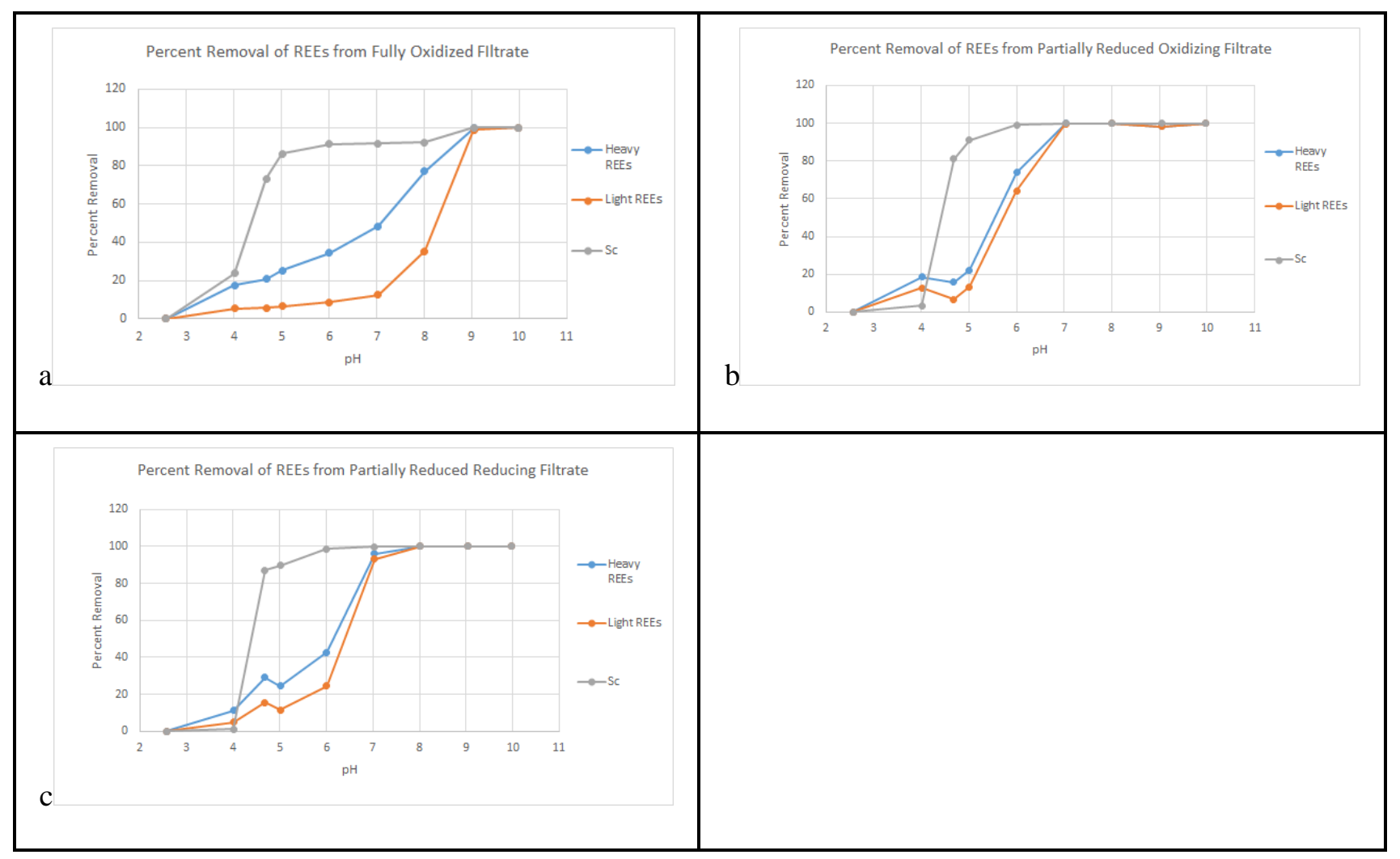

Figure 4-2: Percent removal of the REEs from the fully oxidized AMD (a), partially reduced with oxidizing conditions (b), and partially reduced with reducing conditions (c). The REEs were separated into the heavy REEs (Y, Gd-Lu), light REEs ( $\mathrm{La}$ - Eu), and scandium

\subsubsection{Seeding Test for REE Recovery}

The recovery of REEs due to the iron precipitate, aluminum precipitate, and raw water is shown below in Figure 4-3. The additional removal of REEs due to seeding was calculated by comparing concentrations of the pre- and post-seeding filtrates. The HREE showed greater recovery than the LREE for all three seeding media. After seeding, the LREEs averaged 77\% recovery, while HREEs averaged $87 \%$ recovery. For all lanthanides except lanthanum, cerium, praseodymium, and neodymium, the aluminum precipitate had an equal or higher percentage of recovery when compared to the iron and raw water seeding method. The raw water had significantly less recovery when compared to both the iron and aluminum precipitate. The aluminum precipitate averaged $85 \%$ recovery across all REEs, iron precipitate averaged $83 \%$ recovery, and the raw water averaged $69 \%$ 


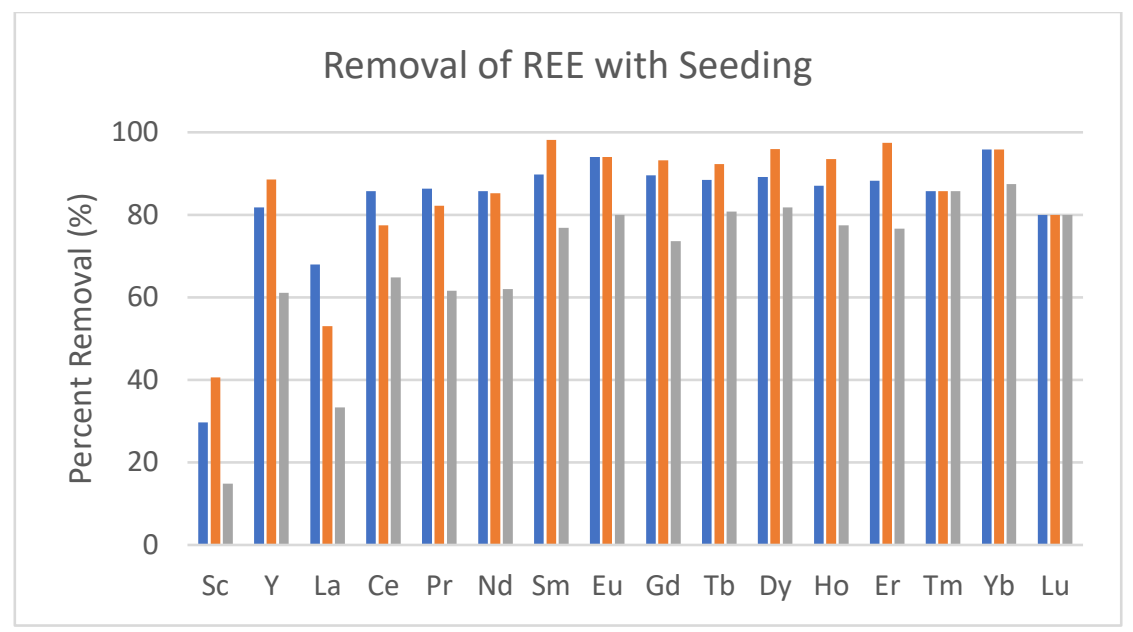

Figure 4-3: Removal of REEs from $\mathrm{pH} 8.0$ filtrate after seeding with iron precipitate, aluminum precipitate, and raw AMD.

\subsection{Discussion}

\subsubsection{Effects of Redox Conditions on Major Metal Removal}

Not all sources of acid mine drainage are completely oxidized. Many sources are either partially oxidized or heavily reduced. The effects of redox conditions were observed during the $\mathrm{pH}$ adjustments of fully oxidized and partially reduced AMD samples. As expected, the removal range and efficiency of the metals changed depending on redox conditions. Comparisons of metal and REE removal between the three redox conditions are seen in Figure 4-4. The major difference between the fully oxidized, unsparged, and sparged conditions was the precipitation range of iron. As discussed previously, iron is one of the major constituents in AMD, and is considered a contaminant in REE sludge products due to its issues in downstream refinement processes. As seen in Figure 4-4a, more oxidized conditions led to removal of iron at lower $\mathrm{pH}$ ranges. The iron was completely removed by $\mathrm{pH} 4.0$ in the fully oxidized sample. However, both the partially reduced samples showed delayed removal of the iron. The unsparged sample had complete iron removal by $\mathrm{pH}$ 7.0, and the sparged sample had removal by $\mathrm{pH}$ 8.0.

The differences in iron removal were expected and are most likely due to the differences in precipitation $\mathrm{pH}$ between ferric iron and ferrous iron. Ferric iron precipitates out of solution around $\mathrm{pH} 3.5$, while ferrous iron precipitates much later at around $\mathrm{pH} 8.0$ (Beverskog \& Puigdomenech 1996). This is consistent with the data shown in Figure 4-4a. The fully oxidized sample contains only ferric iron, which was completely removed by $\mathrm{pH} 4.0$. The sparged sample contains both ferric and ferrous iron. The first sharp peak between $\mathrm{pH} 2.5$ and 4.0 for the sparged sample is the precipitation of ferric iron present. The removal of iron plateaus until $\mathrm{pH} 6.0$, and then significant removal is observed between $\mathrm{pH} 6.0$ and 8.0. At this range, the ferrous iron was removed as a blue-green precipitate. The removal of the iron from the unsparged sample was 
more gradual due to the oxidation of ferrous iron to ferric during the $\mathrm{pH}$ adjustments, which caused the total removal of iron to be sooner than the sparged sample.

Other metals which were heavily affected by redox conditions were cobalt, nickel, copper, cadmium, and manganese. Cobalt, nickel, copper, and manganese removal occurred at a higher $\mathrm{pH}$ range for the oxidized sample when compared to the two partially reduced samples. For the fully oxidized sample, the bulk of cobalt, nickel, and manganese removal occurred between $\mathrm{pH} 9.0$ and 10.0. However, removal began as early as $\mathrm{pH} 5.0$ for the unsparged reduced sample and $\mathrm{pH} 7.0$ for the sparged reduced sample. However, it is important to note that complete removal of cobalt and nickel did not occur in the unsparged reduced sample. Copper removal was gradual over the $\mathrm{pH}$ range of 3.0 to 10.0 for the oxidized sample, while the reduced samples displayed appreciable removal between $\mathrm{pH} 4.0$ and 7.0. Conversely, the removal of cadmium was observed at a lower $\mathrm{pH}$ range for the oxidized sample when compared to the reduced samples. Complete removal was seen at $\mathrm{pH} 4.0$ for the oxidized sample but was not observed until pH 7.0 and 8.0 for the unsparged and sparged reduced samples, respectively. Along with iron, these elements are transition metals which often have multiple oxidation states. As such, it is highly likely that the changes in redox conditions between samples affected the oxidation states of these elements, and thus their $\mathrm{pH}$ range for precipitation.

The remaining elements $(\mathrm{Al}, \mathrm{Cr}, \mathrm{Cu}, \mathrm{Ca}$, and $\mathrm{Mg}$ ) showed little to no difference between the three redox conditions. The removal of aluminum did not appear to be significantly affected by the redox conditions of the $\mathrm{pH}$ adjustment. The removal of aluminum between the 3 samples is seen in Figure $4-4 \mathrm{~b}$ below. For all three samples, the aluminum precipitated beginning at $\mathrm{pH}$ 2.5 , with bulk removal between $\mathrm{pH} 4.0$ and 6.0. The only difference in removal appeared to be that slightly more aluminum was removed by $\mathrm{pH} 4.0$ in the more oxidized samples. The fully oxidized sample had $12 \%$ of the aluminum removed by $\mathrm{pH} 4.0$, while the unsparged and sparged samples had $6 \%$ and $1 \%$ removal, respectively. However, the general trend of removal was the same for all three samples. This is probably due to the fact that the dominant form of aluminum was $\mathrm{Al}(\mathrm{III})$ for all three redox conditions. While aluminum can have other oxidation states (Al(I), $\mathrm{Al}(\mathrm{II})$, and $\mathrm{Al}(\mathrm{V})$ ), the most stable oxidation state for aluminum is $\mathrm{Al}(\mathrm{III})$ (Myers et al. 2011).

Calcium and magnesium also showed minimal differences between the three redox samples. The bulk of both calcium and magnesium stayed in solution during the experiments, showing little to no overall recovery. Calcium had $0 \%$ overall recovery for all three samples, while magnesium had $8 \%$ removal for the unsparged reduced sample and $0 \%$ removal for the other two. This was expected because calcium and magnesium are not included in the transition metals and are most stable in the +2 oxidation states. While they both can be found in the +1 oxidation state, they are much less stable.

Conversely, it was not expected that chromium had very similar removals across the three samples as it is a transition metals and have multiple possible oxidation states. Chromium removal followed the same pattern of removal between $\mathrm{pH} 2.5$ and 4.5 for both the oxidized and reduced samples. It was expected that chromium would have shown earlier removal in the reduced samples much like cobalt for nickel. 


\subsubsection{Effects of Redox Conditions on REE Recovery}

The recovery of REEs were also impacted by the effects of redox conditions as seen in Figure 4-4. The scandium recovery appeared to only be minorly impacted by the redox conditions of the $\mathrm{pH}$ adjustments, as seen in Figure 4-4c. The bulk of recovery occurred in the same range as aluminum, $\mathrm{pH} 4.0$ to $\mathrm{pH}$ 6.0. The recovery of scandium from both the sparged and unsparged samples were very similar, only differing by a few percentages. The fully oxidized sample showed the greatest deviation, with a larger percentage of scandium being removed by $\mathrm{pH} 4.0$ (24\%), as well as a higher $\mathrm{pH}$ of complete removal. The scandium of the fully oxidized sample was not fully removed until $\mathrm{pH}$ 9.0. It is unlikely that the changes in scandium removal are due to the different oxidation states of scandium. Scandium mainly exists as $\mathrm{Sc}^{3+}$ but has been shown to exist in other uncommon oxidation states like $\mathrm{Sc}^{2+}$. This form of scandium mainly occurs under high temperatures in a gaseous form, so it is unlikely that it is present in this AMD sample (Smith 1973).

Both the HREEs and LREEs displayed a larger variation in removal between samples due to the redox conditions. The HREE recovery is shown in Figure 4-4d, while the LREE recovery is shown in Figure 4-4e. For both HREE and LREE recovery, the unsparged sample had the earliest REE recovery, followed by the sparged and fully oxidized sample. For HREE, both the unsparged and sparged samples had similar recovery between $\mathrm{pH} 2.5$ and 7.0. The fully oxidized sample had a more gradual recovery and did not show full recovery until pH 9.0. The LREEs displayed a similar pattern, with the sparged and unsparged samples having the bulk of recovery by $\mathrm{pH} 7.0$, and recovery by $\mathrm{pH} 9.0$ for the fully oxidized sample. Much like scandium, the lanthanides are mainly found as 3+ oxidation states but are capable of being 2+ (Macdonald et al. 2013). While it is possible that the reduced samples might be affected by a change in oxidation state, it is likely that the incomplete removal of iron and aluminum had a larger effect.

\subsubsection{REE Recovery when Seeding with Iron, Aluminum, and Raw AMD}

Both iron- and aluminum-based compounds have previously been used in REE sorption experiments and proven effective (Verplanck et al. 2004, Schaider et al. 2014). The effect of the presence of both iron and aluminum was determined to be significant from the seeding experiment. As seen in Figure 4-3, the aluminum averaged 85\% REE recovery, and the iron averaged $83 \%$ recovery. The raw AMD only recovered an additional $69 \%$ of REEs, which was much lower than the iron or aluminum precipitates. It is possible that the lower recovery of REEs using AMD was because the precipitates were not preformed and needed to be created during $\mathrm{pH}$ adjustment. It is also possible that the addition of more dissolved metals REEs negatively affected recovery. Aluminum removal was not significantly altered by redox conditions, but the removal of iron was not completed until $\mathrm{pH} 6.5$ or 8.0 for the unsparged and sparged samples, respectively. The presence of the iron precipitate at a higher $\mathrm{pH}$ range promoted greater $\mathrm{REE}$ recovery. As seen in Figure 4-2b and Figure 4-2c, the removal of REEs in the partially reduced samples increased when in the presence of increased iron relative to the fully oxidized sample. 
For both LREE and HREE recovery, the recovery of REE at a later $\mathrm{pH}$ is preferred for the proposed 3-step precipitation procedure. Similar to why it is ideal to remove iron early, the later removal of REEs helps to separate the REE precipitation from the precipitation of the bulk of the metals (iron and aluminum). The sparged and unsparged samples showed partial HREE and LREE by $\mathrm{pH}$ 5.0. The fully oxidized sample did display some recovery in HREEs by $\mathrm{pH}$ 5.0, but the LREE recovery did not occur until $\mathrm{pH} 7.0$

Having a having a fully oxidized sample is preferential to a partially reduced sample (either sparged or unsparged). The iron is completely removed from the fully oxidized sample at a much lower $\mathrm{pH}$ than the partially reduced sample. This creates a clear separation between iron removal and REE recovery. Both the partially reduced samples had significant iron removal between $\mathrm{pH} 5.0$ and 8.0, which is the range of the REE precipitation. This would both dilute the sludge and decrease the REE grade, as well as create issues in downstream refinement processes. The fully oxidized sample also showed increased HREE and LREE recovery. The recovery of HREE and LREE was delayed compared to the sparged and unsparged samples. Similar to the explanation for iron removal, the delayed REE recovery is beneficial because it further separates the recovery of REEs from the precipitation of waste metals. Although the removal of scandium is slightly more efficient with the partially reduced samples, the early removal of iron and late removal of HREE/LREE of the fully oxidized sample is more significant to the 3-step precipitation procedure. As such, following precipitation procedures were conducted in fully oxidized conditions. 


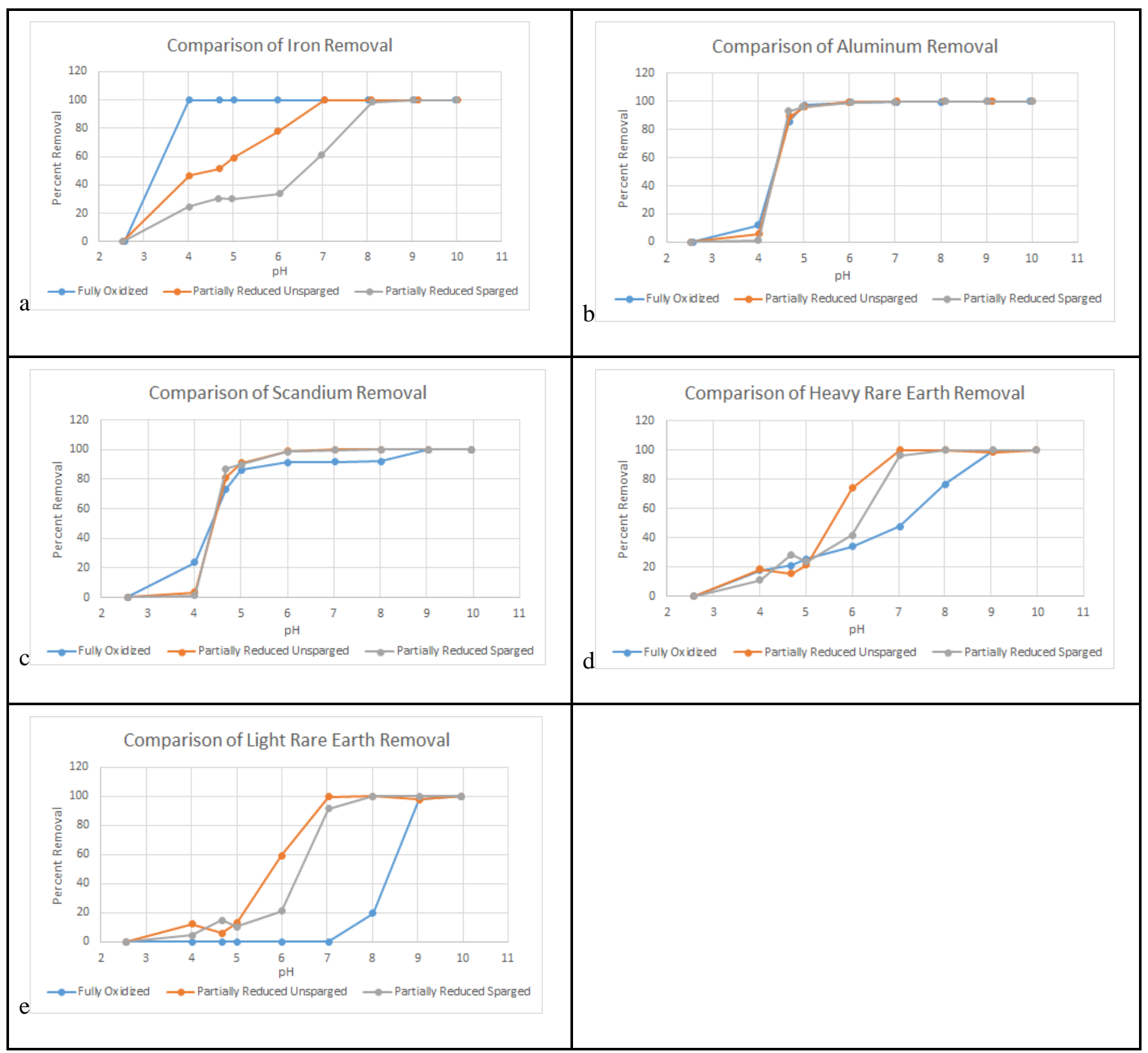

Figure 4-4: Comparison of metal and REE removal from AMD in fully oxidized conditions, oxidizing conditions, and reducing conditions. The removal of iron (a), aluminum (b), scandium (c), HREE (d), and LREE (e) were compared between the three precipitation conditions 


\section{Comparison of Seven Acid Mine Drainage Locations for REE Recovery}

\subsection{Introduction}

The importance of rare earth elements will continue to increase as new technological advancements are made, particularly in green technologies. REEs are used both during the production of products as well as components within products. Examples of REEs acting as process enablers include fluid-cracking catalysts, polishing media, and automotive catalytic converters (Hatch 2012). While REEs are important for developing technologies like super magnets and rechargeable batteries, they are also found in more common items like fluorescent lamps and televisions (Ayora et al. 2016 and Binnemans et al 2013).

The United States imported $\$ 150$ million of rare earth materials in 2017, an increase from the $\$ 118$ million imported in 2016 (Gambogi, 2018). During 2018, the United States did not mine any rare earths and were required to import from various countries. The main supplier of REEs to the US in 2018 was China. Sociopolitical tensions between the US and China and the limitations on export from China add to the need for developing a secondary source of REEs. These sources can include recovery from industrial waste streams as well as recycling from enduse products (Binnemans et al. 2013 and Jowitt et al. 2018).

Recycling of REEs from end-use products requires the extraction of the rare earths from products like rechargeable neodymium batteries and magnets. While progress has been made in this field, the limitations of recycling REEs from end-use products include the low concentrations of REEs and inefficient extraction processes as well as the poor economic value (Jowitt et al. 2018). It is possible that the concentrations of REEs can be much higher in industrial waste streams like mine tailings, metallurgical slags, and waste-water streams.

Acid mine drainage has been shown to contain REE concentrations above what can be found in natural water sources (Ayora et al. 2016, Stewart et al. 2017). However, each source of acid mine drainage is unique to the parent material it was leached from leading to large variations in AMD quality (Merten et al. 2005). Both variations in heavy metal and REE concentrations have been reported (Pellicori et al. 2005, Sharifi et al. 2013, Worrall \& Pearson 2001, and Zhao et al. 2007). For example, iron concentrations from these papers were as low as 6 $\mathrm{mg} / \mathrm{L}$ and ranged up to $264 \mathrm{mg} / \mathrm{L}$ (Pellicori et al. 2005 and Sharifi et al. 2013). The REE concentrations ranged from $2.69 \mathrm{ug} / \mathrm{L}$ up to $622 \mathrm{ug} / \mathrm{L}$ (Worrall \& Pearson 2001 and Zhao et al. 2007). Because the raw water characteristics of AMD varies substantially between sources, it is important to understand how they affect the precipitation patterns of the major metals and REEs.

The previous experiments were conducted using AMD from a single source (AQ-2). While variations in concentration occurred daily, it was unclear how different sources of AMD would react to the selective precipitation procedure. It was possible that the quality of REE 
precipitates collected vary between sources like the raw water characteristics. To determine if raw water quality significantly impacts the REE precipitate quality, seven AMD sites were sampled and tested for comparison. Alongside the comparison of the precipitates, linear regression was used to determine possible correlations between raw water and precipitate quality. In addition, possible correlations could be used to easily predict REE precipitate quality when surveying AMD locations. The analysis of aqueous REE concentrations is typically performed using inductively coupled plasma mass spectrometry (ICP-MS) which can be costly when analyzing multiple samples. According to Sindern (2017), the cost of ICP-MS analysis is due to the labor and time intensive steps for sample preparation and machine maintenance. If raw water characteristics could be used to estimate REE precipitate grade instead, it could greatly lower the costs of analysis.

\subsection{Methods}

\subsubsection{Site Characterization}

Seven acid mine drainage sites with varying concentrations of rare earth elements in the raw water were chosen from a survey of AMD sites across northern West Virginia. Figure 5-1 is a map displaying the AMD collection sites. The AMD sites were chosen based on concentration data gathered from a previous study. The sites showing a range of REE and gangue metal concentrations were chosen for this analysis. Site AQ-2 is located 6.5 miles south of Morgantown and is an AMD treatment plant. Raw AMD was collected from the pipes upstream of the treatment. AQ-8 was is located 2 miles north of Cheat Lake, within the boundary of a luxury housing community. The raw AMD was collected from a small pond upstream of the treatment process (a lime silo). AQ-3 is 5.5 miles northeast of Kingwood. Like AQ-2, this site is also an active treatment plant, and receives the AMD from the T\&T mines. The AMD was pumped from one of the inlet pipes to the treatment facility. AQ-50 is 7 miles east of Grafton and was a reclaimed mine site which was being used as pasture for Angus cows. On-site remediation was a sodium hydroxide drip into the stream. Samples were collected upstream of the drip using a pump. AQ-51-5 is 12 miles west of Aurora and was located in an active construction zone. A larger AMD treatment facility was being constructed at the time of collection. Raw water was hand sampled directly from a pipe located upstream of the sodium hydroxide treatment. AQ-65 is located 5.5 miles southwest of Mt. Storm, and is located above a calcium hydroxide treatment silo and settling ponds. Raw AMD was collected upstream from a culvert by hand-filling buckets. AQ-67 is located across Corridor H, 6.5 miles to the south. The site is farther back from the road, and was a large, flat area with shallow AMD from multiple sources which flowed into a stream towards a sodium hydroxide drip and settling pond. AMD samples were collected via pump from the location with the highest specific conductance. 


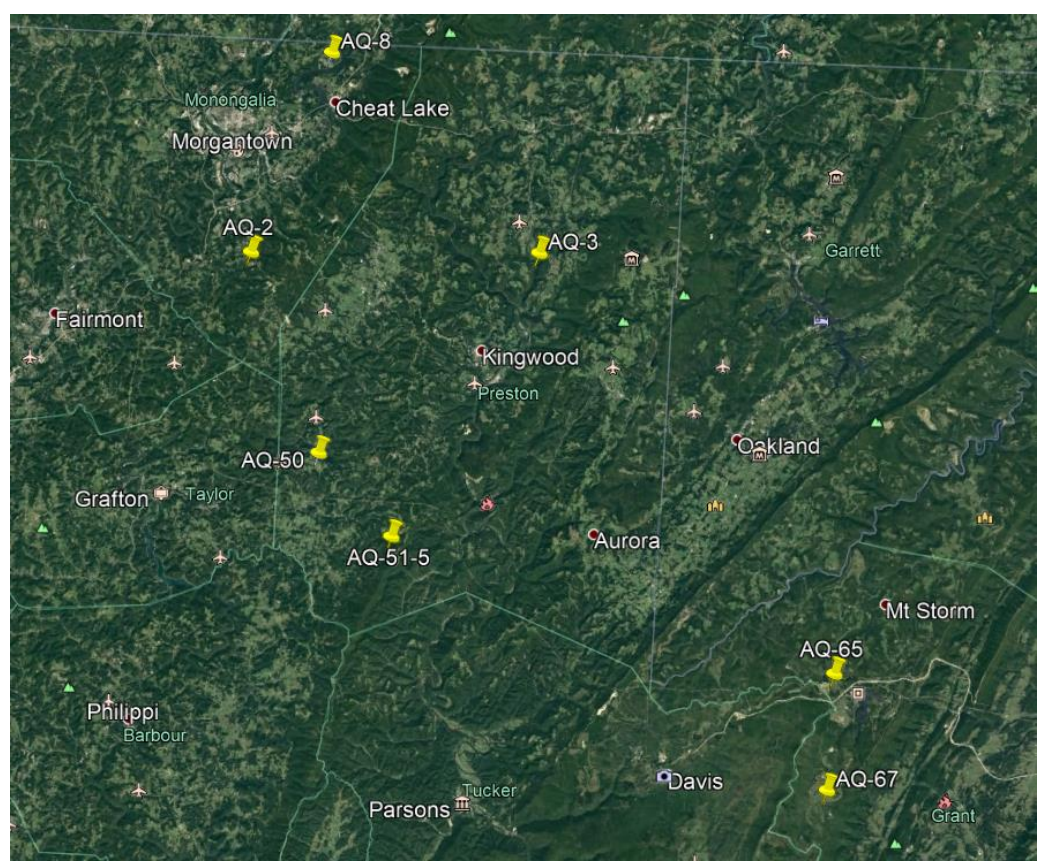

Figure 5-1: Locations across northern West Virginia of the seven AMD collection sites: AQ-2, AQ-8, AQ-50, AQ-51-5, AQ-3, AQ-65, and AQ-67.

The seven sites varied physicochemically. The specific conductance, $\mathrm{pH}$, and ORP for each collection site is shown below in Table 5-1. Data was collected on-site using a YSI field meter. The raw water metal and rare earth element concentrations were determined by the lab at NRCCE using ICP-OES and ICP-MS. The metal concentrations for each site are seen in Table 52 , and the rare earth element concentrations are located in Table 5-3.

Table 5-1: Raw water specific conductance, $\mathrm{pH}$, and ORP for the collection sites

\begin{tabular}{|c|c|c|c|}
\hline & $\begin{array}{c}\text { Specific } \\
\text { Conductance }\end{array}$ & pH & ORP \\
\hline & $\mathrm{uS} / \mathrm{cm}$ & & $\mathbf{m V}$ \\
\hline AQ-2 & 1031 & 2.73 & 522.8 \\
\hline AQ-8 & 2360 & 3.11 & 502.9 \\
\hline AQ-50 & 2032 & 2.87 & 448.9 \\
\hline AQ-51-5 & 1074 & 2.96 & N.D.* \\
\hline AQ-3 & 1591 & 2.82 & N.D. \\
\hline AQ-65 & 2019 & 3.03 & 460.5 \\
\hline AQ-67 & 991 & 3.23 & 417.6 \\
\hline
\end{tabular}


*There is no ORP data for sites AQ-51-5 or AQ-3 due to a probe malfunction during sampling.

Table 5-2: Dissolved metal concentrations in $\mathrm{mg} / \mathrm{L}$ for the raw AMD collected at all seven sites

\begin{tabular}{|c|c|c|c|c|c|c|c|c|c|c|c|}
\hline & $\mathbf{A l}$ & $\mathbf{C a}$ & $\mathbf{C o}$ & $\mathbf{C u}$ & $\mathbf{F e}$ & $\mathbf{M g}$ & $\mathbf{M n}$ & $\mathbf{N i}$ & $\mathbf{Z n}$ & $\mathbf{S O 4}$ & $\mathbf{S i}$ \\
\hline & $\mathbf{m g} / \mathbf{L}$ & $\mathbf{m g} / \mathbf{L}$ & $\mathbf{m g} / \mathbf{L}$ & $\mathbf{m g} / \mathbf{L}$ & $\mathbf{m g} / \mathbf{L}$ & $\mathbf{m g} / \mathbf{L}$ & $\mathbf{m g} / \mathbf{L}$ & $\mathbf{m g} / \mathbf{L}$ & $\mathbf{m g} / \mathbf{L}$ & $\mathbf{m g} / \mathbf{L}$ & $\mathbf{m g} / \mathbf{L}$ \\
\hline Omega & 68.6 & 90.2 & 0.2 & 0.3 & 95.5 & 30.0 & 1.2 & 0.6 & 1.7 & N.D. & N.D. \\
\hline AQ-8 & 72.2 & 208.6 & 0.9 & 0.0 & 34.5 & 129.8 & 44.5 & 1.1 & 3.5 & N.D. & N.D. \\
\hline AQ-50 & 36.7 & 128.6 & 1.1 & 0.1 & 260.9 & 76.6 & 36.2 & 1.0 & 3.1 & N.D. & N.D. \\
\hline AQ-51-5 & 28.6 & 53.7 & 0.2 & 0.0 & 2.7 & 40.8 & 15.1 & 0.3 & 0.7 & N.D. & N.D. \\
\hline AQ-3 & 27.2 & 160.8 & 0.1 & 0.1 & 27.1 & 33.9 & 1.2 & 0.2 & 0.7 & N.D. & N.D. \\
\hline AQ-65 & 66.3 & 172.5 & 0.9 & 3.3 & 3.3 & 108.8 & 27.3 & 1.0 & 2.8 & $1,385.0$ & 17.6 \\
\hline AQ-67 & 45.3 & 62.8 & 0.4 & N.D. & 5.3 & 26.6 & 14.9 & 0.5 & 1.4 & 540.5 & 18.3 \\
\hline
\end{tabular}

Table 5-3: Rare earth element concentrations of the raw AMD collected at all seven sites

\begin{tabular}{|c|c|c|c|c|c|c|c|c|c|c|c|c|c|c|c|c|c|}
\hline & Sc & $Y$ & La & $\mathrm{Ce}$ & $\mathrm{Pr}$ & Nd & Sm & $\mathrm{Eu}$ & Gd & $\mathrm{Tb}$ & Dy & Ho & Er & $\mathrm{Tm}$ & $\mathrm{Yb}$ & Lu & TREE \\
\hline & ug/L & ug/L & ug/L & ug/L & $\mathrm{ug} / \mathrm{L}$ & ug/L & ug $/ \mathrm{L}$ & $\mathrm{ug} / \mathrm{L}$ & $\mathrm{ug} / \mathrm{L}$ & ug/L & $\mathrm{ug} / \mathrm{L}$ & $\mathrm{ug} / \mathrm{L}$ & ug/L & ug/L & ug/L & ug/L & $\mathrm{ug} / \mathrm{L}$ \\
\hline Omega & 37.6 & 75.5 & 11.6 & 43.3 & 7.1 & 35.6 & 10.9 & 2.8 & 16.3 & 2.8 & 18.1 & 3.4 & 9.8 & 1.3 & 7.5 & 1.1 & 284.5 \\
\hline AQ-8 & 6.6 & 388.4 & 91.9 & 260.8 & 40.6 & 204.5 & 61.4 & 17.4 & 96.3 & 14.6 & 80.4 & 14.6 & 38.2 & 5.0 & 28.7 & 4.3 & 1353.7 \\
\hline AQ-50 & 4.3 & 355.0 & 136.4 & 293.1 & 36.5 & 158.7 & 37.4 & 10.5 & 58.6 & 9.6 & 57.2 & 11.5 & 31.3 & 4.1 & 23.7 & 3.4 & 1231.4 \\
\hline AQ-51-5 & 4.3 & 96.4 & 29.4 & 77.7 & 10.8 & 49.8 & 14.5 & 4.1 & 21.5 & 3.3 & 18.4 & 3.4 & 9.2 & 1.2 & 7.2 & 1.0 & 352.2 \\
\hline$A Q-3$ & 3.6 & 36.0 & 8.5 & 27.5 & 4.7 & 23.9 & 7.0 & 1.7 & 9.2 & 1.4 & 8.1 & 1.5 & 4.1 & 0.6 & 3.1 & 0.4 & 141.3 \\
\hline AQ-65 & 17.2 & 389.6 & 80.0 & 221.6 & 42.6 & 218.0 & 64.0 & 16.6 & 95.4 & 13.8 & 75.3 & 13.8 & 36.2 & 4.8 & 25.9 & 3.8 & 1318.6 \\
\hline AQ-67 & 1.7 & 196.8 & 41.0 & 136.6 & 21.4 & 110.0 & 31.5 & 7.9 & 45.7 & 7.0 & 38.0 & 7.2 & 18.8 & 2.5 & 12.3 & 5.0 & 683.5 \\
\hline
\end{tabular}

\subsubsection{Collection Procedure}

All raw AMD samples were collected upstream of any treatment. Before collecting the water samples, a YSI multimeter was placed to measure the water temperature, pressure, conductance, specific conductance, $\mathrm{pH}$, and redox potential (ORP). Raw AMD was collected in 5-gallon buckets for transport to the lab. For sites AQ-2, AQ-50, AQ-3, and AQ-67, a pump was placed into the stream or pond to fill the buckets. When unable to use the pump, the buckets were filled by hand-dipping bottles. For each site, a separate raw water sample was collected for analysis. All bottles and buckets used were rinsed with the raw water prior to use

\section{$\underline{\text { 5.2.3 Precipitation Procedure }}$}

The same precipitation procedure was used for all 7 AMD samples, the only exception being the volume of AMD used for AQ-2. $75 \mathrm{~L}$ of AMD (32L for AQ-2) was placed into a 20 gallon cone bottom tank. The concentration of ferrous iron was determined using Hach method 8146. The AMD was then completely oxidized using $30 \%$ hydrogen peroxide. The initial $\mathrm{pH}$ of the water was recorded prior to $\mathrm{pH}$ adjustment. Mixing at $325 \mathrm{rpm}$, a slurry of $2 \mathrm{~N}$ calcium hydroxide was added dropwise to raise the first $\mathrm{pH}$ endpoint of 4.0. Once the $\mathrm{pH}$ was adjusted, the stirrer was removed, and the precipitate was allowed to settle to the bottom of the conical tank overnight (approximately 15 hours). 
After settling, the supernatant was carefully removed from the tank using a siphon and then transferred to a second 20-gallon cone bottom tank. The $\mathrm{pH} 4.0$ precipitate was collected from the bottom of the cone-bottom tank through a valve at the bottom. The transferred supernatant was then adjusted to the next $\mathrm{pH}$ endpoint. Mixing at $325 \mathrm{rpm}, 2 \mathrm{~N}$ calcium hydroxide was added dropwise to the AMD until the $\mathrm{pH}$ reached 5.0. The precipitate was allowed to settle overnight.

The supernatant was transferred to a clean 20-gallon tank using a siphon. The $\mathrm{pH} 5.0$ precipitate was collected from the bottom of the cone-bottom tank through the valve. The transferred $\mathrm{pH} 5.0$ supernatant was mixed at $325 \mathrm{rpm}$ while $2 \mathrm{~N}$ calcium hydroxide was added dropwise to raise the $\mathrm{pH}$ to 8.0. The precipitate was allowed to settle overnight, and the supernatant was separated via the siphon. The $\mathrm{pH} 8.0$ precipitate was collected after the supernatant was removed.

\subsubsection{Sample Preparation for Analysis}

Samples of the raw AMD, $\mathrm{pH} 4.0$ supernatant, $\mathrm{pH} 5.0$ supernatant, and $\mathrm{pH} 8.0$ supernatant were collected for each AMD site. The aqueous samples were preserved using $70 \%$ trace metal grade nitric acid to prevent metal precipitation prior to analysis. The precipitate samples were collected were collected from the cone bottom tanks and dewatered via vacuum filtration through 0.22 um filters. The moisture content $(\%)$ for each sample was determined during analysis so that the dry weight of collected precipitate could be determined.

Both aqueous and precipitate samples were sent to the NRCCE Analytical Laboratory for testing. The precipitate samples were acid digested with trace metal grade nitric acid. Major metal concentrations (Al, $\mathrm{Ca}, \mathrm{Co}, \mathrm{Fe}, \mathrm{Mg}, \mathrm{Mn}, \mathrm{Ni}, \mathrm{Zn}$ ) were determined via ICP-OES and REE concentrations were determined via ICP-MS

\subsubsection{Data Analysis}

The compositions of the precipitates were determined using the concentrations $(\mathrm{mg} / \mathrm{kg})$ reported by NRCCE for the solid samples. Those concentrations were converted into weight percent using the dry mass for each element. The major metals tested for all samples included aluminum, calcium, cobalt, iron, magnesium, manganese, nickel, and zinc. Sites AQ-65 and AQ67 were also analyzed for silica, sodium, sulfates, and chlorides. These compounds were not analyzed at prior sites because their prevalence in the precipitates had not been discovered. All 16 of the rare earth elements were analyzed for as well, being categorized as light rare earths (LREEs) or heavy rare earths (HREEs). The LREEs consist of lanthanum, cerium, praseodymium, neodymium, promethium, samarium, and europium. The heavy rare earths include gadolinium, terbium, dysprosium holmium, erbium, thulium, ytterbium, and lutetium. Neither scandium nor yttrium fit either category. 
Overall percent recovery of gangue metals and rare earth elements was determined using the raw water concentrations and $\mathrm{pH} 8.0$ filtrate concentrations. The difference between the raw water concentration and the filtrate was determined for each element. The differences in concentrations were then divided by the respective initial concentration and converted into a percentage.

The relationships between raw water characteristics and REE grade were analyzed using the data from all seven AMD sites. Linear regression (Excel, Microsoft Corp., Redmond, WA) was then utilized to evaluate these correlations. The parameters, which were compared to both REE concentration and precipitate grade, included the metal concentrations ( $\mathrm{Al}, \mathrm{Fe}, \mathrm{Mg}, \mathrm{Mn}, \mathrm{Ni}$, and $\mathrm{Zn}$ ), the ratio of aluminum to iron, the ratio of metals to REEs, sulfate concentration, and specific conductance. The $\mathrm{R}^{2}$ value derived from each linear regression was used to determine the significance of the correlation between the raw water characteristics and the REE grade.

\subsection{Results}

\section{$\underline{\text { 5.3.1 Composition } \mathrm{pH} \text { 4.0 Precipitates }}$}

The metal and REE concentrations of the seven $\mathrm{pH} 4.0$ precipitates are shown below in Table 5-4. Figure 5-2 compares the weight percentage of the major metals and REEs for all seven sites. The $\mathrm{pH} 4.0$ precipitates were mainly composed of iron for all seven AMD samples, ranging from $28.1 \%$ for AQ-50 to $57.5 \%$ for AQ-2. Sulfate was also found in relatively high concentrations, with $15.6 \%$ for AQ-65 and 5.5\% for AQ-67 solids. The next most abundant metal in the $\mathrm{pH} 4.0$ precipitates was aluminum. The percentage of aluminum ranged between $0.2 \%$ for AQ-50 to $3.8 \%$ for AQ-65. The remaining metals contributed far less to the overall compositions of the precipitates for all seven AMD samples. Calcium ranged between below $0.1 \%$ to $0.4 \%$ by weight. Magnesium was below $0.1 \%$ for all samples except for AQ-8 which was $0.2 \%$. Manganese ranged from below $0.1 \%$ (AQ-2 and AQ-3) up to $1.0 \%$ (AQ-65). Cobalt, nickel, and zinc did not $\%$ surpass $0.1 \%$ in any of the seven precipitates. The rare earths did not show enrichment in the $\mathrm{pH} 4.0$ precipitates, as all samples were below $0.1 \%$ REEs. 
Table 5-4: Composition of the $\mathrm{pH} 4.0$ precipitates of the seven AMD sites analyzed.

\begin{tabular}{|c|c|c|c|c|c|c|c|}
\hline \multicolumn{8}{|c|}{ pH 4.0 Precipitates } \\
\hline & AQ-2 & AQ-8 & $\mathbf{A Q - 5 0}$ & AQ-51-5 & AQ-3 & AQ-65 & AQ-67 \\
\hline Concentration & $\begin{array}{c}\mathbf{m g} / \mathbf{k g} \\
(\%)\end{array}$ & $\begin{array}{c}\mathbf{m g} / \mathbf{k g} \\
(\%)\end{array}$ & $\begin{array}{c}\mathrm{mg} / \mathrm{kg} \\
(\%)\end{array}$ & $\begin{array}{c}\mathrm{mg} / \mathrm{kg} \\
(\%)\end{array}$ & $\begin{array}{c}\mathrm{mg} / \mathrm{kg} \\
(\%)\end{array}$ & $\begin{array}{c}\text { mg/kg } \\
(\%)\end{array}$ & $\begin{array}{c}\mathrm{mg} / \mathrm{kg} \\
(\%)\end{array}$ \\
\hline Al & $\begin{array}{c}17372 \\
(1.7 \%)\end{array}$ & $\begin{array}{l}25698 \\
(2.6 \%)\end{array}$ & $\begin{array}{c}2336 \\
(0.2 \%)\end{array}$ & $\begin{array}{l}26932 \\
(2.7 \%)\end{array}$ & $\begin{array}{l}14035 \\
(1.4 \%)\end{array}$ & $\begin{array}{l}37677 \\
(3.8 \%)\end{array}$ & $\begin{array}{l}17616 \\
(1.8 \%)\end{array}$ \\
\hline $\mathbf{C a}$ & $\begin{array}{c}823 \\
(0.1 \%) \\
\end{array}$ & $\begin{array}{c}4103 \\
(0.4 \%) \\
\end{array}$ & $\begin{array}{c}702 \\
(0.1 \%) \\
\end{array}$ & $\begin{array}{c}726 \\
(0.1 \%) \\
\end{array}$ & $\begin{array}{c}139 \\
(0.0 \%) \\
\end{array}$ & $\begin{array}{c}1296 \\
(0.1 \%) \\
\end{array}$ & $\begin{array}{c}559 \\
(0.1 \%) \\
\end{array}$ \\
\hline Co & $\begin{array}{c}1 \\
(0.0 \%)\end{array}$ & $\begin{array}{c}44 \\
(0.0 \%) \\
\end{array}$ & $\begin{array}{c}11 \\
(0.0 \%)\end{array}$ & $\begin{array}{c}20 \\
(0.0 \%) \\
\end{array}$ & $\begin{array}{c}1 \\
(0.0 \%) \\
\end{array}$ & $\begin{array}{c}48 \\
(0.0 \%) \\
\end{array}$ & $\begin{array}{c}6 \\
(0.0 \%) \\
\end{array}$ \\
\hline $\mathbf{F e}$ & $\begin{array}{l}474752 \\
(57.5 \%)\end{array}$ & $\begin{array}{l}394565 \\
(39.5 \%)\end{array}$ & $\begin{array}{l}280926 \\
(28.1 \%)\end{array}$ & $\begin{array}{c}374094 \\
(37.4 \%)\end{array}$ & $\begin{array}{l}474794 \\
(47.5 \%)\end{array}$ & $\begin{array}{l}373600 \\
(37.4 \%)\end{array}$ & $\begin{array}{l}463882 \\
(46.4 \%)\end{array}$ \\
\hline Mg & $\begin{array}{c}137 \\
(0.0 \%) \\
\end{array}$ & $\begin{array}{c}2111 \\
(0.2 \%)\end{array}$ & $\begin{array}{c}209 \\
(0.0 \%) \\
\end{array}$ & $\begin{array}{c}114 \\
(0.0 \%) \\
\end{array}$ & $\begin{array}{c}79 \\
(0.0 \%)\end{array}$ & $\begin{array}{c}397 \\
(0.0 \%) \\
\end{array}$ & $\begin{array}{c}216 \\
(0.0 \%)\end{array}$ \\
\hline Mn & $\begin{array}{c}49 \\
(0.0 \%)\end{array}$ & $\begin{array}{c}1055 \\
(0.1 \%)\end{array}$ & $\begin{array}{c}1981 \\
(0.2 \%) \\
\end{array}$ & $\begin{array}{c}2261 \\
(0.2 \%)\end{array}$ & $\begin{array}{c}28 \\
(0.0 \%) \\
\end{array}$ & $\begin{array}{c}9788 \\
(1.0 \%)\end{array}$ & $\begin{array}{c}1599 \\
(0.2 \%)\end{array}$ \\
\hline $\mathbf{N i}$ & $\begin{array}{c}0 \\
(0.0 \%)\end{array}$ & $\begin{array}{c}174 \\
(0.0 \%)\end{array}$ & $\begin{array}{c}10 \\
(0.0 \%)\end{array}$ & $\begin{array}{c}76 \\
(0.0 \%) \\
\end{array}$ & $\begin{array}{c}7 \\
(0.0 \%) \\
\end{array}$ & $\begin{array}{c}108 \\
(0.0 \%) \\
\end{array}$ & $\begin{array}{c}12 \\
(0.0 \%) \\
\end{array}$ \\
\hline SO4 & N.D.* & N.D. & N.D. & N.D. & N.D. & $\begin{array}{l}156082 \\
(15.6 \%)\end{array}$ & $\begin{array}{l}55493 \\
(5.5 \%) \\
\end{array}$ \\
\hline $\mathbf{S i}$ & N.D. & N.D. & N.D. & N.D. & N.D. & $\begin{array}{c}4623 \\
(0.5 \%) \\
\end{array}$ & $\begin{array}{c}1792 \\
(0.2 \%) \\
\end{array}$ \\
\hline $\mathbf{Z n}$ & $\begin{array}{c}13 \\
(0.0 \%) \\
\end{array}$ & $\begin{array}{c}116 \\
(0.0 \%) \\
\end{array}$ & $\begin{array}{c}12 \\
(0.0 \%) \\
\end{array}$ & $\begin{array}{c}361 \\
(0.0 \%) \\
\end{array}$ & $\begin{array}{c}10 \\
(0.0 \%) \\
\end{array}$ & $\begin{array}{c}50 \\
(0.0 \%) \\
\end{array}$ & $\begin{array}{c}66 \\
(0.0 \%) \\
\end{array}$ \\
\hline HREE & $\begin{array}{c}17 \\
(0.0 \%) \\
\end{array}$ & $\begin{array}{c}81 \\
(0.0 \%) \\
\end{array}$ & $\begin{array}{c}27 \\
(0.0 \%) \\
\end{array}$ & $\begin{array}{c}57 \\
(0.0 \%) \\
\end{array}$ & $\begin{array}{c}16 \\
(0.0 \%) \\
\end{array}$ & $\begin{array}{c}66 \\
(0.0 \%) \\
\end{array}$ & $\begin{array}{c}8 \\
(0.0 \%) \\
\end{array}$ \\
\hline LREE & $\begin{array}{c}22 \\
(0.0 \%)\end{array}$ & $\begin{array}{c}119 \\
(0.0 \%)\end{array}$ & $\begin{array}{c}64 \\
(0.0 \%)\end{array}$ & $\begin{array}{c}112 \\
(0.0 \%)\end{array}$ & $\begin{array}{c}31 \\
(0.0 \%)\end{array}$ & $\begin{array}{c}221 \\
(0.0 \%)\end{array}$ & $\begin{array}{c}23 \\
(0.0 \%)\end{array}$ \\
\hline Sc & $\begin{array}{c}17 \\
(0.0 \%)\end{array}$ & $\begin{array}{c}4 \\
(0.0 \%) \\
\end{array}$ & $\begin{array}{c}1 \\
(0.0 \%)\end{array}$ & $\begin{array}{c}8 \\
(0.0 \%) \\
\end{array}$ & $\begin{array}{c}5 \\
(0.0 \%) \\
\end{array}$ & $\begin{array}{c}18 \\
(0.0 \%)\end{array}$ & $\begin{array}{c}3 \\
(0.0 \%) \\
\end{array}$ \\
\hline TREE & $\begin{array}{c}56 \\
(0.0 \%)\end{array}$ & $\begin{array}{c}204 \\
(0.0 \%)\end{array}$ & $\begin{array}{c}92 \\
(0.0 \%)\end{array}$ & $\begin{array}{c}177 \\
(0.0 \%)\end{array}$ & $\begin{array}{c}52 \\
(0.0 \%)\end{array}$ & $\begin{array}{c}305 \\
(0.0 \%)\end{array}$ & $\begin{array}{c}34 \\
(0.0 \%)\end{array}$ \\
\hline
\end{tabular}

*N.D. - No data was collected for the sulfate and silica concentrations for sites visited prior to AQ-65 and AQ-67. The importance of sulfate and silica concentration was discovered after visiting the first 5 AMD locations 


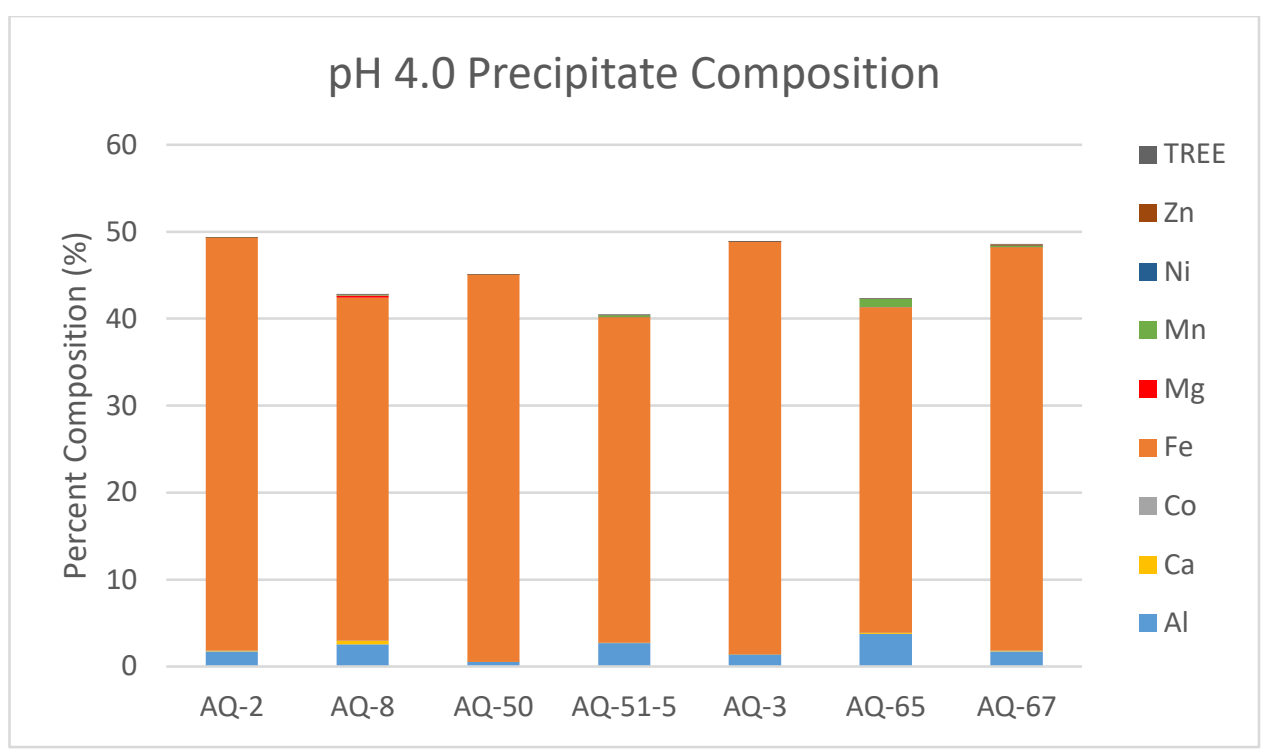

Figure 5-2: Weight percentages of the $\mathrm{pH} 4.0$ precipitates of the seven AMD sites

\subsubsection{Composition pH 5.0 Precipitates}

The metal and REE concentrations of the $\mathrm{pH} 5.0$ precipitates are shown below in Table 55. A comparison of precipitate composition for all sites is seen below in Figure 5-3. The major component of the $\mathrm{pH} 5.0$ precipitates is aluminum accounting for $15.1 \%$ to $24.3 \%$ of the total precipitate weights. Sulphate contributed to $7.2 \%$ and $8.6 \%$ of the total precipitate weight for AQ-65 and AQ-67, respectively. The remaining metals did not significantly contribute to the weight of the precipitates. Calcium ranged from below 0.1\% (AQ-3) to 4.1\% (AQ-8). The lowest iron concentration was $0.1 \%$ for the AQ-2 solid and the highest concentration was $2.0 \%$ in the AQ-51-5 solid. Magnesium was below 0.1\% of the solids for AQ-50, AQ-3, and AQ-67. It reached as high as $1.3 \%$ in the precipitate from AQ-8. Similarly, manganese was as low as below $0.1 \%$ for the AQ-2 and AQ-3 solids, and as high as $1.4 \%$ for the AQ-8 solids. Cobalt, nickel, and zinc did not surpass $0.1 \%$ in any of the $\mathrm{pH} 0.5$ precipitates. As seen in the $\mathrm{pH} 4.0$ precipitates, the bulk of the $\mathrm{pH} 5.0$ precipitates did not reach $0.1 \%$ for the REEs. The only $\mathrm{pH} 5.0$ solids to do so were from AQ-8 and AQ-65. 
Table 5-5: Percent composition of the $\mathrm{pH} 5.0$ precipitates of the seven AMD sites analyzed.

\begin{tabular}{|c|c|c|c|c|c|c|c|}
\hline \multicolumn{8}{|c|}{ pH 5.0 Precipitates } \\
\hline & AQ-2 & AQ-8 & AQ-50 & AQ-51-5 & AQ-3 & AQ-65 & AQ-67 \\
\hline Concentration & $\begin{array}{c}\mathrm{mg} / \mathrm{kg} \\
(\%)\end{array}$ & $\begin{array}{c}\mathrm{mg} / \mathrm{kg} \\
(\%)\end{array}$ & $\begin{array}{c}\mathrm{mg} / \mathrm{kg} \\
(\%)\end{array}$ & $\begin{array}{c}\mathrm{mg} / \mathrm{kg} \\
(\%)\end{array}$ & $\begin{array}{c}\mathrm{mg} / \mathrm{kg} \\
(\%)\end{array}$ & $\begin{array}{c}\mathbf{m g} / \mathbf{k g} \\
(\%)\end{array}$ & $\begin{array}{c}\mathbf{m g} / \mathbf{k g} \\
(\%)\end{array}$ \\
\hline Al & $\begin{array}{l}242678 \\
(24.3 \%)\end{array}$ & $\begin{array}{l}180012 \\
(18.0 \%)\end{array}$ & $\begin{array}{l}168964 \\
(16.9 \%)\end{array}$ & $\begin{array}{c}151363 \\
(15.1 \%) \\
\end{array}$ & $\begin{array}{l}216919 \\
(21.7 \%) \\
\end{array}$ & $\begin{array}{l}235055 \\
(23.5 \%) \\
\end{array}$ & $\begin{array}{l}238984 \\
(23.9 \%) \\
\end{array}$ \\
\hline $\mathrm{Ca}$ & $\begin{array}{l}11519 \\
(1.2 \%) \\
\end{array}$ & $\begin{array}{l}41141 \\
(4.1 \%) \\
\end{array}$ & $\begin{array}{c}2235 \\
(0.2 \%) \\
\end{array}$ & $\begin{array}{c}2455 \\
(0.2 \%) \\
\end{array}$ & $\begin{array}{c}410 \\
(0.0 \%) \\
\end{array}$ & $\begin{array}{c}2387 \\
(0.2 \%) \\
\end{array}$ & $\begin{array}{c}1357 \\
(0.1 \%) \\
\end{array}$ \\
\hline Co & $\begin{array}{c}5 \\
(0.0 \%)\end{array}$ & $\begin{array}{c}102 \\
(0.0 \%)\end{array}$ & $\begin{array}{c}63 \\
(0.0 \%)\end{array}$ & $\begin{array}{c}12 \\
(0.0 \%)\end{array}$ & $\begin{array}{c}6 \\
(0.0 \%)\end{array}$ & $\begin{array}{c}35 \\
(0.0 \%)\end{array}$ & $\begin{array}{c}17 \\
(0.0 \%)\end{array}$ \\
\hline $\mathbf{F e}$ & $\begin{array}{c}1271 \\
(0.1 \%) \\
\end{array}$ & $\begin{array}{c}4694 \\
(0.5 \%) \\
\end{array}$ & $\begin{array}{l}11963 \\
(0.2 \%) \\
\end{array}$ & $\begin{array}{l}19869 \\
(2.0 \%) \\
\end{array}$ & $\begin{array}{c}2059 \\
(2.0 \%) \\
\end{array}$ & $\begin{array}{c}2436 \\
(0.2 \%) \\
\end{array}$ & $\begin{array}{l}10366 \\
(1.0 \%) \\
\end{array}$ \\
\hline Mg & $\begin{array}{c}998 \\
(0.1 \%)\end{array}$ & $\begin{array}{l}13392 \\
(1.3 \%)\end{array}$ & $\begin{array}{c}387 \\
(0.0 \%)\end{array}$ & $\begin{array}{c}809 \\
(0.1 \%)\end{array}$ & $\begin{array}{c}223 \\
(0.0 \%)\end{array}$ & $\begin{array}{c}616 \\
(0.1 \%)\end{array}$ & $\begin{array}{c}241 \\
(0.0 \%)\end{array}$ \\
\hline Mn & $\begin{array}{c}154 \\
(0.0 \%)\end{array}$ & $\begin{array}{l}13862 \\
(1.4 \%)\end{array}$ & $\begin{array}{l}6205 \\
(0.6 \%)\end{array}$ & $\begin{array}{c}3825 \\
(0.4 \%)\end{array}$ & $\begin{array}{c}83 \\
(0.0 \%)\end{array}$ & $\begin{array}{c}4181 \\
(0.4 \%)\end{array}$ & $\begin{array}{c}1598 \\
(0.2 \%)\end{array}$ \\
\hline $\mathbf{N i}$ & $\begin{array}{c}441 \\
(0.0 \%)\end{array}$ & $\begin{array}{c}279 \\
(0.0 \%)\end{array}$ & $\begin{array}{c}82 \\
(0.0 \%)\end{array}$ & $\begin{array}{c}59 \\
(0.0 \%)\end{array}$ & $\begin{array}{c}31 \\
(0.0 \%)\end{array}$ & $\begin{array}{c}109 \\
(0.0 \%)\end{array}$ & $\begin{array}{c}61 \\
(0.0 \%)\end{array}$ \\
\hline SO4 & N.D.* & N.D. & N.D. & N.D. & N.D. & $\begin{array}{l}72459 \\
(7.2 \%) \\
\end{array}$ & $\begin{array}{l}85972 \\
(8.6 \%)\end{array}$ \\
\hline $\mathbf{S i}$ & N.D. & N.D. & N.D. & N.D. & N.D. & $\begin{array}{l}13504 \\
(1.4 \%) \\
\end{array}$ & $\begin{array}{l}16771 \\
(1.7 \%) \\
\end{array}$ \\
\hline Zn & $\begin{array}{c}99 \\
(0.0 \%)\end{array}$ & $\begin{array}{c}837 \\
(0.1 \%)\end{array}$ & $\begin{array}{c}104 \\
(0.0 \%)\end{array}$ & $\begin{array}{c}109 \\
(0.0 \%)\end{array}$ & $\begin{array}{c}138 \\
(0.0 \%)\end{array}$ & $\begin{array}{c}478 \\
(0.0 \%)\end{array}$ & $\begin{array}{c}137 \\
(0.0 \%)\end{array}$ \\
\hline HREE & $\begin{array}{c}43 \\
(0.0 \%)\end{array}$ & $\begin{array}{c}391 \\
(0.0 \%)\end{array}$ & $\begin{array}{c}136 \\
(0.0 \%)\end{array}$ & $\begin{array}{c}115 \\
(0.0 \%)\end{array}$ & $\begin{array}{c}164 \\
(0.0 \%)\end{array}$ & $\begin{array}{c}619 \\
(0.1 \%)\end{array}$ & $\begin{array}{c}207 \\
(0.0 \%)\end{array}$ \\
\hline LREE & $\begin{array}{c}15 \\
(0.0 \%)\end{array}$ & $\begin{array}{c}361 \\
(0.0 \%)\end{array}$ & $\begin{array}{c}206 \\
(0.0 \%)\end{array}$ & $\begin{array}{c}117 \\
(0.0 \%)\end{array}$ & $\begin{array}{c}79 \\
(0.0 \%)\end{array}$ & $\begin{array}{c}313 \\
(0.0 \%)\end{array}$ & $\begin{array}{c}101 \\
(0.0 \%)\end{array}$ \\
\hline Sc & $\begin{array}{c}125 \\
(0.0 \%)\end{array}$ & $\begin{array}{c}15 \\
(0.0 \%)\end{array}$ & $\begin{array}{c}16 \\
(0.0 \%)\end{array}$ & $\begin{array}{c}26 \\
(0.0 \%)\end{array}$ & $\begin{array}{c}38 \\
(0.0 \%)\end{array}$ & $\begin{array}{c}59 \\
(0.0 \%)\end{array}$ & $\begin{array}{c}10 \\
(0.0 \%)\end{array}$ \\
\hline TREE & $\begin{array}{c}183 \\
(0.0 \%) \\
\end{array}$ & $\begin{array}{c}767 \\
(0.1 \%) \\
\end{array}$ & $\begin{array}{c}357 \\
(0.0 \%) \\
\end{array}$ & $\begin{array}{c}258 \\
(0.0 \%) \\
\end{array}$ & $\begin{array}{c}281 \\
(0.0 \%)\end{array}$ & $\begin{array}{c}991 \\
(0.1 \%) \\
\end{array}$ & $\begin{array}{c}318 \\
(0.0 \%) \\
\end{array}$ \\
\hline
\end{tabular}

*N.D. - No data was collected for the sulfate and silica concentrations for sites visited prior to AQ-65 and AQ-67. The importance of sulfate and silica concentration was discovered after visiting the first 5 AMD locations

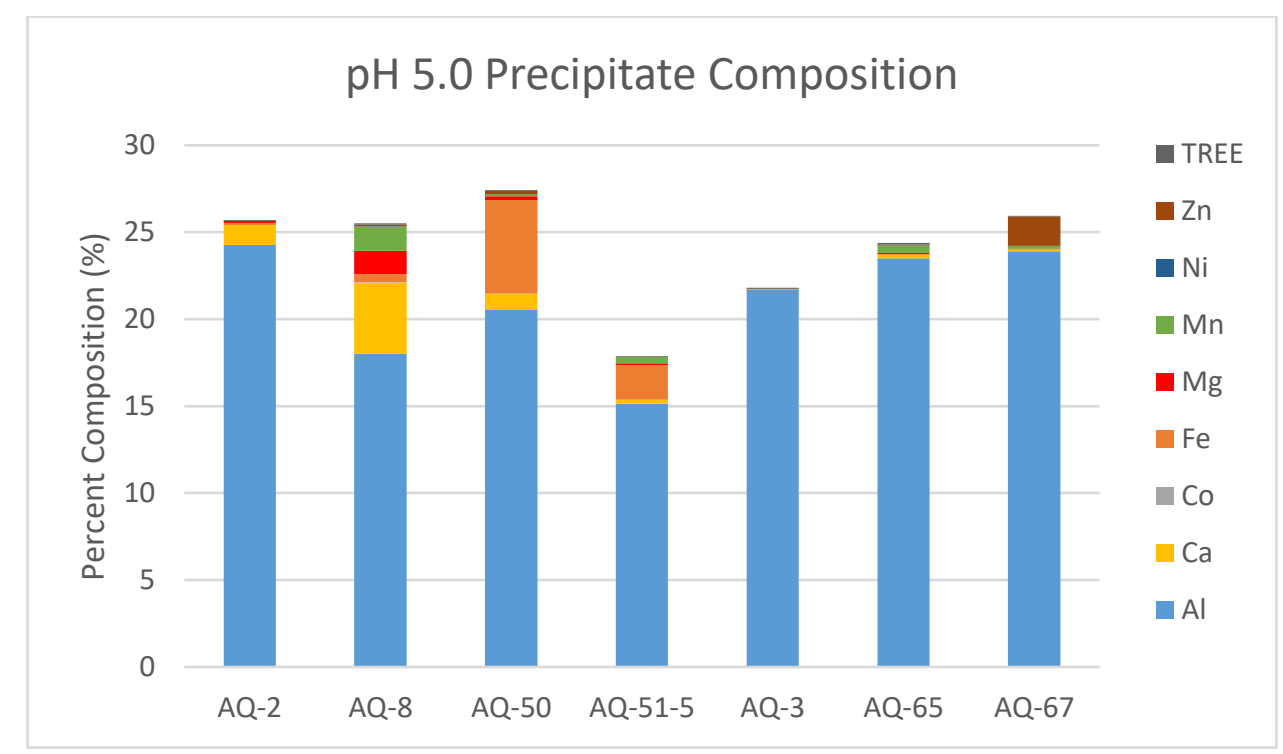


Figure 5-3: Weight percentages of the $\mathrm{pH} 5.0$ precipitates of the seven AMD sites

\subsubsection{Composition $\mathrm{pH}$ 8.0 Precipitates}

The major components of the $\mathrm{pH} 8.0$ precipitates were aluminum, manganese, and zinc. The metal and REE concentrations are shown below in Table 5-6. The comparison of weight percentages is shown in Figure 5-4. The aluminum concentrations ranged between 3.6\% (AQ-65) to $10.7 \%$ (AQ-2). Manganese was as low as $0.1 \%$ in AQ-2 solids, but as high as $7.5 \%$ in AQ-515 solids. Zinc ranged from $1.7 \%$ (AQ-50) to 22.6 (AQ-50) by weight. Calcium contributed between $0.5 \%$ (AQ-50) to $4.6 \%$ (AQ-8). There is no calcium concentration data available for AQ-67 pH 8.0 precipitates. Cobalt concentration was as low as $0.0 \%$ in AQ-2 solids, and as high as $0.8 \%$ in the AQ-65 solids. Iron ranged between $0.2 \%$ in the AQ- 8 precipitate and $2.5 \%$ in the AQ-3 precipitate. The concentration of magnesium went as low as $0.2 \%$ as seen in the AQ-50 precipitate and as high as $3.3 \%$ in the AQ-65 precipitate. Nickel did not surpass $0.1 \%$ in the AQ2 precipitate but reached $0.6 \%$ in the AQ-65 precipitate. Sulphate contributed to $0.7 \%$ and $0.5 \%$ of the AQ-65 and AQ-67 solids, respectively. The TREE concentration varied from 1.1\% precipitate weight for AQ-51-5 to 4.8\% precipitate weight for AQ-65.

Table 5-6: Percent composition of the $\mathrm{pH} 8.0$ precipitates of the seven AMD sites analyzed.

\begin{tabular}{|c|c|c|c|c|c|c|c|}
\hline \multicolumn{8}{|c|}{ pH 8.0 Precipitates } \\
\hline & AQ-2 & AQ-8 & AQ-50 & AQ-51-5 & AQ-3 & AQ-65 & AQ-67 \\
\hline Concentration & $\begin{array}{c}\mathrm{mg} / \mathrm{kg} \\
(\%)\end{array}$ & $\begin{array}{c}\mathrm{mg} / \mathrm{kg} \\
(\%)\end{array}$ & $\begin{array}{c}\mathrm{mg} / \mathrm{kg} \\
(\%)\end{array}$ & $\begin{array}{c}\mathrm{mg} / \mathrm{kg} \\
(\%)\end{array}$ & $\begin{array}{c}\mathrm{mg} / \mathrm{kg} \\
(\%)\end{array}$ & $\begin{array}{c}\mathrm{mg} / \mathrm{kg} \\
(\%)\end{array}$ & $\begin{array}{c}\mathrm{mg} / \mathrm{kg} \\
(\%)\end{array}$ \\
\hline Al & $\begin{array}{c}10668 \\
(10.7 \%) \\
\end{array}$ & $\begin{array}{l}77109 \\
(7.8 \%) \\
\end{array}$ & $\begin{array}{l}30942 \\
(3.1 \%) \\
\end{array}$ & $\begin{array}{l}86880 \\
(8.7 \%) \\
\end{array}$ & $\begin{array}{l}55300 \\
(5.5 \%) \\
\end{array}$ & $\begin{array}{l}35704 \\
(3.6 \%)\end{array}$ & $\begin{array}{l}69829 \\
(7.0 \%) \\
\end{array}$ \\
\hline $\mathbf{C a}$ & $\begin{array}{l}12419 \\
(1.2 \%) \\
\end{array}$ & $\begin{array}{l}45955 \\
(4.6 \%)\end{array}$ & $\begin{array}{l}12184 \\
(1.2 \%)\end{array}$ & $\begin{array}{l}18251 \\
(1.8 \%)\end{array}$ & $\begin{array}{l}16568 \\
(1.7 \%)\end{array}$ & $\begin{array}{c}9930 \\
(1.0 \%)\end{array}$ & N.D \\
\hline Co & $\begin{array}{c}240 \\
(0.0 \%)\end{array}$ & $\begin{array}{l}2296 \\
(0.2 \%)\end{array}$ & $\begin{array}{c}2094 \\
(0.2 \%)\end{array}$ & $\begin{array}{l}4060 \\
(0.4 \%)\end{array}$ & $\begin{array}{c}1160 \\
(0.1 \%)\end{array}$ & $\begin{array}{c}8025 \\
(0.8 \%)\end{array}$ & $\begin{array}{l}43445 \\
(0.4 \%)\end{array}$ \\
\hline $\mathrm{Fe}$ & $\begin{array}{l}11149 \\
(1.1 \%)\end{array}$ & $\begin{array}{l}2213 \\
(0.2 \%)\end{array}$ & $\begin{array}{l}36382 \\
(3.6 \%)\end{array}$ & $\begin{array}{l}5116 \\
(0.5 \%)\end{array}$ & $\begin{array}{l}25298 \\
(2.5 \%)\end{array}$ & $\begin{array}{c}7053 \\
(0.7 \%)\end{array}$ & $\begin{array}{c}4760 \\
(0.5 \%)\end{array}$ \\
\hline Mg & $\begin{array}{c}3019 \\
(0.3 \%)\end{array}$ & $\begin{array}{l}30858 \\
(3.1 \%)\end{array}$ & $\begin{array}{l}14307 \\
(3.6 \%)\end{array}$ & $\begin{array}{l}22859 \\
(2.3 \%)\end{array}$ & $\begin{array}{l}15139 \\
(1.5 \%)\end{array}$ & $\begin{array}{l}32540 \\
(3.3 \%)\end{array}$ & $\begin{array}{l}22747 \\
(2.3 \%)\end{array}$ \\
\hline Mn & $\begin{array}{c}972 \\
(0.1 \%)\end{array}$ & $\begin{array}{l}50522 \\
(5.1 \%)\end{array}$ & $\begin{array}{l}26719 \\
(2.7 \%)\end{array}$ & $\begin{array}{l}74638 \\
(7.5 \%)\end{array}$ & $\begin{array}{c}6194 \\
(0.6 \%)\end{array}$ & $\begin{array}{l}63521 \\
(6.4 \%)\end{array}$ & $\begin{array}{l}64162 \\
(6.4 \%)\end{array}$ \\
\hline $\mathbf{N i}$ & $\begin{array}{c}475 \\
(0.0 \%)\end{array}$ & $\begin{array}{c}2468 \\
(0.2 \%) \\
\end{array}$ & $\begin{array}{c}1829 \\
(0.2 \%)\end{array}$ & $\begin{array}{c}3081 \\
(0.3 \%) \\
\end{array}$ & $\begin{array}{c}1365 \\
(0.1 \%) \\
\end{array}$ & $\begin{array}{l}5710 \\
(0.6 \%)\end{array}$ & $\begin{array}{c}3665 \\
(0.4 \%) \\
\end{array}$ \\
\hline SO4 & N.D.* & N.D. & N.D. & N.D. & N.D. & $\begin{array}{c}7107 \\
(0.7 \%)\end{array}$ & $\begin{array}{l}4753 \\
(0.5 \%)\end{array}$ \\
\hline $\mathbf{S i}$ & N.D. & N.D. & N.D. & N.D. & N.D. & $\begin{array}{l}98068 \\
(9.8 \%)\end{array}$ & $\begin{array}{l}110201 \\
(11.0 \%)\end{array}$ \\
\hline Zn & $\begin{array}{l}17516 \\
(1.8 \%)\end{array}$ & $\begin{array}{l}95805 \\
(9.6 \%)\end{array}$ & $\begin{array}{l}226134 \\
(22.6 \%)\end{array}$ & $\begin{array}{l}28305 \\
(2.8 \%)\end{array}$ & $\begin{array}{l}38115 \\
(3.8 \%)\end{array}$ & $\begin{array}{l}110268 \\
(11.0 \%)\end{array}$ & $\begin{array}{l}68018 \\
(6.8 \%)\end{array}$ \\
\hline HREE & $\begin{array}{l}11380 \\
(1.1 \%)\end{array}$ & $\begin{array}{l}13151 \\
(1.3 \%)\end{array}$ & $\begin{array}{l}8430 \\
(0.8 \%)\end{array}$ & $\begin{array}{l}4965 \\
(0.5 \%)\end{array}$ & $\begin{array}{c}8060 \\
(0.8 \%)\end{array}$ & $\begin{array}{l}21675 \\
(2.2 \%)\end{array}$ & $\begin{array}{l}15598 \\
(1.6 \%)\end{array}$ \\
\hline LREE & $\begin{array}{l}6100 \\
(0.6 \%)\end{array}$ & $\begin{array}{l}13698 \\
(1.4 \%)\end{array}$ & $\begin{array}{l}10271 \\
(1.0 \%)\end{array}$ & $\begin{array}{l}6090 \\
(0.6 \%)\end{array}$ & $\begin{array}{l}10429 \\
(1.0 \%)\end{array}$ & $\begin{array}{l}26322 \\
(2.6 \%)\end{array}$ & $\begin{array}{l}18311 \\
(1.8 \%)\end{array}$ \\
\hline Sc & $\begin{array}{c}176 \\
(0.0 \%)\end{array}$ & $\begin{array}{c}7 \\
(0.0 \%)\end{array}$ & $\begin{array}{c}8 \\
(0.0 \%)\end{array}$ & $\begin{array}{c}20 \\
(0.0 \%)\end{array}$ & $\begin{array}{c}23 \\
(0.0 \%)\end{array}$ & $\begin{array}{c}18 \\
(0.0 \%)\end{array}$ & $\begin{array}{c}7 \\
(0.0 \%)\end{array}$ \\
\hline TREE & $\begin{array}{l}17656 \\
(1.8 \%)\end{array}$ & $\begin{array}{l}26856 \\
(2.7 \%) \\
\end{array}$ & $\begin{array}{l}18709 \\
(1.9 \%) \\
\end{array}$ & $\begin{array}{l}11075 \\
(1.1 \%) \\
\end{array}$ & $\begin{array}{l}18512 \\
(1.9 \%)\end{array}$ & $\begin{array}{l}48015 \\
(4.8 \%) \\
\end{array}$ & $\begin{array}{l}33916 \\
(3.4 \%) \\
\end{array}$ \\
\hline
\end{tabular}


*N.D. - No data was collected for the sulfate and silica concentrations for sites visited prior to AQ-65 and AQ-67. The importance of sulfate and silica concentration was discovered after visiting the first 5 AMD locations

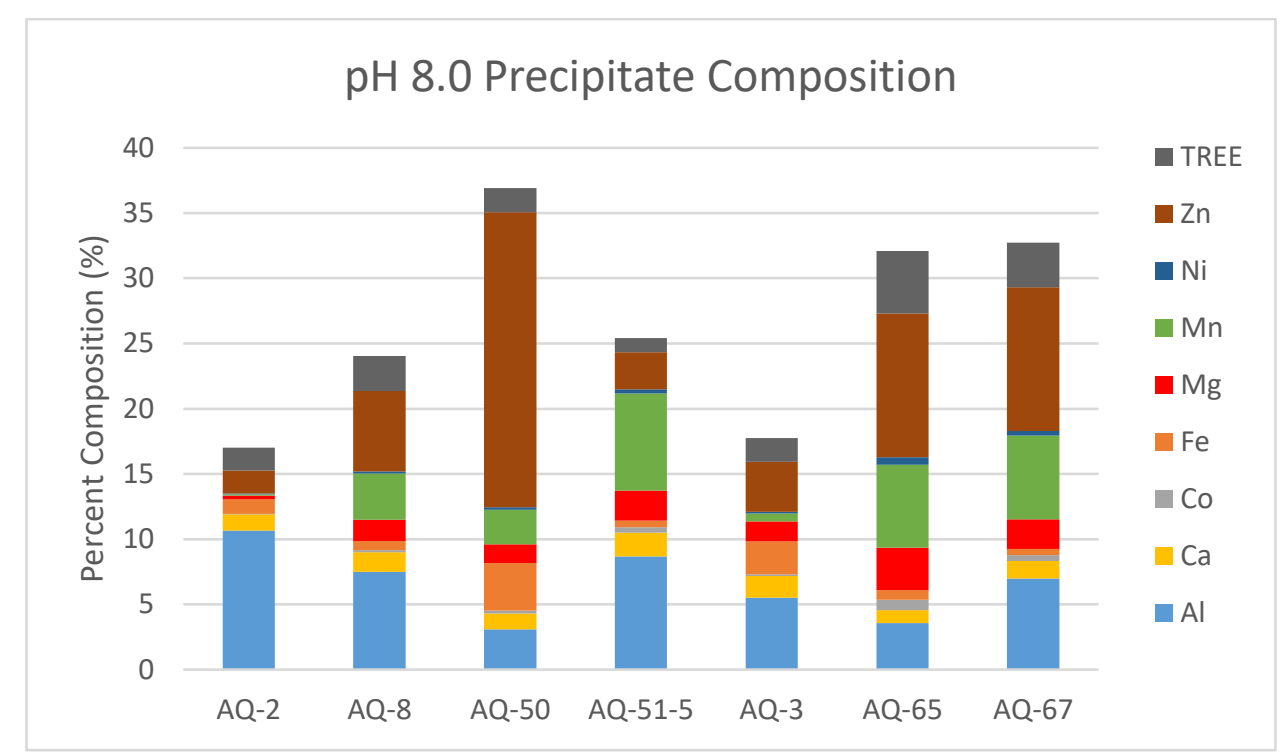

Figure 5-4: Weight percentages of the $\mathrm{pH} 8.0$ precipitates of the seven AMD sites

\subsubsection{Rare Earth Recovery}

The overall recovery of the LREEs and HREEs are shown below in Figures 5-5 and 5-6, respectively. The recovery of rare earth elements ranged from $46.2 \%$ to $98.8 \%$. The site with the lowest REE recovery was AQ-67, which only recovered $46.2 \%$ of the REE from the raw water. AQ-2 recovered $75.0 \%$ of the REE, AQ-50 recovered 93.5\%, AQ-65 recovered 95.2\%, AQ-8 recovered 96.5\%, and AQ-3 recovered 96.7\% REE. AQ-51-5 had the highest REE recovery at 98.8\%. For all seven sites, the recovery of LREEs was lower than the HREEs, with lanthanum having the lowest recovery. 


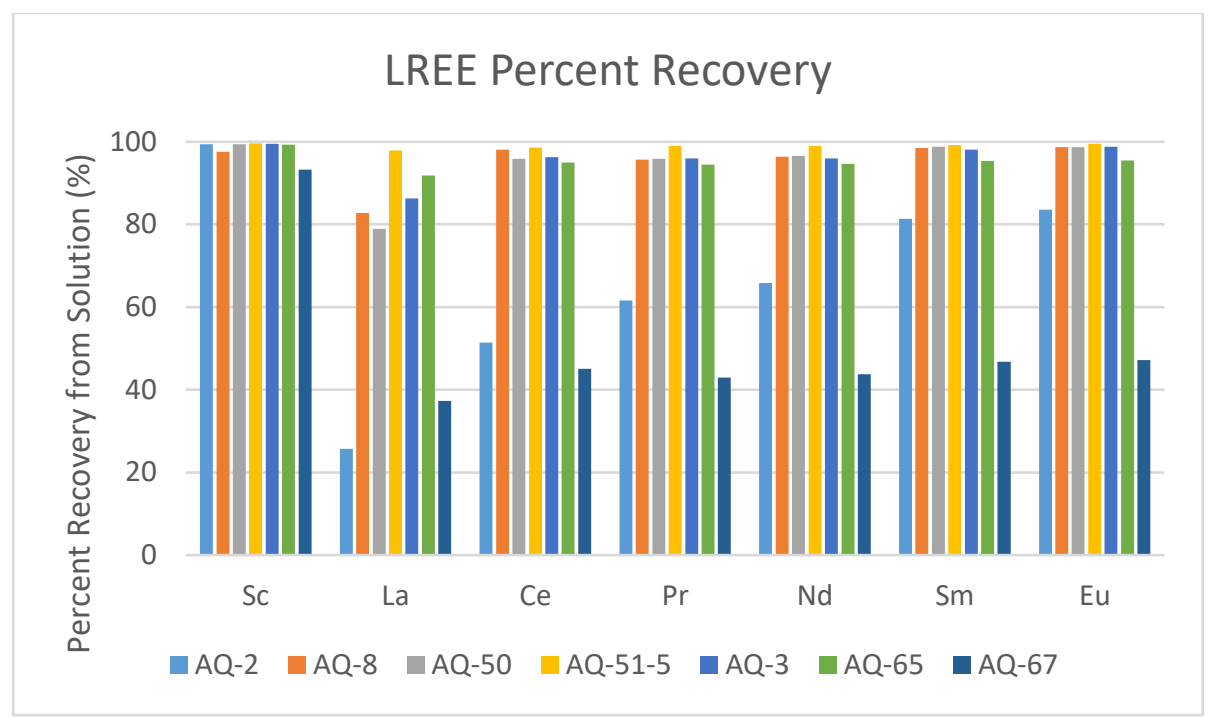

Figure 5-5: Percent recovery of the light rare earth elements and scandium for the seven AMD samples.

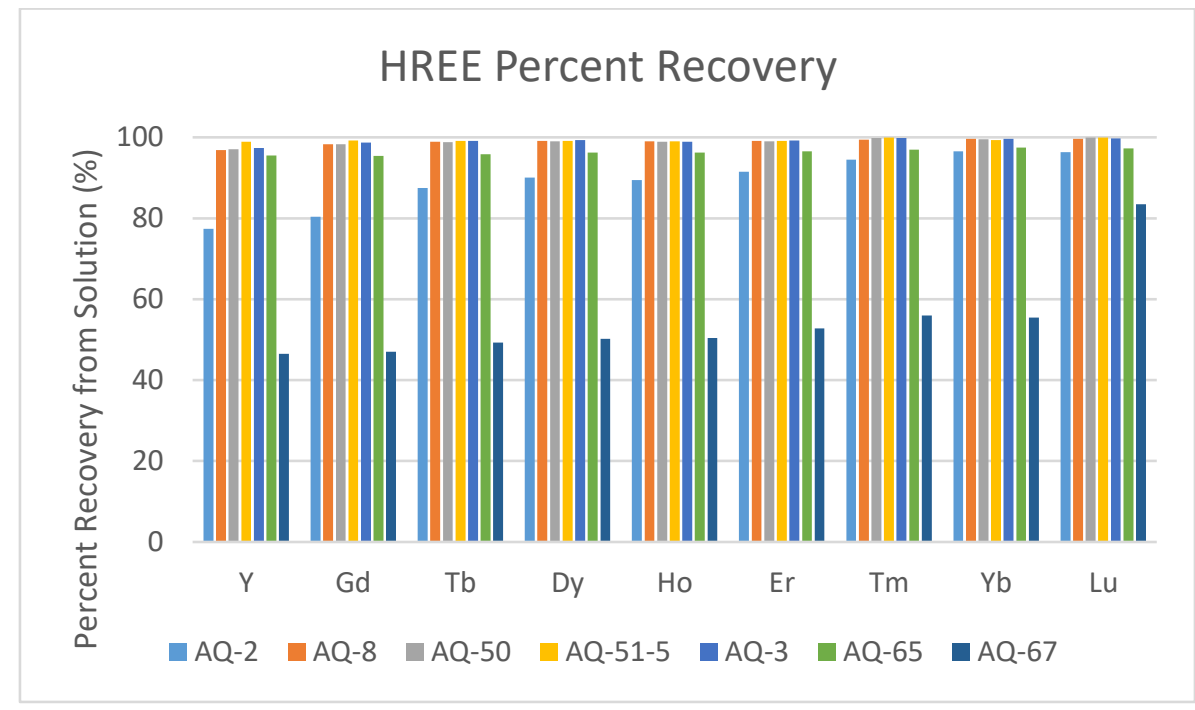

Figure 5-6: Percent recovery of the heavy rare earth elements and yttrium for the seven AMD samples

\subsubsection{Correlation of Raw Water Characteristics and REE Grade and Abundance}

The relationship between raw water TREE concentration and the resulting $\mathrm{pH} 8.0$ precipitate REE weight percentage is shown in Figure 5-7. TREE concentration varied greatly across the seven sites. The lowest concentration of TREE was $141 \mathrm{ug} / \mathrm{L}$ at AQ-3. AQ-2 contained $275 \mathrm{ug} / \mathrm{L}$ TREE and AQ-51-5 contained $352 \mathrm{ug} / \mathrm{L}$. The TREE concentration of AQ-67 was $684 \mathrm{ug} / \mathrm{L}$. AQ-50, AQ-65, and AQ-8 were the highest concentrations at $1231 \mathrm{ug} / \mathrm{L}, 1326$ $\mathrm{ug} / \mathrm{L}$, and $1354 \mathrm{ug} / \mathrm{L}$ respectively. 
Possible relationships between raw water characteristics and REE grade and abundance were assessed via linear regression The raw water parameters assessed were aluminum, iron, zinc, magnesium, manganese, and nickel concentrations, the ratio of iron to aluminum, the ratio of major metals to REEs, and specific conductance. The $\mathrm{R}^{2}$ values of the linear regression for the REE grade of the $\mathrm{pH} 8.0$ precipitates are shown below in Table 5-7. The majority of the raw water parameters were poorly coordinated with $\mathrm{pH} 8.0$ precipitate REE grade. While all parameters were below an $\mathrm{R}^{2}$ value of 0.5 , the two which were the highest were the ratio of iron to aluminum and the ratio of major metals to REEs. The $\mathrm{R}^{2}$ value of the iron-aluminum ratio was 0.4701 and the $\mathrm{R}^{2}$ value of the major metal-REE ratio was 0.2821 .

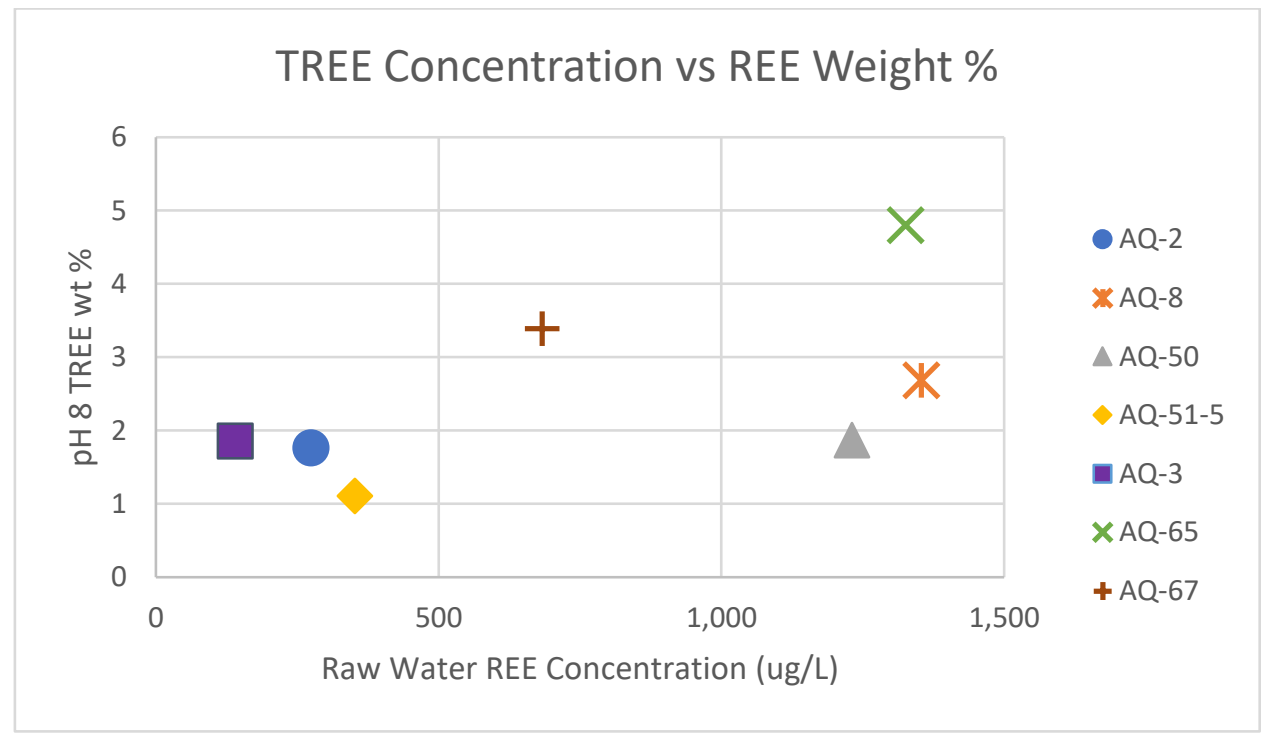

Figure 5-7: Comparison of the raw water REE concentration and the resulting $\mathrm{pH} 8.0$ precipitate REE grade for all seven AMD sources. 
Table 5-7: Correlation of raw water characteristics to the REE grade of the $\mathrm{pH} 8.0$ precipitates.

\begin{tabular}{|c|c|c|}
\hline REE Grade & & \\
\hline Raw Water Parameter & Trendline & R2 \\
\hline Al Concentration (mg/L) & Logarithmic & 0.1426 \\
\hline Fe Concentration (mg/L) & Logarithmic & 0.198 \\
\hline Fe:Al Concentration Ratio & Logarithmic & 0.4701 \\
\hline Zn Concentration (mg/L) & Power & 0.1207 \\
\hline Mn Concentration (mg/L) & Logarithmic & 0.0552 \\
\hline Mg Concentration (mg/L) & Linear & 0.0515 \\
\hline Ni Concentration (mg/L) & Logarithmic & 0.1219 \\
\hline MM:REE Concentration Ratio & Logarithmic & 0.2821 \\
\hline Specific Conductance (uS/cm) & Logarithmic & 0.0172 \\
\hline
\end{tabular}

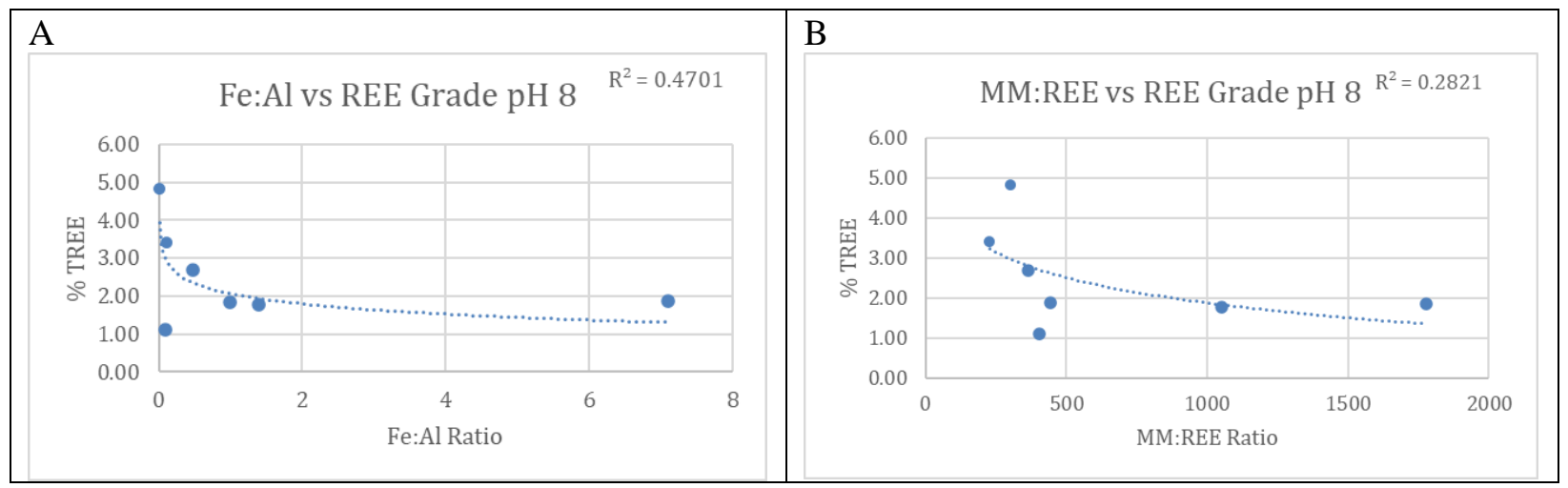

Figure 5-8: The comparison of REE grade to the ratio of iron to aluminum (A) and major metals to RREs (B). 


\subsection{Discussion}

\subsubsection{Precipitate Composition}

As seen in Figures 5-2, 5-3, and 5-4 above, the weight percentages of the precipitates do not equal $100 \%$. The weight accounted for ranges between $17 \%$ to $50 \%$. The remaining weight unaccounted for in the $\mathrm{pH} 4.0, \mathrm{pH} 5.0$, and $\mathrm{pH} 8.0$ precipitates are most likely the hydroxides complexed with the major metals, sulphate, and silica. The major metal contributions towards precipitate weight were calculated from the metal concentrations. The hydroxide complexes formed during precipitation were not assumed, so the weight of the oxygen and hydrogen is not included in the compositions shown above. Although sulphate and silica were not measured at sites AQ-2 through AQ-3, they are well known constituents of acid mine drainage and were substantial at AQ-65 and AQ-67 (Gray 1996).

The compositions of the $\mathrm{pH} 4.0$ precipitates collected from all seven sites followed similar trends. They were mainly composed of iron, with smaller amounts of aluminum. All other metals were in such low concentration that they did not significantly impact the precipitate mass. Very little of the REE precipitated at this stage, so the REE grade was very low for all $\mathrm{pH}$ 4.0 precipitates. The is consistent with what was observed during the $0.5 \mathrm{pH}$ step precipitation procedure and redox procedures previously discussed. In the previous experiments, iron was completely removed between $\mathrm{pH} 2.5$ and 4.0 for oxidized samples. Minimal aluminum removal was also observed, with less than $20 \%$ removal occurring below $\mathrm{pH} 4.0$. These precipitation patterns were also reported by Jenke \& Diebold (1983), Balintova et al. (2011), and Wei et al. (2005). The precipitation of REEs was not expected in this $\mathrm{pH}$ step due to the range for bulk removal being between $\mathrm{pH} 5.0$ and 7.0. This is consistent with the previous experiments, as well as with what was reported by Verplanck et al. (2004) and Zhang \& Honaker (2018).

The $\mathrm{pH} 5.0$ precipitates had larger quantities of aluminum with smaller amounts of iron. It was expected that all iron would have been precipitated out by $\mathrm{pH} 4.0$, however there was some carry over into the $\mathrm{pH} 5.0$ precipitates. Iron concentrations of the AMD sites varied greatly, with sites such as AQ-2 having an iron concentration of $95.5 \mathrm{mg} / \mathrm{L}$ while AQ-51-5 only had 2.7 $\mathrm{mg} / \mathrm{L}$. While the raw AMD was oxidized using 30\% hydrogen peroxide, it is possible that some iron remained reduced in some samples and did not completely oxidize and precipitate by $\mathrm{pH}$ 4.0. It is possible that this occurred for the AQ-50 sample due to the high initial concentrations of ferrous iron. It is more likely that the iron found after $\mathrm{pH} 4.0$ was colloidal, which only settled with the assistance of aluminum precipitate. As seen in the $\mathrm{pH} 4.0$ precipitates, the bulk of the REEs stayed in solution. The only rare earth which substantially precipitated out between $\mathrm{pH} 4.0$ and 5.0 was scandium, although removal occurred between $\mathrm{pH} 5.0$ and 8.0. The precipitation of scandium did not significantly impact the REE grade due to the much higher quantities of aluminum "diluting" the precipitate. The recovery of scandium between $\mathrm{pH} 4.0$ and 5.0 was also was consistent with the result of the $0.5 \mathrm{pH}$ step precipitations and the redox experiments.

The composition of the $\mathrm{pH} 8.0$ precipitates were more variable than the $\mathrm{pH} 4.0$ or 5.0 precipitates. All $\mathrm{pH} 8.0$ precipitates contained residual aluminum and iron, as well as various metals which were found to precipitate out at higher $\mathrm{pHs}$ during the previous experiments. These 
metals included magnesium, manganese, nickel, and zinc. The differences in $\mathrm{pH} 8.0$ precipitate composition are not likely directly caused by the concentrations of the raw water. For example, the AQ-50 precipitate had the highest concentration of zinc ( $22.6 \%$ of solids by weight). However, AQ-50 did not have the highest concentration of zinc in the raw water $(3.1 \mathrm{mg} / \mathrm{L})$. Both AQ-8 and AQ-65 had comparable raw water zinc concentrations (3.5 mg/L and $2.8 \mathrm{mg} / \mathrm{L})$ but yielded precipitates with substantially lower zinc concentrations $(9.6 \%$ and $11.0 \%)$. It is more likely that the overall solution chemistry was affected by the differences in raw water concentrations, which led to differences in precipitation patterns.

Except for scandium, the bulk of the REEs were recovered in the $\mathrm{pH} 8.0$ precipitates. This recovery was consistent with what was observed in previous experiments, as well as what has been reported in the literature. Verplanck et al. (2004) reported their REE recovery beginning at pH 5.13 and Zhang \& Honaker (2018) reported REE recovery across the pH range of 4.85 to 6.11. Both the increased REE recovery and decreased metal precipitation contributed to the REE grade of the $\mathrm{pH} 8.0$ precipitates. The REE grade of the precipitates ranged from $1.1 \%$ at AQ-515 to $4.8 \%$ at AQ-65. The grades of the AQ-65 and AQ-67 precipitates were considerably higher than the other AMD sites. The REE grade of AQ-65 was $4.8 \%$ and AQ-67 was 3.4\%, while the other precipitates averaged an REE grade of $1.6 \%$. It is unclear why the grades of AQ-65 and AQ-67 were much higher than the other 5 sites, as the rare earth element and metal concentrations of the raw waters are within the ranges of the other sites. It is likely that raw water characteristics other than metal and REE concentrations influenced the grade of the $\mathrm{pH} 8.0$ precipitates.

As previously mentioned, the major differences in raw water concentrations of the seven AMD samples likely altered the precipitation patterns of each sample. In spite of these differences, there are patterns that all the precipitates followed regardless of raw water characteristics. The $\mathrm{pH} 4.0$ precipitates were all mainly composed of iron with minimal aluminum precipitates. The remaining major metals and REEs largely stayed in solution during this $\mathrm{pH}$ step. The $\mathrm{pH} 5.0$ precipitates were mostly aluminum, with the colloidal iron settling out as well. Elements like calcium, magnesium, and manganese began to precipitate during this $\mathrm{pH}$ step, although did not substantially contribute to the weight of the solids. Finally, the $\mathrm{pH} 8.0$ precipitates were where the bulk of the REEs were recovered for all seven samples. Small concentrations of aluminum were present, as well as zinc, manganese, magnesium, and calcium. While these varied in concentration across the samples, the overall effect was that the REEs were recovered in the $\mathrm{pH} 8.0$ precipitates with grades above $1.0 \%$.

\subsubsection{Rare Earth Recovery}

The REE recoveries between the seven sites ranged between $46.2 \%$ to $98.8 \%$. The majority of the sites maintained recoveries above 95\%. However, both AQ-67 and AQ-2 did not show efficient recovery. While AQ-2 showed less than $30 \%$ recovery for lanthanum, the recoveries for the remaining LREEs ranged between $50 \%$ and $80 \%$. The HREE recovery of AQ2 ranged between $80 \%$ and $97 \%$. Although this significant difference in LREEs and HREE was 
not observed for the other AMD samples, the preferential recovery of HREEs over LREEs has been reported by multiple sources (Hedin et al. 2019 and Verplanck et al. 2004)). The total recovery of rare earths was $75 \%$ for AQ-2. AQ-67 did not have the differences in LREE and HREE recoveries that AQ-2 showed. Apart from lutetium at $80 \%$ recovery, all HREE and LREEs were below $60 \%$ recovery. The overall recovery of rare earths was $46 \%$ for AQ-67. It is unlikely that the difference in recovery is due to incomplete $\mathrm{pH}$ adjustments. All samples were adjusted to $\mathrm{pH} 8.0$ using $2 \mathrm{~N}$ calcium hydroxide until equilibrium was reached after a few hours. It is possible that the differences in recoveries are due to differences in complexation and coprecipitation during the precipitation procedures. The raw water characteristics varied greatly between sites, so it is possible that the presence or absence of competing ions influenced REE recovery.

\subsubsection{Correlation of REE Grade to Raw Water Characteristics}

Both the recovery of the rare earth elements and the grade of the $\mathrm{pH} 8.0$ precipitates are important factors to consider when scaling up the precipitation procedures to a commercial level. It is undesirable to have low recovery because it is a loss of potential profit. Grade must be considered because it may affect downstream purification procedures, as well as increasing transportation costs. A lower grade would mean that a larger quantity of $\mathrm{pH} 8.0$ precipitate would need to be produced and transported to achieve the same mass of REE when compared to a precipitate with higher grade.

The first question that is asked when considering large scale application of this precipitation procedure is where to place the treatment facility. While the sources of AMD are plentiful, each varies greatly in terms of physicochemical characteristics and the full analysis of multiple sites would prove costly. Determining if raw water characteristics can predict REE concentration or $\mathrm{pH}$ 8.0 REE grade would be beneficial when determining possible treatment sites. If one or two parameters could be measured per site instead of a full suite of REEs, the cost and speed of AMD sites would be improved. The data collected from the seven sites was used to assess possible correlations between raw water characteristics and grade.

One of the largest differences in the raw water was the TREE concentration, which had a range of $141-1353 \mathrm{ug} / \mathrm{L}$. The $\mathrm{pH} 8.0$ precipitate grades were compared to their respective REE concentration, which can be seen below in Figure 5-7. It was expected that a higher concentration of REE in the raw water would result in a higher grade in the $\mathrm{pH} 8.0$ precipitate. However, there is no significant correlation between the two. While AQ-65 had a higher REE concentration and the highest grade, both AQ-50 and AQ-8 had similar REE concentrations and much lower grades. AQ-8 was the site with the highest REE concentration and had a REE grade similar to AQ-3 which had the lowest concentration (grades of AQ-8 and AQ-3 are 1.5\% and $1.9 \%$, respectively). As seen in Figure 5-7, the grade of the $\mathrm{pH} 8.0$ precipitate is independent of REE raw water concentration. The only impact that the REE concentration will have is the mass of precipitate created per volume of AMD treated. A larger volume of AMD with a low 
concentration of REEs will need to be treated to create the same amount of precipitated REEs as AMD with a high concentration of REEs

In addition to REE concentration, other raw water characteristics were assessed for correlations with $\mathrm{pH} 8.0$ precipitate grade. The concentrations of iron and aluminum, as well as the ratio of the two were assessed due to being major components of the AMD collected, and have been shown to be efficient for REE recovery (Verplanck et al. 2004, Schaider et al. 2014). The concentrations of magnesium, manganese, nickel, and zinc were assessed because these are major components of the $\mathrm{pH} 8.0$ precipitate. The major metal and REE ratio and specific conductance was tested because these are measures of how concentrated the AMD is as well as if that concentration is specific to the REEs.

These raw water characteristics were plotted against the precipitate grades to determine any trends. The $\mathrm{R}^{2}$ values of these graphs are shown above in Table 5-7 along with the type of equation used. There were no significant correlations between these raw water characteristics and grade. The highest correlation was with the ratio of iron to aluminum with an $\mathrm{R}^{2}$ value of 0.2838, which showed an inverse relationship. However, the data point for AQ-50 is far removed from the others to the right, which could incorrectly inflate the correlation to the grade. This graph is shown below in Figure 5-8A. The next highest $\mathrm{R}^{2}$ value is for the correlation with the ratio of major metals and REE concentrations, as seen below in Figure 5-8B. This inverse relationship was expected, because the lower metal concentrations in the $\mathrm{pH} 8.0$ supernatant and recovery of the bulk of the $\mathrm{pH} 8.0$ precipitate are what yield the high grade. If the metal concentration were high in comparison to the REE, this would create the dilution effect discussed earlier. However, this is still a weak correlation, and its impact on grade is most likely minimal. Considering the data shown in Table 5-7, It is probable that the grade of the precipitate is dependent on multiple factors and a single raw water characteristic is not capable of accurately predicting precipitate grade. However, it would be beneficial to collect raw AMD from more sample sites for more data. It is possible that having more data points will improve understanding of the relationships between raw water characteristics and precipitate grade. 


\section{Precipitation Procedure Optimization}

\subsection{Introduction}

A procedure to remove REEs from acid mine drainage via selective precipitation can be developed from the data previously reported in sections 3 and 4 . The separation of metals and REEs observed around $\mathrm{pH} 5.0$ was congruent with what has been reported in the literature (Balintova \& Petrilakova 2011, Jenke \& Diebold 1983, Skousen et al. 1998, Verplanck et al 2004, Wei et al. 2004, and Zhao et al. 2007). The reported data could support either a 2-step or 3step precipitation procedure. The $\mathrm{pH}$ endpoints of the 2-step procedure would be $\mathrm{pH} 5.0$ and 8.0. The endpoints for the 3-step procedure would be $\mathrm{pH} 4.0,5.0$, and 8.0.

The major reasoning for the difference in procedure is the possibility of recovering scandium as well as the REEs which typically precipitate above $\mathrm{pH}$ 5.5. With the 3-step precipitation procedure, the bulk of the iron would be likely removed during the $\mathrm{pH} 4.0 \mathrm{step}$. The scandium and aluminum would be removed between $\mathrm{pH} 4.0$ and 5.0. The remaining REEs would be recovered in the $\mathrm{pH} 8.0$ precipitates with the other major metals. A 2-step procedure would remove the iron, aluminum, and scandium in the $\mathrm{pH} 5.0$ precipitate and recover the remaining REEs in the $\mathrm{pH} 8.0$ precipitate. If the concentration of scandium were substantial in the raw AMD, it could be profitable to recover the scandium using a 3-step precipitation procedure. The removal of iron during a previous $\mathrm{pH}$ step would lead to a higher REE grade of the $\mathrm{pH} 5.0$ precipitate. The addition of iron to that precipitate would significantly decrease the REE grade and would not be efficient for downstream purification.

In addition to determining the effects of a 2-step and 3-step precipitation procedure, the effects of flocculant use were assessed. Flocculants are commonly used in wastewater and active AMD treatment facilities (Bratby 2016). They are chemicals which are added to promote coagulation and flocculation of the precipitates to improve settling. The addition of flocculant to acid mine drainage has been shown to improve the settling velocity of the precipitate sludges, as well as improve the settling of suspended colloids (Nui et al. 2013).

There are many different types of flocculants which can be added to improve settling and dewatering. Polymer flocculants are one of the more popular options, which are comprised of long-chained organics. These polymers can either be anionic (negatively charged) or cationic (positively charged) (Coagulation and Flocculation 2012). The charge of the polymer flocculant used is determined based on what the opposite charge is to the target. If the suspended solids are positively charged, an anionic polymer would be chosen to neutralize the overall surface charge. The polymer flocculants improve the settleability through the processes of coagulation and flocculation.

Coagulation is the process by which the surface of a particle is destabilized to allow for flocculation to occur. The charges on the surfaces of the particles is neutralized, which allows for 
flocculation to occur. Flocculation is when the destabilized particles form larger aggregates, or flocs, which lead to improved removal from solution (whether through settling for filtration) (Bratby 2016). As chemical flocculants interfere with the surfaces of particles, it is possible that it would interfere with the interactions between the metals and REEs which lead to coprecipitation/adsorption.

\subsection{Methods}

\section{$\underline{6.2 .1 \text { Collection Procedure }}$}

All raw AMD samples were collected upstream of any $\mathrm{pH}$ adjustment treatment. Before collecting the water samples, a YSI multimeter was placed to measure the water temperature, pressure, conductance, specific conductance, $\mathrm{pH}$, and redox potential (ORP). Raw AMD was collected in 5-gallon buckets for transport to the lab. The raw AMD was pumped from the upstream inlet pipe into each of the 5-gallon buckets. A separate $250 \mathrm{~mL}$ raw water sample was collected for analysis. All bottles and buckets used were rinsed with the raw water prior to being filled.

\subsubsection{2-Step and 3-Step Precipitation Procedure}

For both the 2-step and 3-step precipitations, 75 L of raw AMD collected from site AQ-2 was placed into a 20-gallon tank. The ferrous concentration of the AMD was measured using the Hach Permachem ferrous reagent, and $30 \%$ hydrogen peroxide was used to fully oxidize the samples. For the 2-step precipitation, the AMD was adjusted to a $\mathrm{pH}$ of 5.0, and then 8.0. For the 3-step precipitation, the AMD was adjusted to $\mathrm{pHs} 4.0,5.0$, and then 8.0. The $\mathrm{pH}$ was adjusted using $2 \mathrm{~N}$ calcium hydroxide dropwise until the target $\mathrm{pH}$ was achieved. Equilibrium was assumed when there was no change in $\mathrm{pH}$ after one hour. Once equilibrium was achieved, the precipitate was allowed to settle overnight. The supernatant was siphoned off and used for the next $\mathrm{pH}$ adjustment. A $50 \mathrm{~mL}$ sample of the supernatant was filtered through a $0.22 \mathrm{um}$ filter paper and preserved for analysis. The precipitate was collected and removed between each $\mathrm{pH}$ step by vacuum filtration, using 0.22 um filter papers.

\subsubsection{Precipitation with the Addition of Flocculant}

The effects of flocculant addition were tested for both the 2-step and 3-step precipitation procedures. The procedure performed was the same which was detailed previously with the exception of the added flocculant. The flocculant added to the AMD was AQ-590, which was the flocculant used during AMD treatment at the AQ-2 site. Currently, the AQ-2 site has switched to a new flocculant, PE-6070. The doses of the flocculant for the 2- and 3-step precipitation procedures were determined by conducting jar tests. The ideal dose for both the 2-step and 3-step procedures was $50 \mathrm{ppm}$ of a $0.2 \%$ flocculant solution. This solution was prepared by adding 200 $\mathrm{uL}$ of flocculant to $100 \mathrm{~mL}$ of DI and mixing with an immersion blender. The flocculant dose 
was added to the 20-gallon tank once the AMD reached equilibrium at $\mathrm{pH} 4.0$ for the 3-step and $\mathrm{pH} 5.0$ for the 2-step. The flocculant was then rapidly mixed at $800 \mathrm{rpm}$ for one minute before removing the stirrer and allowing the precipitate to settle. The precipitate settled overnight, while the supernatant was siphoned off to be adjusted to the next $\mathrm{pH}$ step as described in the procedure above.

\subsubsection{Sample Preparation for Analysis}

Samples of the raw AMD and filtrates from each $\mathrm{pH}$ step were collected for all experiments. The collected precipitate slurries were dewatered, and the weight and volume of each were recorded. The aqueous samples which were collected during the staged-precipitation process were preserved with $70 \%$ trace metal grade nitric acid to prevent metal precipitation before analysis. For each sample, $50 \mathrm{~mL}$ was transferred to a plastic centrifuge tube with a screw cap closure. Each precipitate sample was filtered with a 0.22 um filter paper via vacuum filtration. The samples were then labeled with the corresponding code and set aside for analysis. Samples were sent to the NRCCE Analytical Laboratory for testing. All samples were analyzed using inductively coupled plasma optical emission spectrometry (ICP-OES) and inductively coupled plasma mass spectrometry (ICP-MS) for metal and REE concentrations.

\subsection{Results}

\subsubsection{2-Step Precipitation Procedure}

The 2-step procedure brought the raw AMD to $\mathrm{pH} 5.0$ and 8.0 with calcium hydroxide. The compositions of the $\mathrm{pH} 5.0$ precipitate from the experiments with and without flocculant are seen below in Table 6-2. The 2-step precipitation without flocculant generally had higher concentrations of both the metals and REEs when compared to the 2-step with flocculant. The sample without flocculant was mainly aluminum and iron, at $10.9 \%$ and $39.7 \%$ of mass, respectively. Calcium contributed to $1.7 \%$ of the mass. The remaining metals did not significantly impact the mass of the precipitate $(<0.1 \%$ of total mass). As observed in previous experiments ( $0.5 \mathrm{pH}$ Step and Redox), very little REE was recovered during this $\mathrm{pH}$ adjustment, resulting in a $0.02 \%$ grade. The $\mathrm{pH} 5.0$ precipitate from the sample with flocculant addition showed similar composition, with the main components being aluminum $(9.5 \%)$ and iron (28.8\%), with calcium being $0.1 \%$ of mass and the remaining metals insignificant. Again, the REEs mainly stayed in solution, with little precipitation resulting in low grade. For both the samples with and without flocculant, the bulk of scandium precipitated at this stage along with the aluminum. However, the total mass of scandium did not significantly impact precipitate REE grade.

The compositions of the $\mathrm{pH} 8.0$ precipitates from both samples are detailed in Table 6-3. The $\mathrm{pH} 8.0$ precipitate from the sample without flocculant was comprised mainly of aluminum (14.2\%), calcium, (1.7\%), iron (3.8\%), and zinc (5.8\%). The remaining metals did not significantly impact precipitate mass. The majority of the REEs (excluding scandium) were 
recovered in the $\mathrm{pH} 8.0$ precipitate, resulting in a grade of $1.2 \%$ The 2 -step precipitation procedure with flocculant yielded a similar metalcomposition. The precipitate contained $17.6 \%$ aluminum, $2.2 \%$ calcium, and $1.9 \%$ zinc. Unlike the precipitate from the no flocculant sample, this precipitate had significantly less iron $(0.4 \%)$, with decreased zinc as well. The REE grade also decreased substantially down to $0.45 \%$.

The recovery of REE from raw water for both 2-step procedures is seen below in Figure 6-1a and Figure 6-1b. The recovery of REE from both samples followed patterns similar to previous precipitations, with decreased recovery observed for LREEs, particularly lanthanum. The lowest recovery of the 2-step without flocculant was lanthanum at approximately $80 \%$ recovery. Lanthanum was also the lowest REE recovery of the 2-step with the flocculant, at approximately $93 \%$. The overall recovery of REE from the 2-step without flocculant was $96 \%$, and the recovery from the 2-step with flocculant was $99 \%$.

\subsubsection{3-Step Precipitation Procedure}

The 3-step precipitation procedure adjusted the raw AMD to $\mathrm{pHs} 4.0,5.0$, and 8.0. The compositions of the $\mathrm{pH} 4.0$ precipitates from the samples with and without flocculant addition are seen in Table 6-1. Similar to the 2-step procedures, the sample which did not receive flocculant had metals and REEs in higher concentration than the sample which did receive flocculant. For the sample lacking flocculant, the $\mathrm{pH} 4.0$ precipitate was composed of $1.7 \%$ aluminum and $47.5 \%$ iron, with minimal concentrations of the remaining metals. The REEs did not partition into the solid phase during this step, with the REE grade only reaching $0.006 \%$. The sample that did receive flocculant was also mostly iron with small traces of aluminum $(34.3 \%$ and $0.5 \%$ respectively). Very little REE was recovered, resulting in a low grade of $0.002 \%$.

The pH 5.0 precipitates for both 2- and 3-step procedures are shown in Table 6-2. Both were mainly aluminum, with smaller amounts of calcium and iron. The 3 -step precipitate without flocculant was $24.3 \%$ aluminum, $1.2 \%$ calcium, and $0.1 \%$ iron. The remaining metals and REEs did not impact precipitate mass, although the bulk of scandium was recovered during this step. The $\mathrm{pH} 5.0$ precipitate with flocculant was $21.7 \%$ aluminum, $0.2 \%$ calcium, and $0.9 \%$ iron. The remaining metals and REEs did not contribute significantly. Again, the bulk of scandium was precipitated out at this step, but what not enough to increase REE grade.

For $\mathrm{pH} 8.0$, the 3 -step precipitate without flocculant was $10.7 \%$ aluminum, $1.2 \%$ calcium, $1.2 \%$ copper, and $1.1 \%$ iron. The rest of the metals analyzed minorly contributed to the overall mass. The precipitate which did receive flocculant was $8.1 \%$ aluminum, $0.5 \%$ calcium, $0.5 \%$ copper, $0.8 \%$ zinc, and $0.6 \%$ iron. The remaining metals were insignificant to the mass of the precipitate. The $\mathrm{pH} 8.0$ precipitates contained the bulk of the REEs, with the exception of scandium which was recovered in the previous precipitate. The REE grade of the sample without flocculant was $1.7 \%$, which is in the same area as the $\mathrm{pH} 8.0$ precipitate from the 2-step without flocculant. The REE grade of the precipitate with flocculant was significantly reduced to $0.6 \%$, similar to the 2-step with flocculant. 
The overall REE recovery for the 3-step precipitation procedure without flocculant can be seen in Figure 6-1c, and the procedure with flocculant in Figure 6-1d. The REE recovery of the 3 -step without flocculant was lower than that of the 2-step procedures. The lanthanum recovery was incredibly low at $26 \%$. While the average overall REE recovery was low at $83 \%$, the pattern of lower LREE recovery to HREE recovery was still present, just more noticeably. The REE recovery of the 3-step procedure with flocculant was more similar to both 2-step procedures, and averaged $97 \%$ recovery. The REE with the lowest recovery was lanthanum at $84 \%$, with the later LREEs increasing in recovery efficiency towards the HREEs.

Table 6-1: Concentrations of the metals and REEs $(\mathrm{mg} / \mathrm{kg}$ ) for the $\mathrm{pH} 4.0$ precipitates for the 3step precipitations with and without flocculant addition

\begin{tabular}{|c|c|c|c|c|c|c|c|c|c|c|c|c|c|c|c|}
\hline \multirow{2}{*}{ pH 4.0 Grade } & Al & $\mathrm{Ca}$ & $\mathrm{Cd}$ & Co & $\mathrm{Cr}$ & $\mathrm{Cu}$ & $\mathrm{Fe}$ & $\mathrm{Mg}$ & $\mathrm{Mn}$ & $\mathrm{Ni}$ & $\mathrm{Zn}$ & HREE & LREE & Sc & TREE \\
\hline & $\mathrm{mg} / \mathrm{kg}$ & $\mathrm{mg} / \mathrm{kg}$ & $\mathrm{mg} / \mathrm{kg}$ & $\mathrm{mg} / \mathrm{kg}$ & $\mathrm{mg} / \mathrm{kg}$ & $\mathrm{mg} / \mathrm{kg}$ & $\mathrm{mg} / \mathrm{kg}$ & $\mathrm{mg} / \mathrm{kg}$ & $\mathrm{mg} / \mathrm{kg}$ & $\mathrm{mg} / \mathrm{kg}$ & $\mathrm{mg} / \mathrm{kg}$ & $\mathrm{mg} / \mathrm{kg}$ & $\mathrm{mg} / \mathrm{kg}$ & $\mathrm{mg} / \mathrm{kg}$ & $\mathrm{mg} / \mathrm{kg}$ \\
\hline 3-Step No Flocculant & 17372 & 823 & 21 & 1 & 146 & 56 & 474752 & 137 & 49 & 0 & 13 & 17 & 22 & 17 & 56 \\
\hline 3-Step with Flocculant & 5264 & 566 & 14 & 2 & 89 & 15 & 342661 & 113 & 26 & 3 & 5 & 6 & 11 & 5 & 22 \\
\hline
\end{tabular}

Table 6-2: Concentrations of the metals and REEs $(\mathrm{mg} / \mathrm{kg}$ ) for the $\mathrm{pH} 5.0$ precipitates for the 2and 3-step precipitations with and without flocculant addition

\begin{tabular}{|c|c|c|c|c|c|c|c|c|c|c|c|c|c|c|c|}
\hline \multirow{2}{*}{ pH 5.0 Grade } & Al & $\mathrm{Ca}$ & $\mathrm{Cd}$ & Co & $\mathrm{Cr}$ & $\mathrm{Cu}$ & $\mathrm{Fe}$ & $\mathrm{Mg}$ & $\mathrm{Mn}$ & $\mathrm{Ni}$ & $\mathrm{Zn}$ & HREE & LREE & Sc & TREE \\
\hline & $\mathrm{mg} / \mathrm{kg}$ & $\mathrm{mg} / \mathrm{kg}$ & $\mathrm{mg} / \mathrm{kg}$ & $\mathrm{mg} / \mathrm{kg}$ & $\mathrm{mg} / \mathrm{kg}$ & $\mathrm{mg} / \mathrm{kg}$ & $\mathrm{mg} / \mathrm{kg}$ & $\mathrm{mg} / \mathrm{kg}$ & $\mathrm{mg} / \mathrm{kg}$ & $\mathrm{mg} / \mathrm{kg}$ & $\mathrm{mg} / \mathrm{kg}$ & $\mathrm{mg} / \mathrm{kg}$ & $\mathrm{mg} / \mathrm{kg}$ & $\mathrm{mg} / \mathrm{kg}$ & $\mathrm{mg} / \mathrm{kg}$ \\
\hline 2-Step No Flocculant & 109077 & 17340 & 14 & 27 & 139 & 291 & 396726 & 171 & 132 & 33 & 253 & 80 & 72 & 53 & 205 \\
\hline 2-Step with Flocculant & 94818 & 1498 & 12 & 8 & 110 & 71 & 288167 & 171 & 75 & 18 & 79 & 24 & 26 & 55 & 105 \\
\hline 3-Step No Flocculant & 242678 & 11519 & 1 & 5 & 26 & 142 & 1271 & 988 & 154 & 41 & 99 & 43 & 15 & 125 & 183 \\
\hline 3-Step with Flocculant & 216965 & 2188 & 1 & 8 & 227 & 141 & 9643 & 206 & 46 & 36 & 52 & 24 & 8 & 79 & 111 \\
\hline
\end{tabular}

Table 6-3: Concentrations of the metals and REEs $(\mathrm{mg} / \mathrm{kg}$ ) for the $\mathrm{pH} 8.0$ precipitates for the 2and 3-step precipitations with and without flocculant addition

\begin{tabular}{|c|c|c|c|c|c|c|c|c|c|c|c|c|c|c|c|}
\hline \multirow{2}{*}{ pH 8.0 Grade } & Al & $\mathrm{Ca}$ & $\mathrm{Cd}$ & Co & $\mathrm{Cr}$ & $\mathrm{Cu}$ & $\mathrm{Fe}$ & $\mathrm{Mg}$ & Mn & $\mathrm{Ni}$ & $\mathrm{Zn}$ & HREE & LREE & Sc & TREE \\
\hline & $\mathrm{mg} / \mathrm{kg}$ & $\mathrm{mg} / \mathrm{kg}$ & $\mathrm{mg} / \mathrm{kg}$ & $\mathrm{mg} / \mathrm{kg}$ & $\mathrm{mg} / \mathrm{kg}$ & $\mathrm{mg} / \mathrm{kg}$ & $\mathrm{mg} / \mathrm{kg}$ & $\mathrm{mg} / \mathrm{kg}$ & $\mathrm{mg} / \mathrm{kg}$ & $\mathrm{mg} / \mathrm{kg}$ & $\mathrm{mg} / \mathrm{kg}$ & $\mathrm{mg} / \mathrm{kg}$ & $\mathrm{mg} / \mathrm{kg}$ & $\mathrm{mg} / \mathrm{kg}$ & $\mathrm{mg} / \mathrm{kg}$ \\
\hline 2-Step No Flocculant & 141965 & 17454 & 21 & 1010 & 1998 & 4607 & 38071 & 9310 & 4337 & 2314 & 57805 & 6298 & 5748 & 64 & 12110 \\
\hline 2-Step with Flocculant & 175851 & 22460 & 10 & 516 & 343 & 671 & 4370 & 2857 & 1463 & 1221 & 18794 & 2383 & 2034 & 100 & 4517 \\
\hline 3-Step No Flocculant & 106668 & 12419 & 5 & 240 & 31 & 12154 & 11149 & 3019 & 972 & 475 & 17516 & 11380 & 6100 & 176 & 17656 \\
\hline 3-Step with Flocculant & 80875 & 4827 & 3 & 202 & 708 & 5407 & 5895 & 1707 & 634 & 452 & 8161 & 3126 & 2413 & 87 & 5626 \\
\hline
\end{tabular}




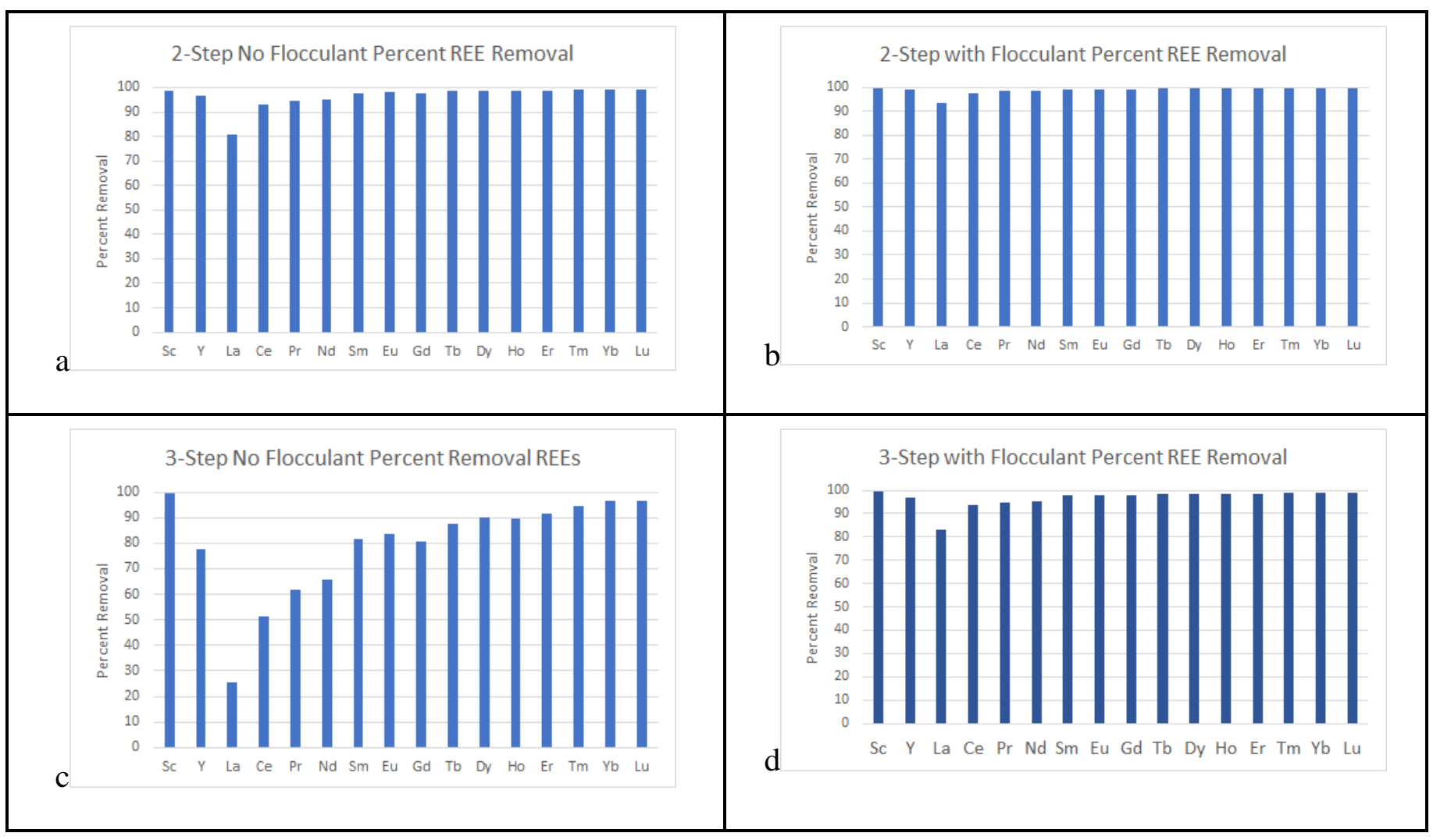

Figure 6-1: Percent of overall recovery of rare earth elements from raw water for the 2-step procedure without flocculant (a), 2-step procedure with flocculant addition (b), 3-step procedure without flocculant (c), and the 3-step procedure with flocculant addition (d)

Table 6-4: Comparison of REE grade and recovery between the 2-step and 3-step precipitation procedures, as well as with and without flocculant addition at $\mathrm{pH} 5.0$

\begin{tabular}{|c|c|c|c|c|}
\hline & \multicolumn{2}{|c|}{ 2-Step Precipitation } & \multicolumn{2}{c|}{ 3-Step Precipitation } \\
\cline { 2 - 5 } & No Flocculant & Flocculant & No Flocculant & Flocculant \\
\hline $\begin{array}{c}\text { pH 8.0 Precipitate } \\
\text { Grade }\end{array}$ & $1.21 \%$ & $0.45 \%$ & $1.77 \%$ & $0.56 \%$ \\
\hline Average REE Recovery & $96 \%$ & $99 \%$ & $83 \%$ & $97 \%$ \\
\hline
\end{tabular}




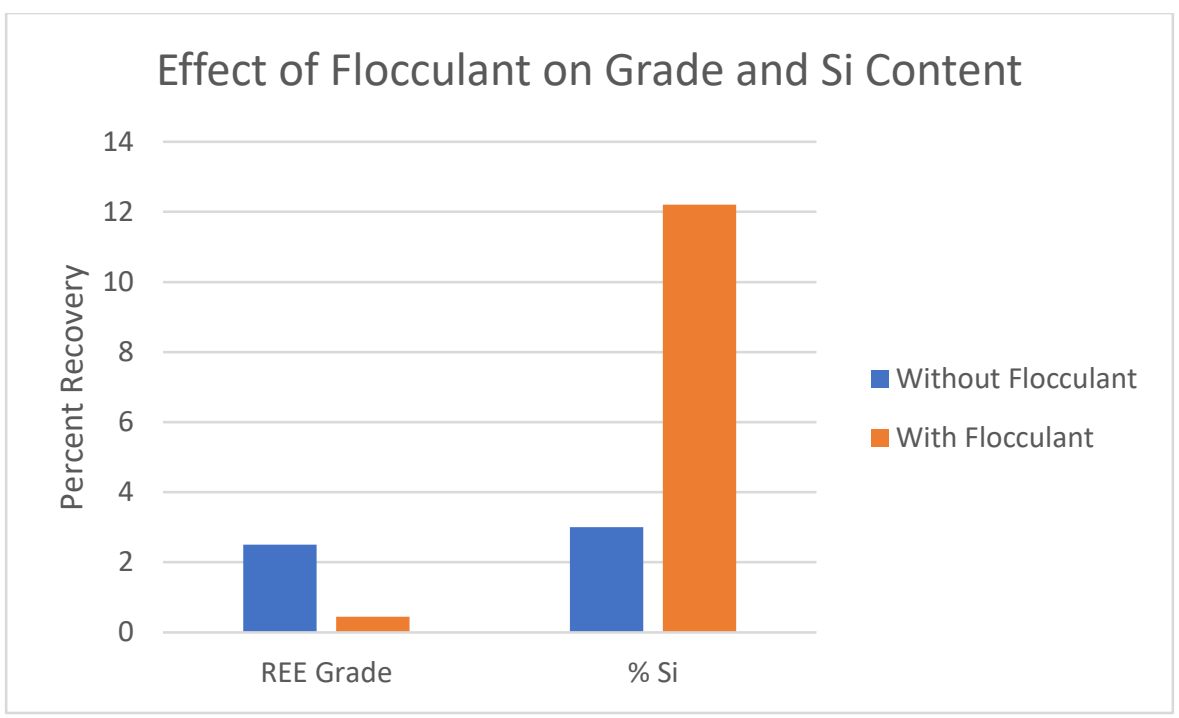

Figure 6-2: Comparison of $\mathrm{pH} 8.0$ precipitate REE and silica percentage. This data was collected from a 3-step precipitation of AQ-50 raw water.

\subsection{Discussion}

\subsubsection{2-Step vs 3-Step Precipitation Procedures}

The only difference between the 2-step and 3-step precipitation procedures was that the $\mathrm{pH} 4.0$ step was removed for the 2-step procedure. Instead, the $\mathrm{pH}$ was adjusted to 5.0 directly. While it was expected that the compositions of the $\mathrm{pH} 5.0$ precipitates would vary greatly between the two procedures, it was unexpected that the $\mathrm{pH} 8.0$ precipitates would vary significantly. However, as seen in Table $6-4$, the grade was $1.21 \%$ for the 2 -step precipitation, while the grade was increased to $1.77 \%$ in the 3 -step procedure. The lowered grade in the 2 -step procedure was most likely due to the larger quantity of aluminum and iron, which had a dilution effect on the REE grade. Because the concentration of the metals is an order of magnitude above the REE concentrations, the precipitation of metals will overpower the REEs in the precipitate, lowering the grade. It is possible that the 2-step precipitation procedure had a lower REE grade due to the effects of the iron and aluminum trying to settle as one precipitate, compared to the separate removals at $\mathrm{pH} 4.0$ and 5.0 of the 3-step precipitation procedure. When the iron precipitate forms, it is very small and does not floc and settle easily. While aluminum precipitate forms larger precipitates and settles quickly on its own, it is possible that the combination of high concentrations of both iron and aluminum in one precipitate affects settling. Unsettled, colloidal precipitates could have been carried over into the $\mathrm{pH} 8.0$ adjustment, adding to the precipitate mass and diluting the REE grade in the process.

The effect on the overall REE recovery was the opposite for the 2- and 3-step procedures. The REE recovery was higher for the 2-step precipitation, with an average of 96\% (Figure 6-1). The REE recovery of the 3-step precipitation was much lower at $83 \%$. The decreased REE recovery from the 3-step might be due to the lower iron and aluminum concentration present in 
solution during $\mathrm{pH}$ adjustment. As observed in the seeding experiment previously discussed, the presence of both iron and aluminum precipitates increased the removal of REEs by $80-90 \%$. While the 2-step had higher concentration of iron and aluminum which diluted grade, these concentrations helped to increase overall REE recovery. Conversely, the 3-step had lower concentrations of iron and aluminum, increasing grade and decreasing recovery.

While this data shows the effects a 2- or 3-step procedure has on the $\mathrm{pH} 8.0$ precipitates, it does not demonstrate one to be better than the other. The results of the 2-step and 3-step precipitation procedures are opposites, but either could be beneficial depending on the circumstances. The first consideration is if the AMD source contains high concentrations of scandium. Scandium is currently one of the more valuable REEs, so it would be profitable to capture the scandium for refinement. If a considerable amount of scandium is present, it could be profitable to run a 3-step procedure. The scandium would be captured in the $\mathrm{pH} 5.0$ precipitate, and would have a higher grade of scandium than the 2-step precipitate due to the lack of iron. However, if scandium is not present, it might be more profitable to have a 2 -step procedure because you would only have one waste sludge of iron and aluminum instead of two waste sludges, one of predominantly iron and one of predominantly aluminum.

While the grade and recovery of rare earths differed between the 2- and 3-step procedures, both were efficient in concentrating the REEs in the $\mathrm{pH} 8.0$ precipitate and recovery the bulk of REEs from solution. The decision between a 2-step vs 3-step procedure will also depend on whether the grade of the precipitate or overall REE recovery is deemed more important. The grade of the $\mathrm{pH} 8.0$ precipitate is important because it will create a more concentrated product which will cut back on transportation costs, and also benefit the downstream refinement processes. It is likely that solvent extraction will be more efficient with a more concentrated influent, whether it be a more pure product, or more product mass after associated losses during the process. While precipitate grade is important to consider, the total recovery of REE is also important. If the recovery of REEs is inefficient, a significant portion of the TREEs is being released in the effluent. This can be viewed as lost potential profits. The 3step procedure had much lower recovery compared to the 2-step, with almost $20 \%$ of REEs still in solution after $\mathrm{pH}$ 8.0. If the downstream refinement processes are efficient and the REE concentration of the stock are unimportant, the recovery of rare earths from the AMD might be considered more valuable than grade. Depending on the circumstances of the AMD site and project specifications, both a 2-step and 3-step procedure could work.

\subsubsection{Effects of Flocculant on Precipitates}

The addition of flocculant to the precipitation procedure had significant impacts on both the grade and recovery of rare earth elements. For both the 2-step and 3-step procedures, the addition of flocculant reduced the grade of the $\mathrm{pH} 8.0$ precipitate to between $30-40 \%$ of the grade of the no flocculant samples. For the 2-step procedure, the precipitate grade went from $1.21 \%$ to $0.45 \%$, while in the 3 -step procedure it decreased from $1.77 \%$ to $0.56 \%$ for the 3 -step procedure. It was initially suspected that the drop in grade was due to a drop in REE recovery. 
However, the overall recovery of REEs was improved with the addition of flocculant. The recovery of the 2-step increased from $96 \%$ to $99 \%$. The recovery of the 3-step had a larger improvement, from $83 \%$ without flocculant to $97 \%$ with the flocculant.

It was determined that the grade was decreased after the addition of flocculant due to the increased recovery of elements not being analyzed. From the data collected from the 2- and 3step procedures, the relative concentrations of the metals and REEs decreased after the addition of flocculant. After reviewing possible compounds, a sample of $\mathrm{pH} 8.0$ precipitate from site AQ50 (which had flocculant added during precipitation) was analyzed. The water from AQ-50 was analyzed in place of AQ-2 due to limitations in collection from AQ-2. The treatment facility was performing maintenance on their pipe system during the time when new water samples were required. Water collection for the grade and silica analysis was collected from AQ-50 in place of AQ-2. The major difference between the samples with and without flocculant were the concentrations of silica, as seen in Figure 6-2. In the sample which did not receive flocculant, the REE grade was $2.51 \%$ while the silica only comprised $3.0 \%$ of the precipitate mass. However, the sample which did receive flocculant had a decreased grade of $0.45 \%$, and silica increased to $12.2 \%$ of the precipitate mass. While the flocculant increased the recovery of REE in the $\mathrm{pH} 8.0$ precipitate, it also increased the recovery of silica. This large quantity of silica diluted the precipitate, lowering the REE grade even though the mass of recovered REE was increased.

The effect of lowered grade for the $\mathrm{pH} 8.0$ precipitate is undesirable, considering that the precipitation process was previously optimized to yield the highest REE grade. However, the flocculants are commonly used in the treatment of acid mine drainage for multiple reasons. The flocculant is often added alongside the base during the $\mathrm{pH}$ adjustment. The flocculant alters the surface chemistry of the formed precipitates, allowing them to form into large flocs which will increase the settling velocity and decrease required retention time/clarifier volume. Depending on the design of the treatment facility, the addition of flocculant improves the settling of precipitates in settling ponds, as well as the retention of precipitates in geotextile tubes. At the AQ-2 site where the raw AMD was collected, the settled waste sludge produced during the neutralization of the AMD is pumped from the clarifier into tubes made of a geotextile fabric to retain the precipitate and allow the treated AMD to be filtered out. The waste sludge is then kept in the geotextile to dewater while the filtrate is transferred to a settling pond and then discharged. The geotextile material contains large pores, which would be unable to efficiently retain the precipitate without the use of flocculant to enlarge the precipitate floc size. The use of flocculant during the 2- and 3-step precipitation procedures for REE recovery will have to be considered weighing the drop in REE grade against the improved recovery and benefits of having larger flocs.

The results of these experiments show the effects of the number of steps during the precipitation procedure as well as the addition of flocculant influence both the grade and recovery of REEs in the $\mathrm{pH} 8.0$ precipitates. They are not meant to dictate which conditions are better than others, but to offer knowledge when considering treatment facility design. The 2-step precipitation procedure showed a decrease in grade with an increase in REE recovery when compared to the 3-step precipitation. It is possible that the differences in grade and recovery are 
due to the differences in metal recovery and settling characteristics between the two procedures. The addition of flocculant significantly decreased the grade of the $\mathrm{pH} 8.0$ precipitate while increasing the overall recovery of REEs. The grade of the precipitate is impacted due to the increased recovery of silica between $\mathrm{pH} 5.0$ and 8.0. However, the increased recovery created from the flocculant also increased the recovery of REEs. There is no clear choice to whether a 2step or 3-step procedure is better based on the collected data. The effects of the two procedures must be considered alongside raw water quality and budget when designing a treatment facility for REE recovery. Similarly, the addition of flocculant will improve the recovery of REEs, as well as silica which will decrease the precipitate grade. While there is a steep drop in grade after the addition of flocculant, the benefits for clarifier and settling pond design include improved settling velocities as well as improved filtration via geotubes. 


\section{Conclusions}

Evaluating the results of the precipitation procedures and AMD site comparison, it can be inferred that:

1. The precipitation of rare earth elements from acid mine drainage via selective precipitation is a viable option for REE recovery. The bulk of the dissolved metals (iron and aluminum) were removed by $\mathrm{pH}$ 5.5. While scandium was recovered at a lower $\mathrm{pH}$ with aluminum, the majority of the remaining REEs were collected between pH 5.0 and 7.0

2. Redox conditions significantly impacted the precipitation patterns of the heavy metals and REEs in AMD. Reducing conditions created ferrous iron which prolonged iron precipitation. Full iron removal was not observed until between $\mathrm{pH} 7.0$ and 8.0. Except for aluminum and scandium, the remaining heavy metals and REEs were removed from solution at lower $\mathrm{pH}$ ranges when compared to oxidizing conditions.

3. The addition of iron and aluminum precipitates formed during selective precipitation improved the overall recovery of REEs from solution. The addition of raw AMD did not improve recovery efficiently.

4. The compositions of the precipitates formed during selective precipitation shared commonalities within each $\mathrm{pH}$ step. The $\mathrm{pH} 4.0$ precipitates were mainly composed of iron with minimal amounts of aluminum. The bulk of the $\mathrm{pH} 5.0$ precipitates was aluminum, with smaller quantities of iron and calcium present for some of the samples. Finally, the $\mathrm{pH} 8.0$ precipitates varied the most. The common constituents included aluminum, magnesium, manganese, and zinc. The bulk of the REEs were recovered in these precipitates, resulting in grades varying between $1.1 \%$ to $4.8 \%$.

5. The REE grade of the $\mathrm{pH} 8.0$ precipitates and overall recovery were independent of raw water characteristics for each AMD site. The grade of the precipitates was maintained above $1.0 \%$ across all seven sites sampled.

6. The $\mathrm{pH} 8.0$ precipitates were impacted by the precipitation procedure used. The 2-step precipitation procedure resulted in a lower grade when compared to the 3-step precipitation. However, the REE recovery was higher for the 2-step precipitation procedure.

7. The addition of flocculant had a more substantial impact on grade and recovery. The flocculant addition reduced the grade of the precipitates from $1.21 \%$ to $0.45 \%$ for the 2 step and $1.77 \%$ to $0.56 \%$ for the 3 -step. The reduction in grade was likely due to the increase in silica removal/precipitation. The addition of flocculant also resulted in a higher percentage of REEs recovered from the raw water. 


\section{References}

Ackman, Terry E. Sludge disposal from acid mine drainage treatment. Vol. 8672. US Department of the Interior, Bureau of Mines, 1982.

Akcil, A., \& Koldas, S. (2006). Acid Mine Drainage (AMD): causes, treatment and case studies. Journal of Cleaner Production, 14(12-13), 1139-1145.

Alonso, E., Sherman, A. M., Wallington, T. J., Everson, M. P., Field, F. R., Roth, R., \& Kirchain, R. E. (2012). Evaluating rare earth element availability: A case with revolutionary demand from clean technologies. Environmental Science \& Technology, 46(6), 3406-3414.

Ayora, C., Macías, F., Torres, E., Lozano, A., Carrero, S., Nieto, J. M., ... \& Castillo-Michel, H. (2016). Recovery of rare earth elements and yttrium from passive-remediation systems of acid mine drainage. Environmental Science \& Technology, 50(15), 8255-8262.

Balintova, M., \& Petrilakova, A. (2011). Study of $\mathrm{pH}$ influence on selective precipitation of heavy metals from acid mine drainage. Chemical Engineering Transactions, 25, 1-6.

Beverskog, B., \& Puigdomenech, I. (1996). Revised pourbaix diagrams for iron at 25-300 C. Corrosion Science, 38(12), 2121-2135.

Binnemans, K., Jones, P. T., Blanpain, B., Van Gerven, T., Yang, Y., Walton, A., \& Buchert, M. (2013). Recycling of rare earths: a critical review. Journal of Cleaner Production, 51, 1-22.

Bratby, J. (2016). Coagulation and flocculation in water and wastewater treatment. IWA publishing.

Byrne, R. H., \& Li, B. (1995). Comparative complexation behavior of the rare earths. Geochimica et Cosmochimica Acta, 59(22), 4575-4589.

Chapman, B. M., D. R. Jones, and R_F Jung. "Processes controlling metal ion attenuation in acid mine drainage streams." Geochimica et Cosmochimica Acta 47.11 (1983): 1957-1973.

Coagulation and Flocculation [PDF]. (2012). Minnesota Rural Water Association.

DeNicola, Dean M., and Michael G. Stapleton. "Impact of acid mine drainage on benthic communities in streams: the relative roles of substratum vs. aqueous effects." Environmental Pollution 119.3 (2002): 303-315.

Dzombak, D. A., \& Morel, F. M. (1990). Surface Complexation Modeling: Hydrous Ferric Oxide. John Wiley \& Sons.

Elberling, B., Balić-Žunić, T., \& Edsberg, A. (2003). Spatial variations and controls of acid mine drainage generation. Environmental Geology, 43(7), 806-813. 
EPA, U. (1994). Acid Mine Drainage Prediction. US Environmental Protection Agency Office of Solid Waste Special Waste Branch, US.

Ferguson, K. D., \& Erikson, P. M. (1988). Environmental Management of Solid Waste. Salomons et al.

Gambogi, Joseph. "Mineral Commodity Summaries 2018." Mineral Commodity Summaries, Jan. 2018, doi:10.3133/70194932.

Gray, N. F. (1996). The use of an objective index for the assessment of the contamination of surface water and groundwater by acid mine drainage. Water and Environment Journal, 10(5), $332-340$.

Gray, N. F. (1997). Environmental impact and remediation of acid mine drainage: a management problem. Environmental Geology, 30(1-2), 62-71.

Hatch, G. P. (2012). Dynamics in the global market for rare earths. Elements, 8(5), 341-346.

Hedin, B. C., Capo, R. C., Stewart, B. W., Hedin, R. S., Lopano, C. L., \& Stuckman, M. Y. (2019). The evaluation of critical rare earth element (REE) enriched treatment solids from coal mine drainage passive treatment systems. International Journal of Coal Geology, 208, 54-64.

Jacoby, M., \& Jiang, J. (2010). SECURING THE SUPPLY OF RARE EARTHS: Green-energy and high-tech industries grow anxious over CHINA'S MONOPOLY on these valuable resources.

Jenke, D. R., \& Diebold, F. E. (1983). Recovery of valuable metals from acid mine drainage by selective titration. Water Research, 17(11), 1585-1590.

Johnson, D. B., \& Hallberg, K. B. (2005). Acid mine drainage remediation options: a review. Science of the Total Environment, 338(1-2), 3-14.

Kim, J., S. Kim, and K. Tazaki. "Mineralogical characterization of microbial ferrihydrite and schwertmannite, and non-biogenic Al-sulfate precipitates from acid mine drainage in the Donghae mine area, Korea." Environmental Geology 42.1 (2002): 19-31.

Kirby, C. S., S. M. Decker, and N. K. Macander. "Comparison of color, chemical and mineralogical compositions of mine drainage sediments to pigment." Environmental Geology 37.3 (1999): 243-254.

Kuyucak, Nural. "Mining, the environment and the treatment of mine effluents." International Journal of Environment and Pollution 10.2 (1998): 315-325.

Kuyucak, Nural. "Acid mine drainage prevention and control options." CIM Bulletin (2002): 96102. 
Massari, S., \& Ruberti, M. (2013). Rare earth elements as critical raw materials: Focus on international markets and future strategies. Resources Policy, 38(1), 36-43.

Matlock, M. M., Howerton, B. S., \& Atwood, D. A. (2002). Chemical precipitation of heavy metals from acid mine drainage. Water Research, 36(19), 4757-4764.

McCauley, C. A., O'Sullivan, A. D., Weber, P. A., \& Trumm, D. (2010). Variability of Stockton Coal Mine drainage chemistry and its treatment potential with biogeochemical reactors. New Zealand Journal of Geology and Geophysics, 53(2-3), 211-226.

Merten, D., Geletneky, J., Bergmann, H., Haferburg, G., Kothe, E., \& Büchel, G. (2005). Rare earth element patterns: a tool for understanding processes in remediation of acid mine drainage. Geochemistry, 65, 97-114.

Naidu, G., Ryu, S., Thiruvenkatachari, R., Choi, Y., Jeong, S., \& Vigneswaran, S. (2019). A critical review on remediation, reuse, and resource recovery from acid mine drainage. Environmental Pollution.

Niu, M., Zhang, W., Wang, D., Chen, Y., \& Chen, R. (2013). Correlation of physicochemical properties and sludge dewaterability under chemical conditioning using inorganic coagulants. Bioresource Technology, 144, 337-343.

Pourret, O., Davranche, M., Gruau, G., \& Dia, A. (2007). Rare earth elements complexation with humic acid. Chemical Geology, 243(1-2), 128-141.

Schaider, L. A., Senn, D. B., Estes, E. R., Brabander, D. J., \& Shine, J. P. (2014). Sources and fates of heavy metals in a mining-impacted stream: temporal variability and the role of iron oxides. Science of the Total Environment, 490, 456-466.

Sindern, S. (2017). Analysis of rare earth elements in rock and mineral samples by ICP-MS and LA-ICP-MS. Physical Sciences Reviews, 2(2).

Skousen, Jeffrey, et al. "Handbook of technologies for avoidance and remediation of acid mine drainage." National Mine Land Reclamation Center, Morgantown 131 (1998).

Skousen, J. G., Sexstone, A., \& Ziemkiewicz, P. F. (2000). Acid mine drainage control and treatment. Reclamation of drastically disturbed lands, 41, 131-168.

Skousen, J. G., Ziemkiewicz, P. F., \& McDonald, L. M. (2019). Acid mine drainage formation, control and treatment: Approaches and strategies. The Extractive Industries and Society, 6(1), 241249.

Soucek, D. J., D. S. Cherry, and G. C. Trent. "Relative acute toxicity of acid mine drainage water column and sediments to Daphnia magna in the Puckett's Creek watershed, Virginia, USA." Archives of Environmental Contamination and Toxicology 38.3 (2000): 305-310. 
Stern, J. C., Sonke, J. E., \& Salters, V. J. (2007). A capillary electrophoresis-ICP-MS study of rare earth element complexation by humic acids. Chemical Geology, 246(3-4), 170-180.

Stewart, B. W., Capo, R. C., Hedin, B. C., \& Hedin, R. S. (2017). Rare earth element resources in coal mine drainage and treatment precipitates in the Appalachian Basin, USA. International Journal of Coal Geology, 169, 28-39.

Sullivan, A. B., \& Drever, J. I. (2001). Spatiotemporal variability in stream chemistry in a highelevation catchment affected by mine drainage. Journal of Hydrology, 252(1-4), 237-250.

Takeno, Naoto. "Atlas of Eh-pH diagrams." Geological survey of Japan open file report 419 (2005): 102 .

U.S. Energy Information Administration - EIA - Independent Statistics and Analysis. (2020). Retrieved from https://www.eia.gov/energyexplained/coal/where-our-coal-comes-from.php

Verplanck, P. L., Nordstrom, D. K., Taylor, H. E., \& Kimball, B. A. (2004). Rare earth element partitioning between hydrous ferric oxides and acid mine water during iron oxidation. Applied Geochemistry, 19(8), 1339-1354.

Water Treatment. (2020). Retrieved from https://dep.wv.gov/dlr/osr/watertreatment/Pages/default.aspx

Webster, J. G., Swedlund, P. J., \& Webster, K. S. (1998). Trace metal adsorption onto an acid mine drainage iron (III) oxy hydroxy sulfate. Environmental Science \& Technology, 32(10), 1361-1368.

Wei, X., Viadero Jr, R. C., \& Buzby, K. M. (2005). Recovery of iron and aluminum from acid mine drainage by selective precipitation. Environmental Engineering Science, 22(6), 745-755.

Zhang, W., \& Honaker, R. Q. (2018). Rare earth elements recovery using staged precipitation from a leachate generated from coarse coal refuse. International Journal of Coal Geology, 195, 189-199.

Zhanheng, C. H. E. N. (2011). Global rare earth resources and scenarios of future rare earth industry. Journal of Rare Earths, 29(1), 1-6.

Zhao, F., Cong, Z., Sun, H., \& Ren, D. (2007). The geochemistry of rare earth elements (REE) in acid mine drainage from the Sitai coal mine, Shanxi Province, North China. International Journal of Coal Geology, 70(1-3), 184-192.

Ziemkiewicz, P. F., Skousen, J. G., \& Simmons, J. (2003). Long-term performance of passive acid mine drainage treatment systems. Mine Water and the Environment, 22(3), 118-129. 